\title{
Um método para paralelização automática de workflows intensivos em dados
}

\author{
Elaine Naomi Watanabe \\ DISSERTAÇÃO APRESENTADA \\ $\mathrm{AO}$ \\ Instituto De Matemática e EstatísticA \\ DA \\ Universidade DE SÃo PAUlo \\ PARA \\ OBTENÇÃO DO TÍTULO \\ DE \\ Mestre em CiÊnCIAS \\ Programa: Ciência da Computação \\ Orientador: Prof ${ }^{\mathrm{a}}$. Dr ${ }^{\mathrm{a}}$. Kelly Rosa Braghetto
}

Durante o desenvolvimento deste trabalho a autora recebeu auxílio financeiro da CAPES 


\section{Um método para paralelização automática de workflows intensivos em dados}

Esta versão da dissertação contém as correções e alterações sugeridas pela Comissão Julgadora durante a defesa da versão original do trabalho, realizada em 22/05/2017. Uma cópia da versão original está disponível no

Instituto de Matemática e Estatística da Universidade de São Paulo.

Comissão Julgadora:

- Prof ${ }^{\mathrm{a}}$. Dr ${ }^{\mathrm{a}}$. Kelly Rosa Braghetto (orientadora) - IME-USP

- Prof. Dr. Daniel Macêdo Batista - IME-USP

- Prof. Dr. Daniel Cardoso Moraes de Oliveira - UFF 


\section{Agradecimentos}

Primeiramente, gostaria de agradecer à minha orientadora, Prof ${ }^{a}$. Kelly Rosa Braghetto, por seus conselhos e dedicação. Você esteve sempre pronta para me ajudar, fosse em tópicos relacionados ao mestrado ou não, mesmo em horários não-convencionais. Muito obrigada por sua paciência e atenção! Aprendi muito com você e espero que no futuro possamos continuar essa parceria.

Agradeço também aos meus pais, que sempre me ajudaram e apoiaram minhas escolhas. $\mathrm{O}$ suporte de vocês, emocional e financeiro, foram essenciais durante essa jornada. Aprendi com vocês a nunca desistir e a me esforçar sempre. Muito obrigada! Amo vocês!

Agradeço aos meus tios Alexandre e Andreia e ao meu primo Gabriel, que me hospedaram em sua casa com todo carinho e bolos de chocolate, em todos os momentos em que precisei.

Aos meus amigos, gratidão, por suas palavras de motivação e por entenderem a minha ausência em diversos momentos do meu mestrado. O apoio de vocês foi muito importante todo esse tempo.

Agradeço aos professores do Departamento de Ciência da Computação, em especial, aos professores de Sistemas, que muito contribuíram para o desenvolvimento do meu trabalho e da minha vida acadêmica.

Agradeço aos meus colegas dos Laboratórios de Sistemas e de Banco de Dados/e-Science, que compartilharam comigo grandes conversas sobre meu trabalho, a vida, o universo e tudo mais. Mesmo um bom dia, boa tarde ou boa noite, alegraram meus dias e me motivaram a continuar. Gratidão!

Agradeço à Playax, empresa para a qual trabalhei neste último período e que permitiu uma carga horária reduzida, além de todo incentivo a participações de eventos acadêmicos. O apoio de todos vocês, principalmente do Daniel Cukier, possibilitaram a conclusão deste trabalho. Muito obrigada!

Em especial, agradeço ao meu companheiro e parceiro Fabio Yukio Toriumi, cujo apoio, paciência e amor foram essenciais para a conclusão desse trabalho, inclusive nos momentos finais, quando o meu notebook parou de funcionar e você me socorreu com seu notebook e suas playlists infinitas de música eletrônica. Não tenho palavras suficientes para descrever o quanto você é importante na minha vida e o quanto o seu apoio significa para mim! Agradeço à sua família também, que me acolheu como filha. Doumo arigatou gozaimasu!

A todos vocês, o meu carinho e gratidão! 


\section{Resumo}

WATANABE, E. N. Um método para paralelização automática de workflows intensivos em dados. 2017. 85 f. Dissertação (Mestrado) - Instituto de Matemática e Estatística, Universidade de São Paulo, São Paulo, 2017.

A análise de dados em grande escala é um dos grandes desafios computacionais atuais e está presente não somente em áreas da ciência moderna mas também nos setores público e industrial. Nesses cenários, o processamento dos dados geralmente é modelado como um conjunto de atividades interligadas por meio de fluxos de dados - os workflows. Devido ao alto custo computacional, diversas estratégias já foram propostas para melhorar a eficiência da execução de workflows intensivos em dados, tais como o agrupamento de atividades para minimizar as transferências de dados e a paralelização do processamento, de modo que duas ou mais atividades sejam executadas ao mesmo tempo em diferentes recursos computacionais. O paralelismo nesse caso é definido pela estrutura descrita em seu modelo de composição de atividades. Em geral, os Sistemas de Gerenciamento de Workflows, responsáveis pela coordenação e execução dessas atividades em um ambiente distribuído, desconhecem o tipo de processamento a ser realizado e por isso não são capazes de explorar automaticamente estratégias para execução paralela. As atividades paralelizáveis são definidas pelo usuário em tempo de projeto e criar uma estrutura que faça uso eficiente de um ambiente distribuído não é uma tarefa trivial. Este trabalho tem como objetivo prover execuções mais eficientes de workflows intensivos em dados e propõe para isso um método para a paralelização automática dessas aplicações, voltado para usuários não-especialistas em computação de alto desempenho. Este método define nove anotações semânticas para caracterizar a forma como os dados são acessados e consumidos pelas atividades e, assim, levando em conta os recursos computacionais disponíveis para a execução, criar automaticamente estratégias que explorem o paralelismo de dados. O método proposto gera réplicas das atividades anotadas e define também um esquema de indexação e distribuição dos dados do workflow que possibilita maior acesso paralelo. Avaliou-se sua eficiência em dois modelos de workflows com dados reais, executados na plataforma de nuvem da Amazon. Usou-se um SGBD relacional (PostgreSQL) e um NoSQL (MongoDB) para o gerenciamento de até 20,5 milhões de objetos de dados em 21 cenários com diferentes configurações de particionamento e replicação de dados. Os resultados obtidos mostraram que a paralelização da execução das atividades promovida pelo método reduziu o tempo de execução do workflow em até $66,6 \%$ sem aumentar o seu custo monetário.

Palavras-chave: Paralelismo de Dados, NoSQL, Workflows Intensivos em Dados. 


\section{Abstract}

WATANABE, E. N. A method for automatic paralelization of data-intensive workflows. 2017. 85 f. Dissertação (Mestrado) - Instituto de Matemática e Estatística, Universidade de São Paulo, São Paulo, 2017.

The analysis of large-scale datasets is one of the major current computational challenges and it is present not only in fields of modern science domain but also in the industry and public sector. In these scenarios, the data processing is usually modeled as a set of activities interconnected through data flows - as known as workflows. Due to their high computational cost, several strategies were proposed to improve the efficiency of data-intensive workflows, such as activities clustering to minimize data transfers and parallelization of data processing for reducing makespan, in which two or more activities are performed at same time on different computational resources. The parallelism, in this case, is defined in the structure of the workflow's model of activities composition. In general, Workflow Management Systems are responsible for the coordination and execution of these activities in a distributed environment. However, they are not aware of the type of processing that will be performed by each one of them. Thus, they are not able to automatically explore strategies for parallel execution. Parallelizable activities are defined by user at workflow design time and creating a structure that makes an efficient use of a distributed environment is not a trivial task. This work aims to provide more efficient executions for data intensive workflows and, for that, proposes a method for automatic parallelization of these applications, focusing on users who are not specialists in high performance computing. This method defines nine semantic annotations to characterize how data is accessed and consumed by activities and thus, taking into account the available computational resources, automatically creates strategies that explore data parallelism. The proposed method generates replicas of annotated activities. It also defines a workflow data indexing and distribution scheme that allows greater parallel access. Its efficiency was evaluated in two workflow models with real data, executed in Amazon cloud platform. A relational (PostgreSQL) and a NoSQL (MongoDB) DBMS were used to manage up to 20.5 million of data objects in 21 scenarios with different partitioning and data replication settings. The experiments have shown that the parallelization of the execution of the activities promoted by the method resulted in a reduction of up to $66.6 \%$ in the workflow's makespan without increasing its monetary cost.

Keywords: Data Parallelism, NoSQL, Data-intensive Workflows. 


\section{Sumário}

$\begin{array}{ll}\text { Lista de Abreviaturas } & \text { ix }\end{array}$

Lista de Figuras $\quad$ xi

Lista de Tabelas $\quad$ xiii

1 Introdução $\quad 1$

1.1 Motivação . . . . . . . . . . . . . . . . . . . . . . . . . . . 1

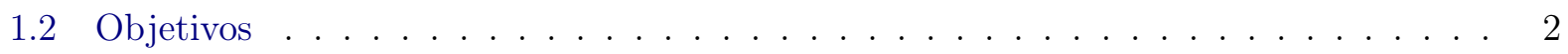

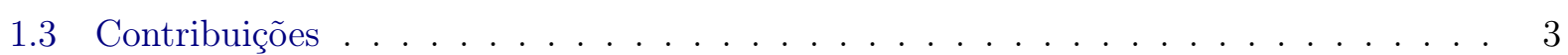

1.4 Organização do Texto . . . . . . . . . . . . . . . . . . . 4

2 Fundamentação Teórica $\quad 5$

2.1 Caracterização e Execução de Workflows . . . . . . . . . . . . . . . . . . . . 5

2.1 .1 Terminologia . . . . . . . . . . . . . . . . 6

2.1.2 Estruturas para a Representação de Fluxos de Dados . . . . . . . . . . . . . . 6

2.1.3 Sistemas de Gerenciamento de Workflows . . . . . . . . . . . . . . . . . . 7

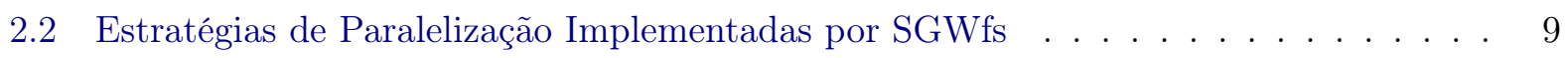

2.2.1 Execução Paralela de Atividades . . . . . . . . . . . . . . . . . . . 9

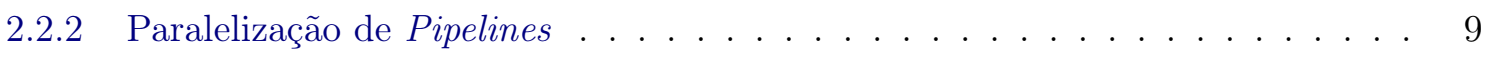

2.2 .3 Paralelismo de Dados . . . . . . . . . . . . . . . . . . . . . . . . . . . . . . 10

2.3 Sistemas Gerenciadores de Banco de Dados . . . . . . . . . . . . . . . . . . . . . 12

2.3.1 Modelo Relacional . . . . . . . . . . . . . . . . . . . . . . . . . . . . . 12

2.3 .2 Sistemas NoSQL . . . . . . . . . . . . . . . . . . . . . . . . . 13

2.3.3 Análise do Ecossistema Atual de SGBDs . . . . . . . . . . . . . . . . . . . 16

2.4 Considerações sobre o Capítulo . . . . . . . . . . . . . . . . . . . . . . . 17

3 Trabalhos Relacionados $\quad 19$

3.1 Modelos de Programação Distribuída . . . . . . . . . . . . . . . . . . . . . . . . 19

3.2 Paralelização de Atividades em SGWfs . . . . . . . . . . . . . . . . . . 20

3.3 Gerenciamento de Dados de Workflows . . . . . . . . . . . . . . . . . . . 22

3.4 Considerações sobre o Capítulo . . . . . . . . . . . . . . . . . 23

4 Paralelização Automática de Workflows Intensivos em Dados 25

4.1 Considerações Iniciais . . . . . . . . . . . . . . . . . . . . . 25

4.2 Anotações sobre o Workflow . . . . . . . . . . . . . . . . . 26 
4.2.1 Caracterização das Atividades . . . . . . . . . . . . . . . . . . . . . 26

4.3 Transformações Baseadas na Semântica da Atividade . . . . . . . . . . . . . . . . . . 34

4.3.1 Reestruturação do Workflow . . . . . . . . . . . . . . . . . . . . . . . 35

4.3.2 Modificações no Banco de Dados . . . . . . . . . . . . . . . . . . . . . . . . . 38

4.4 Implementação do Método: Ferramenta SciWonc-Dataflow . . . . . . . . . . . . . . . 38

4.5 Considerações sobre o Capítulo . . . . . . . . . . . . . . . . . . . . . . . . 42

5 Ambiente Experimental 43

5.1 SGWf Pegasus . . . . . . . . . . . . . . . . . . . . . . . . . . . . . . 43

5.2 SGBDs Avaliados . . . . . . . . . . . . . . . . . . . . . . . . . . . 44

5.2.1 PostgreSQL . . . . . . . . . . . . ............... 44

5.2 MongoDB ............................. . 44

5.3 Plataforma de Computação em Nuvem . . . . . . . . . . . . . . . . . . . . . . . . 45

5.4 Considerações Sobre o Capítulo . . . . . . . . . . . . . . . . . . . . . . . 46

6 Experimento 1: Workflow para Análise de Logs de um Aglomerado 49

6.1 Descrição do Banco de Dados Analisado . . . . . . . . . . . . . . . . . . . . . . . 49

6.2 Modelo de Workflow . . . . . . . . . . . . . . . . . . . . . . . . . . 51

6.3 Execução do Modelo de Workflow . . . . . . . . . . . . . . . . . . . . . . . . . . . 52

6.4 Análise dos Resultados . . . . . . . . . . . . . . . . . . . . . . . . . . . . 60

6.5 Considerações sobre o Capítulo . . . . . . . . . . . . . . . . . . . . . . . 63

7 Experimento 2: Workflow para Análise de Edições da Wikipédia 65

7.1 Modelo de Workflow . . . . . . . . . . . . . . . . . . . . . . 66

7.2 Execução do Modelo de Workflow . . . . . . . . . . . . . . . . . . . . . . 66

7.3 Análise dos Resultados . . . . . . . . . . . . . . . . . . . . . . . . 73

7.4 Considerações sobre o Capítulo . . . . . . . . . . . . . . . . . . . . . . . . . . 74

8 Considerações Finais $\quad 75$

8.1 Pesquisas Futuras . . . . . . . . . . . . . . . . . . . . . . 75

$\begin{array}{ll}\text { Referências Bibliográficas } & 77\end{array}$ 


\title{
Lista de Abreviaturas
}

\author{
SGWf Sistema de Gerenciamento de Workflows \\ SGBD Sistema Gerenciador de Bancos de Dados \\ SciWfA Álgebra de Workflow Científico (do inglês Scientific Workflow Algebra) \\ IaaS Infraestrutura como Serviço (do inglês Infrastructure as a Service)
}




\section{Lista de Figuras}

2.1 Representação da estrutura de um workflow. Os nós representam as atividades e os arcos, as dependências entre as atividades. . . . . . . . . . . . . . . . . . . . 5

2.2 Construções básicas para modelagem de fluxos de dados (extraídas de [BC14]): (a) Processamento; (b) Pipeline; (c) Distribuição de dados; (d) Agregação de dados; (e) Redistribuição de dados. . . . . . . . . . . . . . . . . . . . . . . . .

2.3 Representação de uma estrutura de SGWf em que um nó de submissão é responsável pela transformação do modelo do workflow em instância. . . . . . . . . . . . . . . . . 8

2.4 Representação de um pipeline com duas atividades, $A_{1}$ e $A_{2}$, que consomem um vetor $d 10$

2.5 Comparação da execução sequencial com a execução paralela do pipeline descrito na Figura 2.4. . . . . . . . . . . . . . . . . . . . . . . . . . 10

3.1 Exemplo da composição dos vetores de entrada de um serviço do Moteur: (a) composição um-para-um; (b) composição todos-para-todos . . . . . . . . . . . . . . . . . 22

4.1 Exemplo de uma coleção de objetos definidos pelos atributos ID e Nome em um modelo relacional e em um modelo NoSQL orientado a agregados. . . . . . . . . . . . 26

4.2 Representação do Modelo do Workflow PlayFlow, adotado como exemplo para ilustrar as anotações propostas neste trabalho. . . . . . . . . . . . . . . . . . . . . . . 27

4.3 Exemplo de uso das anotações CE e CS para um banco de dados NoSQL . . . . . . . 29

4.4 Exemplo de uso das anotações CE e CS para um banco de dados relacional . . . . . 29

4.5 Exemplo de uso da anotação SA para um banco de dados relacional . . . . . . . . . . 30

4.6 Exemplo de uso da anotação $O O$ da atividade $A$ sobre os objetos da coleção LogPlaylist, indicando que tais objetos devem ser ordenados pelo atributo Horário de Início, Horário de Término. . . . . . . . . . . . . . . . . . . . . . . . . . . . . . . . . . . . . . 30

4.7 Exemplo de uso da anotação $O O$ da atividade $B$ sobre os objetos da coleção LogPlaylist, indicando que tais objetos devem ser ordenados pelo atributo Duração da Música. . . 31

4.8 Exemplo de duas atividades utilizadas para a análise do perfil de execução das músicas descritas na coleção de entrada LogPlaylist. A atividade $C$ ilustra o uso da anotação PO. . . . . . . . . . . . . . . . . . . . . . . . . . . . . . . . . . . 32

4.9 Exemplo do uso da anotação $P G$ para analisar o artista preferido de um usuário por meio do workflow PlayFlow . . . . . . . . . . . . . . . . . . . . . . . . . 33

4.10 Exemplo de uso da anotação PJT para o cálculo da média de execuções de músicas por dia de um usuário no workflow PlayFlow. . . . . . . . . . . . . . . . . . . . . . 34

4.11 Exemplo de uso da anotação $P V D$ para a computação do total de músicas distintas na coleção LogPlaylist, analisada pelo workflow PlayFlow. . . . . . . . . . . . . . . 35 
4.12 Subconjuntos de uma coleção de entrada definidos a partir de uma anotação $P O$ sobre uma atividade $X$ e de parâmetros de execução de uma instância de workflow que contém esta atividade. O atributo ID define uma chave primária. . . . . . . . . . 36

5.1 Representação de um cluster do MongoDB com três partições de dados (shards) com fator de replicação igual a três, um conjunto de três servidores de configuração (configservers) e serviços de roteamento de consulta (mongos) . . . . . . . . . . .

6.1 Diagrama de estados possíveis durante o ciclo de vida de uma tarefa no arquivo de

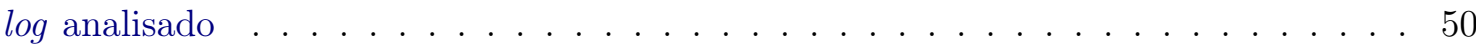

6.2 Modelo inicial do workflow de análise de logs de um cluster do Google . . . . . . . . 52

6.3 Representação da reestruturação aplicável ao modelo de workflow de análise de logs de um cluster do Google gerado a partir das anotações semânticas . . . . . . . . . 53

6.4 Notação gráfica adotada para descrever os cenários apresentados nas Figuras 6.5 a 6.1154

6.5 Makespans médios das execuções do workflow de análise de logs nos diferentes cená-

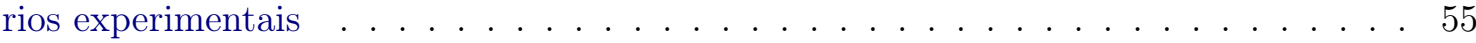

6.6 Custos financeiros médios das execuções do workflow nos diferentes cenários experimentais, considerando a cobrança por hora-cheia. Os custos incluem o uso das máquinas de execução, submissão e do banco de dados.

6.7 Tempos médios das execuções da atividade $\mathrm{F}$ do workflow de análise de logs, com a anotação $P G \ldots \ldots \ldots \ldots \ldots \ldots$

6.8 Tempos médios das execuções da atividade $\mathrm{G}$ do workflow de análise de logs, com a

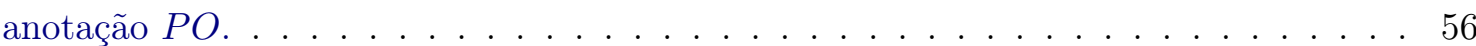

6.9 Tempos médios das execuções da atividade $\mathrm{H}$ do workflow de análise de logs, com a anotação $P G$, que consumiu os dados gerados pela atividade G. . . . . . . . . . . . . 56

6.10 Tempos das Execuções do Workflow de Análise de Logs para o processamento de 43,4 milhões de objetos de dados de entrada . . . . . . . . . . . . . . . . . . . 56

6.11 Custos Financeiros da Execução do Workflow de Análise de Logs com 43,4 milhões de objetos de dados de entrada . . . . . . . . . . . . . . . . . . . . . 57

7.1 Modelo inicial do workflow para análise de edições da Wikipédia. As atividades $A$ e E representam atividades artificiais criadas pelo método. . . . . . . . . . . . . . 67

7.2 Representação da reestruturação aplicável ao modelo de workflow para análise de edições da Wikipédia, gerada a partir das suas anotações semânticas . . . . . . . . . 67

7.3 Notação gráfica adotada para descrever os cenários apresentados nas Figuras 7.4 a 7.868

7.4 Makespans médios das execuções do workflow de análise de edições da Wikipédia . . 69

7.5 Custos financeiros médios das execuções do workflow de análise de edições da Wikipédia 69

7.6 Tempos médios de execução da Atividade B do workflow de análise de edições da Wikipédia . . . . . . . . . . . . . . . . . . . . 69

7.7 Tempos médios de execução da Atividade $\mathrm{C}$ do workflow de análise de edições da Wikipédia . . . . . . . . . . . . . . . . . . . . 69

7.8 Tempos médios de execução da Atividade D do workflow de análise de edições da

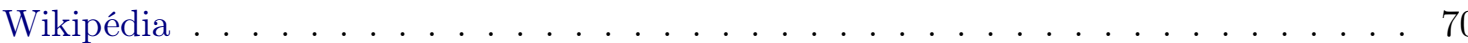




\section{Lista de Tabelas}

3.1 Descrição dos operadores algébricos e sua relação de consumo e geração de tuplas na Álgebra para Workflows Científicos (SciWfA) . . . . . . . . . . . . . . . . 20

5.1 Caracterização dos cenários de execução avaliados. . . . . . . . . . . . . . . . . . 47

6.1 Descrição dos estados disponíveis para tarefas do cluster avaliado . . . . . . . . . . 50

6.2 Tabela com o nível de consistência obtido na execução dos experimentos do workflow para análise de logs. . . . . . . . . . . . . . . . . . . . 54

6.3 Comparação do makespan médio entre as execuções dos workflows do Experimento 1. 58

6.4 Comparação do custo monetário entre as execuções dos workflows do Experimento 159

7.1 Comparação do makespan entre as execuções das instâncias do Experimento 2 . . . . 71

7.2 Comparação do custo entre as execuções das instâncias do Experimento 2 . . . . . . 72 


\section{Capítulo 1}

\section{Introdução}

A exploração de grandes conjuntos de dados é um dos grandes desafios computacionais atuais, não só para a ciência, mas também para a indústria e a administração pública [PZ14, CZ14, HTT09, SLBA11]. No contexto científico, esse fenômeno apresenta-se como uma nova forma de investigação [CBGK13, Wri14], em que o método científico passa a ser dependente de ambientes computacionais de alto desempenho para o processamento dos dados obtidos em domínios como medicina, física e astronomia [HT03]. Temos como exemplo o projeto do acelerador de partículas LHC (Large Hadron Collider), que gera aproximadamente 25 petabytes de dados por ano [CER13]. $\mathrm{Na}$ área industrial, podemos observar o crescimento da análise preditiva de dados [Dha13] e a necessidade de ferramentas escaláveis e tolerantes a falhas, voltadas principalmente para execução distribuída em plataformas de computação em nuvem - um paradigma da computação distribuída que permite o fornecimento de ambientes computacionais como serviços, acessíveis via Internet e provisionados sob demanda [MG09, VRMCL08]. Já no setor público, a criação de políticas e serviços aplicados a áreas como saúde e segurança tem se beneficiado, por exemplo, da análise de dados obtidos a partir de sensores para a monitoração em tempo real de áreas públicas, que podem fornecer alertas sobre possíveis áreas de alagamento, entre outras informações [Kit14].

A manipulação de dados em grande escala é uma tendência; estima-se que, somente na área de negócios, o volume de dados disponíveis duplica a cada 1,2 anos [ $\left.\mathrm{MCB}^{+} 11\right]$. E em todos esses cenários, faz-se necessário o desenvolvimento de técnicas e tecnologias mais escaláveis e com maior desempenho, que sejam capazes de suportar o armazenamento e a análise de grandes volumes de dados e que se apresentam com grande variedade de características e complexidade [CZ14].

\subsection{Motivação}

Os processos de análise de dados geralmente são modelados como atividades interligadas por meio de fluxos de dados - os workflows. Podem ser decompostos em etapas como as de aquisição, filtragem, processamento de dados e análise dos resultados, entre outras. No contexto científico, essas aplicações são conhecidas também como workflows científicos [BC14]. Referenciamos neste trabalho como workflows intensivos em dados os workflows orientados a fluxos de dados que manipulam grandes volumes de dados, não restritos ao domínio científico.

Em muitos tipos de atividades, como as de filtragem, os dados de entrada podem ser particionados ou replicados para habilitar o processamento paralelo e diminuir o tempo da execução. Nesse cenário, duas ou mais atividades podem processar ao mesmo tempo o mesmo conjunto de dados ou diferentes partições desses dados, de modo que cada uma seja executada em um recurso computacional ou processador distinto, normalmente pertencente a uma plataforma de computação distribuída - um ambiente de execução composto por uma coleção de computadores interconectados por uma rede de alto desempenho $\left[\mathrm{BYV}^{+}\right.$09, BB99].

Modelos de programação orientados a fluxos de dados, como o MapReduce [DG10], permitem o processamento distribuído de workflows caso suas atividades possam ser descritas por meio de funções para mapeamento e agregação de dados. Entretanto, o uso desses modelos tem como requisito 
que seus usuários dominem os conceitos da ciência da computação e sejam capazes de especificar, programaticamente, cada tarefa de processamento de acordo com o modelo adotado. Além disso, no geral, eles não apoiam mecanismos para captura de proveniência de dados ${ }^{1}$, aspecto importante no contexto científico. Por essa razão, no processamento de dados científicos de grande escala, os Sistemas de Gerenciamento de Workflows Orientados a Fluxos de Dados (ou, simplesmente, Sistemas de Gerenciamento de Workflows - SGWf) apresentam-se como uma das soluções mais usadas [DGST09].

Um SGWf, em geral, fornece um conjunto de recursos que permitem que a infraestrutura computacional distribuída, necessária para a execução do processamento, seja transparente ao usuário [CBGK13]. Provê, ainda, ferramentas de monitoração, visualização e recuperação de falhas. É voltado para usuários não-especialistas em ciência da computação, tornando-se uma ferramenta interessante para ser aplicada na análise de dados de grande escala, referente a diferentes domínios. Na maioria dos SGWfs, é necessário apenas que o usuário modele, de forma abstrata, as etapas de processamento de dados como atividades para consumo e geração de dados, cuja ordem de execução é descrita a partir do fluxo de dados entre as atividades do workflow.

Os workflows intensivos em dados têm alto custo computacional e, para melhorar a eficiência de suas execuções, diferentes abordagens já foram propostas, tais como o agrupamento de atividades para a redução do volume de dados transferidos [SSV+08], o uso de informações de localidade dos dados no escalonamento [dOBNP15] e a definição de modelos para paralelização da execução [PA06], com o objetivo de reduzir o tempo total de execução (makespan).

Em Ogasawara et al. $\left[\mathrm{OOV}^{+} 11\right]$ é proposta uma abordagem algébrica, em que o nível de paralelismo de dados aplicável a uma atividade é definido por meio de operadores que indicam a relação entre dados consumidos e gerados por ela. Sua implementação mais conhecida é descrita pelo sistema SciCumulus [dOOBM10]. Essa abordagem permite a paralelização automática, no entanto, limita o tipo de processamento descrito a seis operadores e não possibilita, por exemplo, a representação de operações baseada em janelas temporais ou deslizantes. Além disso, ela obriga o projetista do workflow a definir, em tempo de projeto, a cardinalidade do conjunto de dados gerado por cada atividade em relação aos dados consumidos.

O uso de operadores para descrição de processamento paralelo de atividades é implementada também no sistema Swift/T $\left[\mathrm{WHW}^{+} 11, \mathrm{WAW}^{+} 13\right]$, que não possui a restrição de cardinalidade sobre o consumo e produção de itens de dados em cada atividade, no entanto, exige que o paralelismo seja descrito programaticamente. Já no sistema Pegasus [DVJ $\left.{ }^{+} 15\right]$ - SGWf utilizado em diversos domínios da ciência $\left[\mathrm{SVR}^{+} 07, \mathrm{MCD}^{+} 15, \mathrm{JDV}^{+} 09, \mathrm{CDG}^{+}\right.$10] - o paralelismo de atividades é obtido por meio da análise das dependências existentes entre as atividades do workflow, descritas pelo usuário por meio de uma linguagem para especificação de workflows.

De modo geral, é a estrutura do workflow que define o paralelismo da aplicação. O SGWf desconhece o tipo de processamento a ser realizado nas atividades de um workflow, por isso não é capaz de explorar estratégias para execução paralela automaticamente. As atividades paralelizáveis são definidas pelo usuário em tempo de projeto e criar uma estrutura que faça uso eficiente do ambiente de execução não é uma tarefa trivial.

\subsection{Objetivos}

Este trabalho aborda o problema da execução eficiente de workflows intensivos em dados em plataformas de alto desempenho. Nesse contexto, tem-se como objetivo melhorar a eficiência na execução aumentando o processamento paralelo dos dados nos workflows. Além disso, essa paralelização deve ser feita de forma automática, para que o projetista do workflow não necessite ser um especialista em computação paralela e distribuída.

Para isso, propomos anotações semânticas aplicáveis sobre o modelo do workflow para caracterizar as atividades quanto ao tipo de processamento de dados que estas realizam e, assim, indicar as

\footnotetext{
${ }^{1}$ Proveniência é a descrição da origem de um item de dado, incluindo as informações de todos os processos necessários para que ele possa ser produzido.
} 
que podem se beneficiar de uma execução paralela. Além disso, estabelecemos também anotações sobre os atributos utilizados por cada atividade, que possibilitam a recuperação dos dados de forma mais eficiente, por meio, por exemplo, da criação de índices.

As anotações propostas, juntamente com dados sobre o ambiente de execução e o banco de dados utilizados, compõem os parâmetros de entrada para o método desenvolvido neste trabalho e permitem a criação de estratégias para paralelização automática de atividades em workflows de acordo com a plataforma e o sistema de banco de dados utilizados. O paralelismo é explorado tanto na estrutura do workflow, por meio da criação de réplicas de uma atividade anotada, em que subconjuntos disjuntos dos dados de entrada são associados a essas cópias, quanto no acesso aos dados, a partir da definição de um esquema de indexação e distribuição dos dados do workflow que permite maior acesso paralelo aos mesmos. Assume-se que os dados são mantidos em um Sistema Gerenciador de Banco de Dados (SGBD), devido a suas funcionalidades, tais como gerenciamento de acesso concorrente, otimização de consultas, persistência dos dados e controle de acesso de usuários.

O método desenvolvido é aplicável tanto a workflows que utilizam bancos de dados relacionais quanto aos que usam sistemas NoSQL, que usam novos modelos de dados e tecnologias com maior escalabilidade. Os SGBDs relacionais, apesar de serem uma escolha tradicional e bem sucedida para a gestão de bancos de dados, possuem limitações para a execução em ambientes distribuídos devido ao seu controle transacional [SF12] e por isso mostram-se menos viáveis que os sistemas NoSQL orientado a documentos para o gerenciamento de dados dos workflows alvos deste trabalho. Essa característica foi confirmada nos experimentos realizados para a validação do método proposto. No entanto, destacamos que os resultados mostraram que as estratégias aplicadas para paralelização automática dos workflows avaliados geraram redução do tempo de execução tanto em cenários com bancos de dados relacionais quanto em sistemas NoSQL, como consequência do uso mais eficiente do ambiente de execução.

\subsection{Contribuições}

As principais contribuições deste trabalho são as seguintes:

- Um método para criação automática de estratégias de execução paralela de workflows orientados a fluxos de dados; esse método usa como entrada anotações semânticas sobre as atividades do workflow e informações sobre o ambiente de execução;

- A implementação desse método como uma biblioteca em Python, a SciWonC-Dataflow [WGB16], que pode ser usada com workflows gerenciados por meio do SGWf Pegasus.

Essa biblioteca possibilita a adição das anotações propostas pelo método a um modelo de workflow, a transformação do modelo e do banco de dados e o interfaceamento das requisições ao banco de dados conforme as anotações adicionadas em cada atividade do workflow;

- Implementação de dois workflows reais para o SGWf Pegasus, que possibilitaram a validação e avaliação do método em 21 cenários de execução distintos, envolvendo o acesso tanto a um banco de dados NoSQL quanto a um banco de dados relacional.

Os resultados obtidos a partir da execução distribuída desses workflows em um aglomerado virtual mantido em uma plataforma de computação em nuvem pública mostraram que o paralelismo extraído a partir das anotações semânticas propostas neste trabalho diminui significativamente os tempos de execução dos workflows em vários cenários.

Parte dos resultados deste trabalho foram divulgados em um artigo publicado nos Anais do XXXI Simpósio Brasileiro de Banco de Dados (SBBD 2016) [WB16]. 


\subsection{Organização do Texto}

Estruturamos este texto da seguinte forma: no Capítulo 2, descrevemos os principais conceitos relacionados a este trabalho. No Capítulo 3, listamos e discutimos os trabalhos relacionados e, no Capítulo 4, apresentamos o método proposto para explorar o paralelismo em workflows, que descreve as anotações semânticas e as modificações no workflow e no banco de dados resultantes de cada anotação. Para avaliar a eficiência desse método, testamos o uso das anotações em dois modelos de workflow; o ambiente experimental usado na execução é descrito no Capítulo 5 e os resultados obtidos em cada caso são apresentados nos Capítulos 6 e 7. Por fim, no Capítulo 8, discutimos as conclusões obtidas neste trabalho. Analisamos as vantagens e desvantagens do método proposto, assim como destacamos possíveis trabalhos futuros. 


\section{Capítulo 2}

\section{Fundamentação Teórica}

Neste capítulo, são apresentadas as principais definições e fundamentos relacionados ao método proposto neste trabalho para paralelização de workflows. Caracterizamos as aplicações definidas como workflows de análise de dados. Detalhamos a terminologia utiliza nesse contexto, o modo como um workflow é comumente modelado e interpretado pelos sistemas que gerenciam sua execução em ambientes distribuídos. Destacamos ainda como a paralelização é aplicada em workflows e como seus dados podem ser manipulados por um SGBD relacional ou NoSQL.

\subsection{Caracterização e Execução de Workflows}

Um workflow pode ser definido como um Grafo Acíclico Dirigido (Directed Acyclic Graph $D A G)$, cujos vértices representam as atividades de processamento de dados e os arcos definem as dependências de dados existentes entre essas atividades [YB05, CVDK $\left.{ }^{+} 12\right]$. É comumente modelado como um fluxo de dados, de modo que a execução de uma atividade esteja sempre condicionada à disponibilidade dos dados de entrada dos quais ela dependa [BC14]. A Figura 2.1 ilustra essa representação. O término da execução da atividade $A$ habilita a execução paralela das atividades $B, C$ e $D$. Estas, por sua vez, geram dados que serão consumidos pela atividade $E$, que iniciará sua execução somente quando todas as atividades anteriores estiverem concluídas, realizando uma sincronização das linhas de execução paralelas.

Nesta seção, introduzimos os demais conceitos sobre a descrição de um workflow e de seu ciclo de execução.

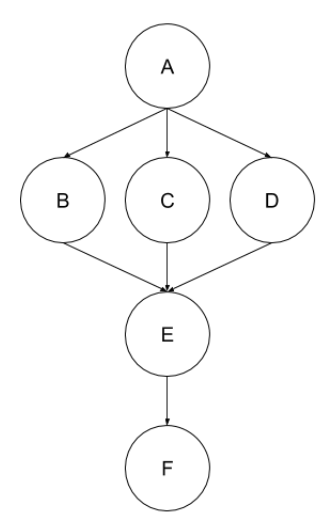

Figura 2.1: Representação da estrutura de um workflow. Os nós representam as atividades e os arcos, as dependências entre as atividades. 


\subsubsection{Terminologia}

Aplicações descritas como Workflows são compostas basicamente por atividades de processamento de dados e por conexões existentes entre essas atividades e seus conjuntos de dados. Utilizamos neste trabalho a seguinte terminologia [BC14]:

- Atividade - É a unidade atômica (indivisível) de trabalho em modelos de workflows, apresentada também na literatura como tarefa, processo, ação, transição e passo de execução. Uma atividade pode representar um acesso a banco de dados, um processo de filtragem, etc. Consideramos como atividade cada tarefa responsável pelo processamento de um conjunto de dados de entrada e geração de um novo conjunto de dados de saída em um workflow.

- Modelo de workflow - Define o conjunto de atividades que serão executadas como um workflow para que uma determinada análise de dados e/ou objetivo seja atingido. O modelo permite estabelecer a ordem (ainda que parcial) na qual as atividades devem ser executadas, podendo ser definido por meio de uma linguagem de especificação ou um arcabouço formal.

Arcabouços formais permitem a análise das propriedades de cada fluxo modelado, enquanto que as linguagens de especificação possibilitam detalhar tais fluxos de maneira mais próxima ao processo de execução do workflow.

- Conectores - Definem as dependências de dados entre as atividades, representando as relações de precedência ou de transferência de dados de uma atividade para outra.

Cada linguagem de especificação de workflows possui seu conjunto de conectores, sendo estes os responsáveis por determinar a expressividade de uma linguagem, pois definem a quantidade e variedade de modelos de workflows que podem ser descritos.

Os conectores para fluxos de dados são descritos na Seção 2.1.2.

- Instância de Workflow - É a instanciação, ou seja, a execução de um modelo de workflow de acordo com uma determinada entrada e parâmetros específicos.

Duas instâncias de um mesmo modelo de workflow não executam obrigatoriamente a mesma sequência de atividades, uma vez que um workflow pode ter caminhos de execução alternativos ou atividades que serão executadas somente se certos tipos de dados estiverem disponíveis.

\subsubsection{Estruturas para a Representação de Fluxos de Dados}

As construções de fluxos de dados retratam as dependências de dados entre as atividades de um workflow. Bharathi et al. $\left[\mathrm{BCD}^{+} 08\right]$ categoriza cinco construções como básicas, que são descritas como:

- Processamento - É o construtor mais simples, que representa o processamento de dados de entrada realizado por uma atividade para geração de dados de saída (Figura 2.2 (a)).

- Pipeline - Pode ser visto como uma sequência de processamentos, em que cada atividade processa os dados originários das saídas das atividades precedentes e sua saída é também a entrada da próxima atividade a ser executada do pipeline (Figura 2.2 (b)).

- Distribuição de dados - É feita por uma atividade que produz dois ou mais conjuntos de dados de saída que serão consumidos por duas ou mais atividades (Figura 2.2 (c)). Esta distribuição pode ter dois objetivos distintos: (i) produzir novos conjuntos de dados que servirão de entradas para múltiplas atividades; (ii) ou particionar em subconjuntos menores um grande conjunto de dados recebido como entrada, para serem processados por outras atividades. O processo de distribuição de dados com o segundo propósito apenas é conhecido também como particionamento ou fragmentação. 
- Agregação de dados - É a junção e processamento de dados de saída de uma ou mais atividades em uma única atividade, que gera uma combinação desses dados como saída (Figura 2.2 (d)). Pode ser vista também como uma sincronização de linhas de execução paralelas de uma instância de workflow.

- Redistribuição de dados: combina a estrutura de agregação de dados à de distribuição. A atividade recebe múltiplos conjuntos de dados como entrada e produz como saída também múltiplos conjuntos de dados, sendo aplicada tanto para sincronização de linhas de execução paralelas quanto para criação de novas linhas de execução paralelas (Figura 2.2 (e)).

Um exemplo de representação gráfica dessas construções pode ser visto na Figura 2.2 (extraída de [BC14]), em que uma atividade é expressa graficamente como um retângulo ligado a seus conjuntos de dados de entrada e saída por meio de setas.

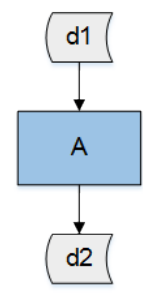

(a)

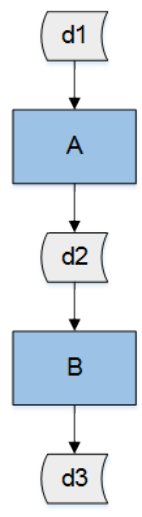

(b)

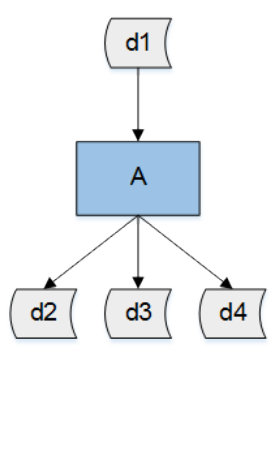

(c)

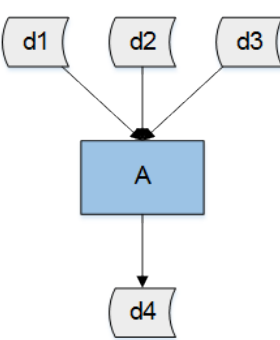

(d)

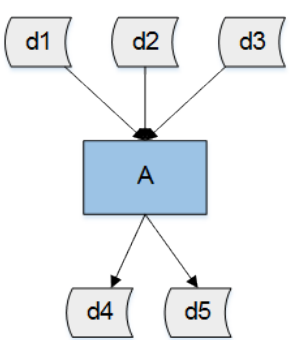

(e)

Figura 2.2: Construções básicas para modelagem de fluxos de dados (extraídas de [BC14]): (a) Processamento; (b) Pipeline; (c) Distribuição de dados; (d) Agregação de dados; (e) Redistribuição de dados.

Essas construções são vistas como conectores de atividades dos workflows orientados a dados e comumente descritas somente na linguagem de especificação e não na ilustração do modelo, como visto na Figura 2.1.

\subsubsection{Sistemas de Gerenciamento de Workflows}

Como vimos na Seção 2.1.1, um modelo de workflow define apenas o fluxo de execução de uma atividade; as informações necessárias para a execução de um workflow em uma plataforma específica são descritas em uma instância do modelo de workflow. O controle de cada etapa do ciclo de vida de um workflow, desde a geração do modelo até a criação e execução de cada instância, pode ser suportado por um Sistema de Gerenciamento de Workflows.

Um Sistema de Gerenciamento de Workflows é um sistema que permite definir, modificar, gerenciar, monitorar e executar workflows científicos [LLF ${ }^{+}$09]. Visa reduzir custos tanto com recursos humanos quanto computacionais e acelerar o processo de transformação dos dados em conhecimento e descobertas. Para isso, deve fornecer interfaces de suporte à interação do usuário, mecanismos para captura de dados de proveniência e integração das ferramentas e serviços utilizados pelos workflows, além de gerenciar os dados e o ambiente computacional utilizado.

Sua arquitetura básica $\left[\mathrm{LLF}^{+} 09\right]$ pode ser descrita como uma composição de subsistemas especializados em funções como descrição de modelos de workflows, visualização e apresentação de dados, controle e monitoração da execução das atividades e gerenciamento de todos os dados consumidos e produzidos.

Em especial, destacamos os subsistemas de execução e de gerenciamento de dados: 
- Subsistema de Execução - É responsável pela instanciação, execução e pelo gerenciamento das atividades de um workflow conforme o modelo especificado pelo usuário. Esse subsistema abrange também o escalonamento do workflow, responsável pela associação das atividades aos recursos computacionais em que serão executadas. Pode ainda controlar execuções concorrentes de diferentes instâncias de workflows.

Em um cenário de execução distribuída, tem-se um conjunto de computadores interconectados para a execução das atividades de uma instância de workflow conhecido como cluster. Nesse conjunto, cada recurso é chamado de nó de execução. Em especial, um desses computadores pode ser eleito como mestre, ou seja, ser encarregado do controle de subsistemas como o de distribuição das tarefas para os demais nós. Um nó pode representar um único computador ou um processador disponível em um computador multi-core. A Figura 2.3 ilustra um SGWf com essa estrutura simplificada; descreve também a interação com o usuário (projetista do workflow), com um ambiente distribuído para execução (composto por quatro nós de execução) e um repositório de dados compartilhado entre os nós.

- Subsistema de Gerenciamento de Dados - É o principal responsável pelo gerenciamento dos dados consumidos e produzidos pelas atividades de um workflow durante a sua execução. Esse subsistema deve lidar com a heterogeneidade e distribuição dos dados derivados e fazer o acesso e movimentação desses dados de modo eficiente, o que é um importante problema de pesquisa. Pode ainda delegar o controle do gerenciamento de dados a um SGBD, fornecendo apenas a interface de acesso a um banco de dados. Outra característica que pode ser endereçada a esse subsistema é a interoperabilidade ${ }^{1}$ dos produtos de dados gerenciados em diferentes workflows e ambientes de execução, permitindo, por exemplo, a utilização de subsistemas de execução especializados em certos ambientes computacionais ou a criação de novos mecanismos para gerenciamento de dados para novos contextos de execução.

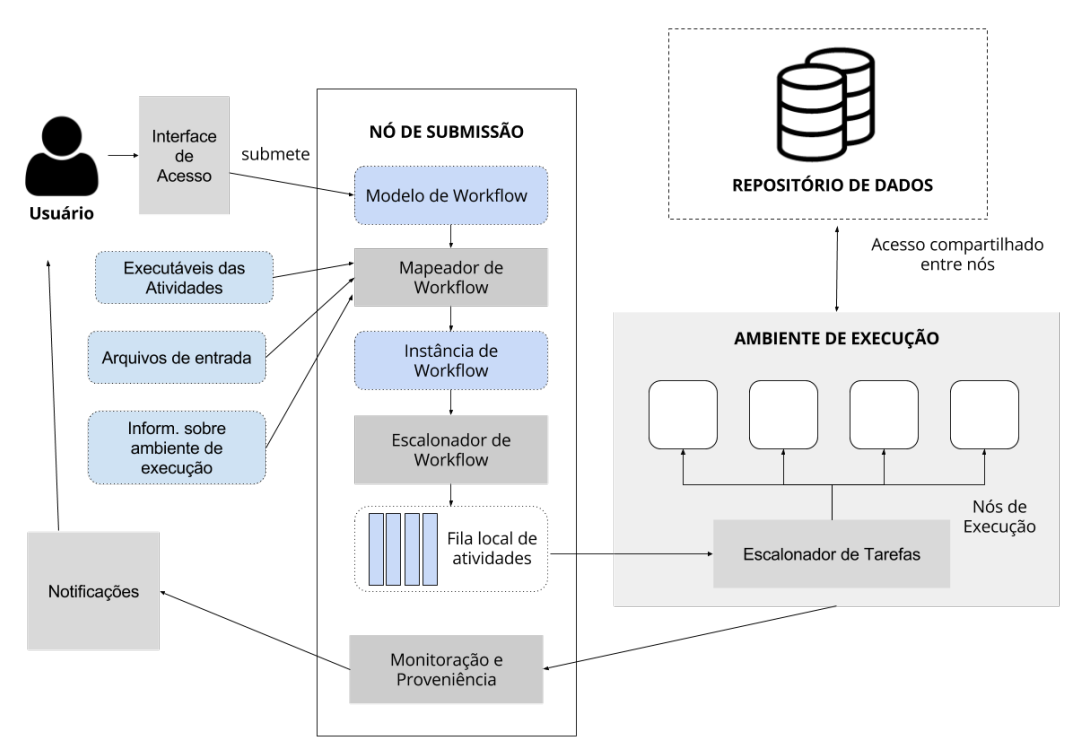

Figura 2.3: Representação de uma estrutura de SGWf em que um nó de submissão é responsável pela transformação do modelo do workflow em instância.

Devido à capacidade de execução paralela de workflows, destacamos neste trabalho três SGWfs para gerenciamento de workflows intensivos em dados: o Pegasus [DVJ ${ }^{+}$15], o SciCumulus [dOOBM10] e o Swift/T WAW $\left.^{+} 13\right]$.

\footnotetext{
${ }^{1}$ Interoperabilidade: é a capacidade de um sistema comunicar-se com outro de forma transparente por meio de um protocolo ou padrão de acesso.
} 
O sistema Pegasus permite o uso de sistemas de arquivos locais ou distribuídos [Peg] para o compartilhamento de arquivos entre os nós de execução que participam da execução de um workflow. É possível ainda a integração via um banco de dados ou por meio de sistemas de armazenamento de objeto, que fornecem interfaces de acesso via web e permitem o armazenamento de maneira escalável de grandes volumes de dados não-estruturados [JDV $\left.{ }^{+} 10\right]$, porém, com operações de consulta e manipulação de dados mais limitadas do que as disponíveis em sistemas de gerenciamento de banco de dados. Em relação ao armazenamento de dados de proveniência das instâncias de workflows, o Pegasus disponibiliza duas opções: o uso de um banco de dados em SQLite [SQL] ou MySQL [Cor].

O SciCumulus tem como principal foco a integração dos dados de proveniência com o processo de controle da execução de workflows. Por padrão, o SGBD PostgreSQL [Gro] é utilizado para o gerenciamento dos metadados, no entanto, é possível a substituição pelo SGBD Cassandra [Foub] um sistema NoSQL. Os dados de domínio, isto é, os dados utilizados pelas atividades da instância de um workflow, podem ser mantidos em um banco de dados, em um sistema de arquivos local ou sistema de armazenamento de objeto [dOOBM10, dAGdOO ${ }^{+} 12$ ].

Em relação ao Swift/T, este possibilita o uso de arquivos para manipulação de dados de domínio em seus workflows [OCWS16]. É possível também utilizar o PostgreSQL ou o SQLite para o gerenciamento de dados de proveniência $\left[\mathrm{MdSO}^{+} 16\right]$.

No contexto de workflows intensivos em dados, o uso de arquivos simples (em sistemas de arquivos locais) como forma de armazenamento de dados de domínio não é uma solução viável. Essa estratégia impossibilita a manipulação de volumes de dados maiores do que a capacidade dos dispositivos de armazenamento de um nó de execução. Além disso, ela dificulta a recuperação eficiente dos dados pelas atividades e o acesso dos usuários finais aos resultados intermediários gerados pelo workflow durante sua execução. Nesses casos, existe a necessidade de um repositório externo de dados, compartilhado entre os nós de execução (conforme descrito pela Figura 2.3). Por essa razão, este trabalho considera que os dados manipulados pelo workflow são mantidos em um sistema gerenciador de banco de dados, que pode prover acessos mais eficientes e armazenamento distribuído.

\subsection{Estratégias de Paralelização Implementadas por SGWfs}

Estratégias de exploração do paralelismo em workflows orientados a fluxos de dados podem permitir a redução de seus tempos de execução. Elas podem ser divididas em paralelismo de atividades, de pipelines e de dados. É possível ainda a combinação dessas estratégias em uma abordagem híbrida, a fim de se obter um maior grau de paralelismo. Esta seção descreve esses três tipos de paralelismo e, em especial, destaca exemplos de implementação do paralelismo de dados, que será explorado por este trabalho.

\subsubsection{Execução Paralela de Atividades}

Esse é o tipo de paralelismo mais simples adotado pela maioria dos SGWfs. Consiste na execução simultânea de atividades independentes entre si, distribuídas em diferentes nós de processamento [LSP $\left.{ }^{+} 14, \mathrm{PA} 06\right]$. Na Figura 2.1, podemos observar esse tipo de paralelismo entre as atividades $\mathrm{B}, \mathrm{C}$ e D.

\subsubsection{Paralelização de Pipelines}

Um pipeline descreve uma sequência de diversas atividades a serem executadas, de modo que os dados produzidos por uma atividade sejam consumidos pela atividade subsequente a medida em que vão sendo produzidos [LSP $\left.{ }^{+} 14\right]$. O paralelismo nesse contexto pode ser explorado no nível do particionamento dos dados, em que o conjunto de dados é descrito como vetores ou listas de tuplas, cujos elementos são itens de dados a serem processados por todo o pipeline [PA06].

Considere como exemplo um vetor $d$ composto por três elementos de dados, $d_{1}, d_{2}$ e $d_{3}$, em que cada elemento será processado por um mesmo pipeline, constituído por duas atividades, $A_{1}$ e $A_{2}$, 
conforme descrito pela Figura 2.4. Uma execução sequencial desse exemplo consistiria no processamento do primeiro elemento $d_{1}$ por todas as atividades que compõem o pipeline. O processamento de $d_{2}$ só seria possível depois do término do processamento de $d_{1}$ pela atividade $A_{2}$. Em uma abordagem paralela, em que cada atividade é executada por um nó de processamento diferente, o processamento de $d_{2}$ pela atividade $A_{1}$ poderia ser habilitado assim que ela terminasse de processar $d_{1}$. Então teríamos em um primeiro momento $A_{1}$ processando $d_{1}$ e em um segundo momento, $A_{1}$ processando $d_{2}$ e $A_{2}$ processando $d_{1}$. Concluída a execução de $d_{1}, A_{2}$ passaria a executar o processamento de $d_{2}$ e $A_{1}$ de $d_{3}$ e, por último, $A_{2}$ executaria $d_{3}$. Podemos observar a redução do tempo de execução em 33,33\% na Figura 2.5, que compara a execução sequencial com a paralela desse exemplo.
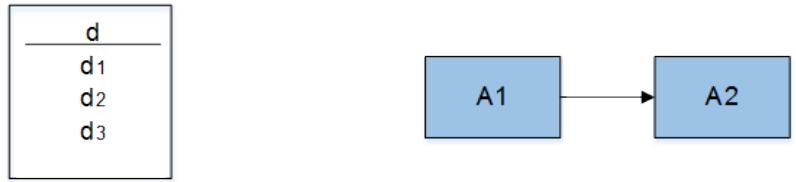

Figura 2.4: Representação de um pipeline com duas atividades, $A_{1}$ e $A_{2}$, que consomem um vetor $d$

\begin{tabular}{l|l|l}
$\mathrm{T}$ & $\mathrm{A} 1$ & $\mathrm{~A} 2$ \\
\hline 1 & $\mathrm{~d} 1$ & $\mathrm{x}$ \\
2 & $\mathrm{x}$ & $\mathrm{d} 1$ \\
3 & $\mathrm{~d} 2$ & $\mathrm{x}$ \\
4 & $\mathrm{x}$ & $\mathrm{d} 2$ \\
5 & $\mathrm{~d} 3$ & $\mathrm{x}$ \\
6 & $\mathrm{x}$ & $\mathrm{d} 3$
\end{tabular}

\begin{tabular}{l|l|l}
$\mathrm{T}$ & $\mathrm{A} 1$ & $\mathrm{~A} 2$ \\
\hline 1 & $\mathrm{~d} 1$ & $\mathrm{x}$ \\
2 & $\mathrm{~d} 2$ & $\mathrm{~d} 1$ \\
3 & $\mathrm{~d} 3$ & $\mathrm{~d} 2$ \\
4 & $\mathrm{x}$ & $\mathrm{d} 3$
\end{tabular}

Exec.Sequencial

Exec. Paralela

Figura 2.5: Comparação da execução sequencial com a execução paralela do pipeline descrito na Figura 2.4.

O conjunto de dados a ser processado pode ser conhecido previamente ou apenas durante a execução, como no caso de processamento em tempo real de dados fornecidos por sensores ou outras fontes de fluxos de dados contínuos (streaming). O método apresentado neste trabalho utiliza o processamento de dados em lote (offline) e considera que todos os dados do conjunto de dados de entrada devem estar disponíveis, ou seja, a atividade responsável pela sua geração precisa ser concluída por completo antes de seus dados de saída serem consumidos.

\subsubsection{Paralelismo de Dados}

O paralelismo de dados consiste na execução da mesma atividade sobre subconjuntos de dados. Essa técnica possibilita acelerar a execução de workflows que manipulam grandes quantidades de dados [PA06].

Nessa abordagem, ao invés de uma única atividade processar um grande conjunto de dados, os dados são particionados e cópias da atividade são criadas, associando uma cópia para cada partição e executando as cópias paralelamente (caso não exista dependência de dados entre as partições).

Devido a essa divisão do conjunto de dados, pode ser necessário pontos de sincronismo para a continuação da execução, tais como esperar a conclusão de todas as cópias da atividade (wait for all), esperar pela conclusão de apenas uma cópia (wait for one) ou esperar pela conclusão de $n$ cópias entre as $m$ cópias da atividade sendo executadas em paralelo (n-out-of- $m$ ) [PA06, vDAHKB03].

Esse modelo de paralelismo pode ser classificado como estático ou dinâmico, sendo que no primeiro caso o número de partições do conjunto de dados é pré-definido e, no segundo caso, 
esse número é determinado durante a execução do workflow por ser dependente, por exemplo, do tamanho atual do conjunto de dados ou do número de recursos disponíveis no momento da execução. O número de partições pode ser definido manualmente ou estimado automaticamente durante a execução.

É possível ainda a adoção de abordagens adaptativas, de modo que o workflow seja capaz de obter informações sobre o ambiente de execução e automaticamente modificar sua execução (no caso dinâmico) ou modificar sua estrutura (no caso estático).

A implementação do paralelismo de dados em workflows científicos pode ser feita das seguintes formas:

- Reescrita do grafo referente ao modelo de workflow - Em uma abordagem estática, essa técnica consiste na substituição de uma atividade do workflow por várias cópias dessa mesma atividade, conforme o número de partições de dados existente. Além disso, mudanças nos demais construtores devem ser feitas para amparar essa estratégia. Já em uma abordagem dinâmica, um vetor de dados pode ser passado como entrada de uma atividade e uma nova instância (cópia) pode ser criada, associada e iniciada em paralelo para cada elemento desse vetor. O número de instâncias criadas varia para cada execução do workflow, em função do número de elementos do vetor.

- Execução de múltiplos processos em uma única atividade - Essa abordagem modifica a suposição de que cada atividade executa apenas um processo computacional. Nesse tipo de modelagem, cada atividade torna-se capaz de executar múltiplos processos computacionais paralelamente, ou seja, pode criar sub-atividades (threads) para o processamento de dados. Desse modo, a criação, gerenciamento e monitoração de cópias de uma mesma atividade pode ficar a encargo de outra atividade do workflow, não sendo necessário, portanto, modificar o modelo de workflow.

- Funções de primeira-ordem - As linguagens de especificação podem basear-se em programação funcional, em que uma função de primeira ordem define os procedimentos a serem aplicados a cada elemento de uma lista de dados passada como entrada. Essa associação entre uma função de primeira-ordem e um elemento de dado permite a execução paralela do processamento. O modelo MapReduce [DG10] implementa esse conceito para a criação de funções do tipo Map, que representam a execução de uma mesma atividade sobre subconjuntos de dados distintos.

- Submissão assincrona de processos - É uma abordagem similar à execução de múltiplos processos em uma única atividade, diferenciando-se pela submissão assíncrona de processos de modo que o gerenciador de tarefas não necessite esperar a conclusão do processo para executar o próximo. Pode combinar o processamento de cada elemento de uma lista de vetores com a criação de um processo para computação dos dados.

Por exemplo, dado um conjunto de dados de entrada descrito como um vetor de dados, é possível especificar a criação de um laço para o processamento de cada elemento desse vetor. Em cada iteração, a atividade é responsável pela criação de um novo processo computacional associado a um dos elementos desse vetor. A atividade inicia a execução paralela desse processo de modo assíncrono, assim, não necessita esperar o seu término para executar a próxima iteração do laço. Entretanto, como essa abordagem não costuma definir pontos de sincronismos entre os processos, não há garantia sobre o acesso aos dados gerados assíncronos.

- Definição de construtores para blocos paralelizáveis (parallel for-each) - Linguagens baseadas em blocos podem utilizar construtores especiais para descrever blocos compostos por atividades que podem ser executadas em paralelo. Esses blocos podem ser definidos dentro de laços, de modo que todas as iterações sejam executadas paralelamente. No entanto, para que essa abordagem seja viável, é necessário que essas atividades não dependam dos resultados das iterações anteriores. Um exemplo de SGWf que implementa esta estratégia é o Swift/T. 
Neste trabalho, implementamos o paralelismo de dados por meio da reescrita do modelo, de maneira estática, associando subconjuntos de dados às réplicas de uma atividade conforme a operação a ser realizada. A atividade subsequente à atividade paralelizada, que consumirá os dados gerados pelas réplicas criadas, aguarda o término da execução de todas as cópias para que receba integralmente o conjunto de dados que irá processar. Para isso, o método proposto, descrito no Capítulo 4, adiciona pontos de sincronismo para garantir o término de execução de todas as réplicas. Considera ainda que, para que a execução paralela de um workflow seja eficiente, a estratégia a ser aplicada para criação de réplicas de uma atividade deve considerar informações sobre o ambiente de execução, de modo a gerar um número de réplicas suficiente para que estas sejam executadas simultaneamente em nós distintos. O tempo de execução de uma atividade paralelizada é medida a partir da execução de sua primeira réplica até o término da última réplica devido, por exemplo, a possíveis desbalanceamentos entre o número de réplicas e o número de nós disponíveis para execução.

\subsection{Sistemas Gerenciadores de Banco de Dados}

Um Sistema Gerenciador de Banco de Dados (SGBD) é uma solução interessante para o gerenciamento de dados em workflows, pois permite a definição, manipulação e compartilhamento de dados entre diferentes usuários e processos. Fornece ainda mecanismos para proteção contra falhas de sistema e hardware, autenticação e autorização de usuários, otimização de consultas, entre outros. Nesta seção, destacamos dois modelos de dados implementados pelos SGBDs e que são comumente utilizados para representação e manipulação de dados em grande escala.

\subsubsection{Modelo Relacional}

Proposto na década de 1970 [Cod70] e amplamente utilizado pela maioria dos SGBDs, o modelo relacional permite a manipulação e gerenciamento de dados estruturados ${ }^{2}$ de forma concorrente e persistente, mantendo a consistência dos dados a cada transação ${ }^{3}$ [EN10].

Em um banco de dados relacional (que implementa o modelo relacional), os dados são organizados em um conjunto de relações (tabelas). Cada relação possui um esquema associado, formado pelo nome desta relação e por uma lista de atributos (colunas) $A_{1}, A_{2}, \ldots, A_{n}$, representado por $R\left(A_{1}, A_{2}, \ldots, A_{n}\right)$. Cada atributo $A_{i}$ é associado a um domínio e identificado por um nome. Representamos esse domínio como $\operatorname{dom}\left(A_{i}\right)$. Um domínio é um conjunto de valores atômicos associado a um tipo de dado, tais como texto ou inteiro. Uma relação $r$ do esquema $R\left(A_{1}, A_{2}, \ldots, A_{n}\right)$ é um conjunto de $n$ tuplas (linhas) $r=\left\{t_{1}, t_{2}, \ldots, t_{m}\right\}$. Cada tupla é uma lista ordenada de $m$ valores $t=\left\langle v_{1}, v_{2}, \ldots, v_{m}>\right.$ em que cada valor $v_{i}$, sendo $i \leq i \leq m$, é um elemento do $\operatorname{dom}\left(A_{i}\right)$. Assim, bancos de dados relacionais lidam com dados estruturados porque impõem um esquema único para todas as tuplas de uma relação, enquanto que dados semiestruturados permitem que o esquema possa variar mesmo para tuplas de uma mesma relação.

Restrições de integridade sobre atributos de uma relação, tais como chaves primárias e estrangeiras permitem que o SGBD mantenha a integridade dos dados. Uma chave primária é composta por um ou mais atributos que identificam uma tupla de forma única em uma relação e uma chave estrangeira identifica um ou mais atributos de uma relação que referenciam uma chave primária de outra tupla na mesma ou em outra relação, indicando a dependência entre seus dados. Tais restrições, aliadas ao controle de concorrência baseado nas propriedades ACID (Atomicidade, Consistência, Isolamento e Durabilidade) [EN10] e ao processo de normalização dos dados, permitem que os dados sejam mantidos em um estado consistente e o espaço necessário para seu armazenamento seja minimizado (requisito essencial para a década em que foi projetado) [Cou15].

\footnotetext{
${ }^{2}$ Dados estruturados (convencionais) referem-se a dados que possuem estruturas bem definidas, fixas e tipos de dados simples, como inteiros e strings.

${ }^{3}$ Uma transação é um conjunto de operações de leitura ou modificação de dados realizado em um SGBD.
} 
A descrição e manipulação dos dados baseada no modelo relacional, juntamente com a definição de uma linguagem de consulta padronizada, a SQL, permitiram que os SGBDs modelassem dados de diferentes aplicações de maneira uniforme e se tornassem uma tecnologia bem-sucedida há mais de 30 anos [SF12].

\subsubsection{Sistemas NoSQL}

No contexto de aplicações Web 2.0, a necessidade de gerenciamento de grandes volumes de dados, semiestruturados e não-estruturados, em um SGBD distribuído, escalável sob demanda e capaz de prover os dados com alta disponibilidade motivaram o desenvolvimento de novas tecnologias e paradigmas [LdOdSP11]. O uso de SGBDs relacionais não se mostrou viável nesses cenários pois, além do gerenciamento exclusivo de dados estruturados, o uso de dados normalizados e de um controle transacional $A C I D$ (vide Seção 2.3.1) limitaram sua execução em ambientes distribuídos. A necessidade de junções entre tabelas e bloqueios para manutenção da consistência forte dos dados distribuídos resultam na degradação do desempenho do SGBD, pois aumentam o tempo de acesso às tabelas envolvidas à medida que mais processos se conectam ao mesmo conjunto de dados ou mais dados são adicionados, reduzindo a disponibilidade do sistema [HJ11].

Assim surgiram os sistemas NoSQL, que não adotam o modelo relacional para a representação de seus dados e implementam um controle transacional mais flexível [HYA ${ }^{+} 14$, Cat11]. Por isso são conhecidos também como Não-SQL (do inglês Not SQL - NoSQL) ou Não-Relacionais.

\section{Principais Características}

Não existe um consenso a respeito da definição desses sistemas, no entanto, eles são comumente caracterizados pelos seguintes atributos [Cat11]:

- Escalabilidade horizontal, de modo que operações simples de leitura e escrita de dados sejam distribuídas entre vários servidores

- Replicação e distribuição (particionamento) de dados em vários servidores

- Uso de uma interface simples (API) para comunicação com o banco de dados ao invés do uso da linguagem SQL

- Adoção de um modelo de controle de concorrência mais fraco que as transações ACID usadas nos SGBDs relacionais

- Uso eficiente de índices distribuídos e da memória principal para armazenamento dos dados

- Capacidade de adicionar dinamicamente novos atributos aos registros de dados (esquema dinâmico), sem a necessidade de alterar ou definir um esquema de descrição dos dados previamente, como ocorre no modelo relacional

Operações simples referem-se a buscas de registros por meio de uma chave de indexação e leituras/escritas de um único registro ou de um conjunto pequeno de registros.

A escalabilidade horizontal se refere à habilidade de um SGBD distribuir seus dados e operações de leitura/escrita entre os servidores (nós) de seu cluster. Para escalar horizontalmente, a arquitetura utilizada pelo SGBD para armazenar os dados em diversos servidores não deve se basear no compartilhamento de memória principal ou disco entre esses servidores (o que é chamado de arquitetura shared nothing) [Cat11]. Isso permite que um servidor seja facilmente adicionado ou removido do cluster. Os nós de processamento de um sistema NoSQL podem ser compostos por computadores mais baratos (computadores de commodity) do que os servidores utilizados por ambientes que escalam verticalmente, como é o caso dos SGBDs relacionais. Eles geralmente centralizam sua arquitetura em um único servidor, com compartilhamento de memória (RAM e disco), e sua escalabilidade fica condicionada à adição de processadores com mais CPUs e maior velocidade, mais 
memória RAM e discos maiores para armazenamento de dados [Cou15]. Assim, esse tipo de abordagem (escalabilidade vertical) é limitada fisicamente pelo número máximo de CPUs que podem compartilhar memória em um único computador [Cat11].

Tanto o particionamento quanto a replicação de dados permitem aumentar a paralelismo do sistema, possibilitando que um grande número de operações simples sejam realizadas a cada segundo. Para isso, a criação de cópias de um dado é geralmente feita de maneira assíncrona, resultando em um possível estado temporário de inconsistência do dados. Entretanto, a janela de inconsistência pode ser pequena, por exemplo, no SimpleDB [Amaa] da Amazon, é descrita como menor que um segundo.

Os sistemas NoSQL vêm acompanhados de novas interfaces de acesso aos dados, uma vez que a linguagem SQL não é capaz de lidar com os novos modelos de dados. Ela foi projetada para manipulação de dados estruturados, organizados em bancos de dados relacionais com tabelas de estruturas fixas [Lea10]. As novas interfaces devem ser capazes de recuperar os dados de maneira rápida e eficiente.

O sistema de controle de concorrência nos sistemas NoSQL é mais flexível que o implementado por SGBD relacionais e segue as propriedades BASE (Basicamente disponível, Estado leve e Consistente em momento indeterminado - do inglês Basically Available, Soft state, Eventually consistent) [Pri08, Pok11], que permitem que o sistema tolere inconsistências temporárias de dados a fim de priorizar a sua disponibilidade e desempenho. Esse modelo descreve sistemas que devem estar disponíveis mesmo que ocorram falhas parciais (Basically Available e que podem não possuir dados consistentes o tempo todo (Soft State) devido à consistência eventual (Eventually consistent) dos dados, que garante que a consistência dos dados será obtida assim que todas as gravações forem propagadas para todos os servidores. Essa mudança de paradigma permitiu maior escalabilidade, flexibilidade, disponibilidade e desempenho no armazenamento e gerenciamento de grandes volumes de dados.

\section{Modelos de Dados}

Novos modelos de dados foram introduzidos pelos sistemas NoSQL. A partir de suas características, esses modelos podem ser divididos em duas grandes categorias [SF12]: orientado a grafos e orientado a agregados.

Em um modelo orientado a grafos, os dados são representados como nós e arestas, onde os nós representam as entidades do banco de dados e as arestas representam os relacionamentos que existem entre as entidades, de modo a descrever redes complexas. Não tem como foco a escalabilidade horizontal; visa à eficiência em consultas transversais nos grafos modelados.

Já em um modelo orientado a agregados, o banco de dados é organizado em coleções de agregados, onde um agregado é um registro que pode ter uma estrutura de dados complexa, com registros aninhados e atributos que contêm listas de valores. Dois agregados em uma mesma coleção estão relacionados semanticamente, mas não precisam ter estrutura igual. O agregado é a unidade de manipulação dos dados e gerenciamento de consistência.

Os modelos orientados a agregados podem ser subdivididos em modelos orientados a chavevalor, a documentos ou a família de colunas. Em todos eles, cada agregado está associado a uma chave (atributo) que o identifica de forma única e possibilita a sua recuperação rápida. Um modelo chave-valor permite o armazenamento de qualquer tipo de dado associado a uma chave, no entanto, o valor armazenado é opaco ao SGBD e as operações de consultas são limitadas à busca pela chave. Já no modelo orientado a documentos, é possível executar operações baseadas na estrutura existente dentro do agregado, que pode ser visto como a composição de chaves associadas a valores complexos, caracterizando um documento. Nesse tipo de modelo, pode-se recuperar parte do agregado e submeter consultas baseadas na estrutura interna do agregado, não apenas em sua chave. É possível também criar índices para chaves existentes dentro do agregado. O modelo orientado a família de colunas é interessante para cenários em que as gravações são raras e frequentemente é necessário ler atributos (colunas) de muitos agregados de uma vez. Assim, são definidos grupos (famílias) de colunas, sob a suposição de que os dados de uma família de colunas serão geralmente acessados 
juntos pela aplicação. Cada grupo pode ser definido como uma supercoluna, na qual uma coluna pode conter colunas aninhadas.

Um agregado agrupa os dados que comumente são acessados juntos, de modo a evitar que seja necessário acessar outros agregados para que os mesmos sejam processados. É equivalente ao processo de desnormalização dos dados, em que toda a informação é agregada em uma única tabela a fim de evitar junções, que são operações com grande custo computacional. Esse conceito vem do Projeto Orientado a Domínio (Domain-Driven Design), em que um agregado é definido como um conjunto de objetos relacionados que precisam ser tratados como uma unidade [SF12, Eva04]. É a unidade básica de recuperação dos dados, similar ao conceito de tupla do modelo relacional, em que as garantias ACID só são fornecidas sobre modificações realizadas sobre um único agregado.

\section{Replicação}

A replicação dos dados em diferentes servidores possibilita maior tolerância a falhas e pode melhorar a escalabilidade das operações de leitura. Entretanto, o desempenho obtido das réplicas pode ser diferente, caso os servidores que as mantém sejam heterogêneos, isto é, com diferentes configurações de software e hardware.

Em SGBDs distribuídos com replicação assíncrona, são implementados basicamente dois tipos de replicação [SF12, RG03]: (i) Mestre-Escravo, em que o servidor chamado de mestre ou primário contém a fonte principal de dados e os outros servidores, chamados de réplicas ou secundários, mantêm cópias do dado do mestre; (ii) Ponto-a-Ponto, em que todos os nós se comunicam e atuam como mestres e escravos ao mesmo tempo. No primeiro caso, o servidor mestre pode delegar as operações de leitura para as réplicas, entretanto, mantém-se como único ponto para gravações. Caso um mestre falhe, um nó escravo pode assumir o papel de mestre. O segundo caso não possui um mestre e todas as réplicas podem efetuar leituras e gravações. A replicação ponto-a-ponto permite a escalabilidade horizontal das gravações, contudo, aumenta o risco de conflitos na escrita dos dados. Geralmente, o uso de um fator de replicação mínimo igual a três é suficiente para se obter uma boa tolerância a falhas [SF12].

\section{Fragmentação}

Uma forma de viabilizar a escalabilidade horizontal é por meio da fragmentação (conhecida também como particionamento ou sharding) dos dados de um banco de dados em diferentes servidores. Define-se um atributo-chave a ser usado como entrada para o algoritmo de particionamento; esse atributo é utilizado como índice para a associação de um registro a um servidor específico.

O particionamento pode ser definido de duas formas [SF12]: (i) por meio de uma função de hashing sobre o valor do atributo-chave; (ii) ou por meio da associação de intervalos de valores do atributo-chave a servidores distintos, em que os registros com chaves pertencentes a um mesmo intervalo encontram-se em um mesmo servidor. A abordagem baseada em hashing provê uma melhor distribuição dos dados entre os servidores. É interessante principalmente quando o atributo-chave cresce monotonicamente. Entretanto, reduz o desempenho de consultas baseadas em intervalos de valores. Neste caso, a abordagem por intervalo provê consultas mais eficientes quando a leitura é obtida de intervalos contínuos armazenados em um mesmo servidor.

A fragmentação permite melhorar o desempenho tanto da escrita dos dados quanto da leitura caso se defina o atributo e a estratégia de particionamento adequadamente, pois permite ampliar as gravações dos dados horizontalmente. É normalmente combinada com a replicação, de forma que cada fragmento possua $n$ cópias definidas pelo fator de replicação. Uma facilidade provida por muitos sistemas NoSQL é a chamada autofragmentação, em que o SGBD se encarrega de armazenar o dado no servidor responsável pelo fragmento e por recuperá-lo do fragmento ou réplica de fragmento correto a partir de uma API de consulta. 


\section{Durabilidade/Consistência vs Disponibilidade}

O modelo de replicação impacta diretamente no nível de consistência obtido em um sistema NoSQL. Por exemplo, no modelo mestre-escravo, o nó mestre pode receber um novo item de dado e armazená-lo localmente. Entretanto, caso falhe antes de sincronizar este item com as demais réplicas e um novo mestre seja selecionado, este item de dado pode ser perdido ou entrar em conflito com os dados atuais.

É possível definir o nível de consistência a ser obtido por operação, isto é, quantos nós precisam confirmar uma escrita de um dado a fim de que se assegure a consistência desse dado [SF12]. Para isso, é usado o quórum de gravação $W$ (conhecido também como write concern), que define o número mínimo de réplicas que devem responder a uma requisição confirmando a escrita. Por exemplo, para confirmar a consistência dos dados, pode-se considerar que é suficiente que a maioria de servidores de réplicas respondam à requisição, ao invés de se exigir que todos eles respondam. Em um cenário em que todas as operações são realizadas no nó mestre, é suficiente definir um quórum $W=1$, ou seja, basta o nó mestre confirmar a operação, mesmo que as réplicas não estejam sincronizadas ainda. A aplicação sempre obterá o dado mais atualizado (visto que a leitura e escrita são feitas sempre na réplica mestre), mesmo que os dados não tenham sido persistidos nas demais cópias. Caso a leitura seja realizada em qualquer réplica e a aplicação queira garantir um nível de consistência alto, a confirmação de uma operação de escrita deve ser realizado por um número maior de réplicas, aumentando o tempo desse tipo de operação.

O quórum de gravação é uma forma de balancear a durabilidade/consistência com a disponibilidade; deve-se considerar que quanto maior o fator de replicação e maior a consistência requerida, menor será a disponibilidade do sistema.

\section{Preferência de Leitura}

Em um cenário com replicação dos itens de dados, é possível delegar a execução de operações de leitura aos nós escravos ao invés de atribuir toda operação ao nó mestre. Contudo, quando a replicação é assíncrona, ler os dados de réplicas secundárias pode retornar dados desatualizados. O desempenho também pode ser afetado caso o SGBD utilize nós heterogêneos. Em um modelo mestre-escravo de replicação, para evitar conflitos na gravação de dados, basta que os dados sejam sempre escritos no nó mestre e, para que sejam lidos os dados atualizados, deve-se também ler do nó mestre.

\subsubsection{Análise do Ecossistema Atual de SGBDs}

Os SGBDs relacionais continuam sendo a melhor solução para o gerenciamento de transações críticas, que demandam forte consistência dos dados, como é o caso de operações bancárias. Seu modelo relacional e a descrição de consultas por meio de operadores algébricos permitem a realização de consultas complexas bem-definidas pela linguagem de consulta padronizada SQL. Entretanto, esse modelo de dados, por não refletir geralmente a estrutura de dados utilizadas na maioria das aplicações devido a sua normalização, comumente necessita de diversas operações de junções de tabelas para obtenção de dados de uma requisição. Essa diferença entre o modelo para armazenamento dos dados no SGBD e o modelo utilizado pela aplicação é conhecida como incompatibilidade de impedância e reduz a escalabilidade horizontal aplicável aos SGBDs relacionais, por causa da necessidade de realizar buscas em diversas tabelas para atender a uma única requisição.

Os sistemas NoSQL orientados a agregados possibilitam maior compatibilidade entre o modelo de dados armazenado e o utilizado por uma aplicação. No entanto, a definição desse modelo passa a se tornar dependente da forma como a aplicação que o utiliza. Nesse caso, um agregado pode conter todos os atributos necessários para processar uma requisição $r 1$ e não conter os atributos utilizados por uma requisição r2, mesmo que esta manipule o mesmo domínio do conjunto de dados e apenas apresente-o de outra forma. Por exemplo, em um banco de dados de livros e autores, um agregado pode ser definido como um livro que contém um ou mais autores ou pode ser um autor com um ou mais livros. Caso seja necessária a busca por livro e autor, a requisição pode ser 
modelada como duas consultas em agregados diferentes - um que representa a estrutura de um livro e o outro, as informações de um autor - ainda que ambos representem o mesmo domínio, gerando informações redundantes, o que não ocorreria no modelo relacional, dada a normalização. Além disso, outro aspecto negativo é a ausência de uma linguagem padrão para consulta aos dados; cada sistema implementa a sua API de acesso aos dados. No entanto, apesar disso, os sistemas NoSQL mostraram-se melhores adaptados à escalabilidade horizontal, proporcionando maior desempenho e tolerância a falhas e por isso vêm sendo utilizados por grandes empresas em larga escala, mesmo com esses sistemas suportando apenas operações de consultas mais simples e menor garantia de consistência dos dados.

E, apesar da escalabilidade fornecida pelos sistemas NoSQLs, um novo tipo de SGBD relacional vem ganhando destaque na indústria, voltado para o gerenciamento de grandes volumes de dados em ambientes escaláveis horizontalmente. São chamados de NewSQL ou SGBD relacionais escaláveis [Cat11]. Entretanto, além de serem no geral soluções comerciais, encontram-se em estágio inicial de desenvolvimento, não fornecendo suporte a todos os mecanismos de gerenciamento dos SGBDs relacionais atuais.

As soluções de bancos de dados discutidas neste capítulo tem seus pontos positivos e deficiências e ainda sim continuam sendo amplamente utilizadas. Uma vez que não existe uma solução que atenda a todos os requisitos, muitas aplicações têm adotado sistemas híbridos para persistência dos dados, em que são utilizadas diferentes tecnologias para o gerenciamento de dados; isso é caracterizado como persistência poliglota [SF12].

\subsection{Considerações sobre o Capítulo}

Vimos que os processos envolvidos na análise de grandes volumes de dados podem ser modelados como workflows orientados a fluxos de dados e se beneficiarem do uso de SGWfs para o controle de sua execução em um ambiente distribuído de forma transparente ao usuário. Apresentamos também os mecanismos utilizados para prover melhorias no desempenho durante a execução de tais aplicações e a importância do uso de um SGBD para gestão dos dados. Em especial, no contexto de dados em grande escala, destacamos a aplicabilidade dos SBGDs NoSQL em workflows para processamento de dados devido ao uso de modelos de dados mais flexíveis, tolerância a falhas, alta disponibilidade dos dados e melhor suporte ao acesso paralelo aos dados por meio da indexação e do particionamento e replicação de dados nativos desses sistemas. Esses conceitos são importantes para a compreensão dos trabalhos relacionados ao método que propomos, apresentados no Capítulo 3 


\section{Capítulo 3}

\section{Trabalhos Relacionados}

Neste capítulo, apresentamos trabalhos relacionados ao que foi desenvolvido neste projeto de mestrado, comparando seus objetivos e contribuições. Para facilitar sua caracterização, esses trabalhos podem ser agrupados em três categorias: modelos de programação distribuída, paralelização de atividades por meio de SGWFs e gerenciamento de dados. Nas seções a seguir, essas categorias são exploradas.

\subsection{Modelos de Programação Distribuída}

Uma solução para processamento intensivo em dados, é o uso de dataflows (modelos de processos orientados a fluxos de dados) [PZ14], tais como o MapReduce [DG10]. Nesse modelo, cuja implementação mais conhecida é o Hadoop [Whi09], o processamento dos dados é descrito pelo usuário por meio de: (i) uma função Map, que seleciona subconjuntos de dados, indexando-os por meio de uma chave; (ii) e uma função Reduce, que agrupa os valores que possuem a mesma chave de indexação. Cada função manipula um subconjunto disjunto de dados e isso permite que elas sejam distribuídas em diferentes recursos computacionais de um aglomerado de computadorese executadas em paralelo, reduzindo o tempo total de execução do dataflow. Outro recurso interessante é a exploração da localidade dos dados, em que o processo responsável por analisar os dados é transferido para o ambiente em que os dados se encontram armazenados, em vez da abordagem tradicional, em que os dados são copiados para um recurso computacional externo a seu repositório, a fim de serem processados. Essa estratégia permite a redução dos custos de comunicação em cenários de grande escala e é implementada pela maioria dos arcabouços de dataflows. O modelo baseado em dataflows exige que seus usuários dominem os conceitos de computação paralela e distribuída para especificar, programaticamente, cada função.

Ferramentas de suporte ao Hadoop, como o Pig [ORS ${ }^{+} 08$ ] e Hive [TSJ ${ }^{+}$09], oferecem aos usuários do Hadoop uma linguagem declarativa similar a SQL para descrição do processamento de dados. Outras, como o Oozie [ $\left.\mathrm{IHB}^{+} 12\right]$, permitem que o Hadoop suporte a execução de múltiplos inquilinos, criando a execução simultânea de diferentes workflows de funções map e reduce, referentes a cada inquilino do sistema. Sua extensão, Nova $\left[\mathrm{OCC}^{+} 11\right]$, permite o processamento de dados contínuos (streamings), em que os dados são processados à medida em que vão chegando ao sistema.

Uma avaliação sobre o impacto da localidade de dados intermediários na execução de dataflows intensivos em dados foi feita por Oliveira et.al. [dOBNP15]. Considerando o uso do Apache Hadoop e do Apache Spark e fluxos de atividades do tipo produtor-consumidor, os autores obtiveram ganho de desempenho em cenários em que foi possível se beneficiar de localidade de acesso nos arquivos intermediários e em que os arquivos eram armazenados totalmente na memória principal. Apesar da redução da transferência dos dados, a utilização dessas abordagens requerem que o projetista do workflow (e conhecedor do domínio da aplicação) seja um especialista em programação paralela e distribuída, limitando o seu uso. O mesmo não ocorre com as ferramentas de SGWfs, pois elas tornam transparente o controle da execução das atividades de processamento. 


\subsection{Paralelização de Atividades em SGWfs}

Para obter um bom desempenho na execução de um workflow e ser capaz de processar dados em grande escala, os SGWfs precisam permitir a execução paralela de atividades e distribuí-las nos recursos computacionais de plataformas de alto desempenho. Nesse contexto, destacam-se os SGWfs SciCumulus [dOOBM10], Swift/T [WAW $\left.{ }^{+} 13\right]$ e Pegasus [DVJ $\left.{ }^{+} 15\right]$.

O SciCumulus é o único sistema que identifica o paralelismo de dados de maneira automática, por meio da representação das atividades de workflow como operadores da Álgebra de Workflows Científicos, a SciWfA (Scientific Workflow Algebra) [OOV $\left.{ }^{+} 11\right]$. Cada operador descreve a semântica do processamento a partir da relação de consumo e produção de conjuntos de dados, caracterizados como listas ordenadas de tuplas, em uma abordagem similar à definição da álgebra relacional [Cod70], uma linguagem de consulta para bancos de dados relacionais. A lista de operadores e a relação entre o número de tuplas produzidas e consumidas é definida na Tabela 3.1. Por exemplo, o operador Map descreve que, para cada tupla consumida, uma nova tupla será gerada. O operador SplitMap define a decomposição de uma tupla consumida em $n$ tuplas geradas. Considera-se, neste último caso em especial, que a tupla de entrada é uma referência para um arquivo; os critérios para fragmentação são definidos pelo programa vinculado à atividade. O operador Reduce define uma operação de agregação de dados. O operador Filter indica uma processo de filtragem de dados de entrada; assume-se que cada tupla gerada possui os mesmos atributos que definem a tupla de entrada correspondente. Os operadores SRQuery e MRQuery são aplicáveis somente a atividades artificiais, inseridas pelo SciCumulus para otimizar a execução de um workflow. Esses operadores são capazes de interpretar expressões algébricas definidas pela SciWfA e criadas a partir da identificação de oportunidades de otimizações na execução de uma instância de workflow; isso possibilita que o sistema altere a ordem de execução de uma atividade, por exemplo, decompondo, antecipando ou procrastinando sua execução. Ao identificar que uma operação de filtragem pode ser executada antes de uma operação de mapeamento mesmo que inicialmente não tenham sido descritas dessa forma, o sistema otimiza a execução dessa aplicação realizando a filtragem antes do mapeamento, diminuindo o volume de dados que seria processado inicialmente sem alterar o resultado final. As otimizações são identificadas por meio da semântica descrita pelos demais operadores (Map, SplitMap, Reduce, Filter) no workflow.

\begin{tabular}{|c|c|}
\hline Operador Algébrico & Relação entre Consumo e Produção de Tuplas \\
\hline \hline Map & $1: 1$ \\
\hline SplitMap & $1: m$ \\
\hline Reduce & $\mathrm{n}: 1$ \\
\hline Filter & $1:(0-1)$ \\
\hline SRQuery & $\mathrm{n}: \mathrm{m}$ \\
\hline MRQuery & $\mathrm{n}: \mathrm{m}$ \\
\hline
\end{tabular}

Tabela 3.1: Descrição dos operadores algébricos e sua relação de consumo e geração de tuplas na Álgebra para Workflows Científicos (SciWfA).

Além da abordagem algébrica para descrição de workflows, o SciCumulus integra dados de domínio aos de controle e proveniência com o objetivo de se obter uma análise mais completa sobre os processos de transformação dos dados pelas atividades do workflow. Nesse sistema, os operadores algébricos exigem que a cardinalidade seja sempre descrita pelo usuário em tempo de projeto. Essa álgebra necessita também que o SGWf implemente o conceito de ativações de atividades, em que o conjunto de dados de entrada é decomposto em tuplas ordenadas, permitindo o paralelismo de dados e de pipelines - estratégias que reduzem o tempo total de execução de workflows.

No SGWf Swift/T, a paralelização dos dados de domínio não exige que seja definida uma relação de produção e consumo de dados e é indicada por meio do operador foreach, definido na linguagem de script Swift $\left[\mathrm{WHW}^{+} 11\right]$ para especificação de workflows. Este operador recebe como entrada um 
vetor e associa cada um de seus elementos a uma réplica de uma atividade (estratégia utilizada para aplicar o paralelismo de dados), passando cada elemento como parâmetro de entrada para a réplica associada à sua posição no vetor. O Swift permite que um elemento possa representar um tipo de dados simples ou um arquivo. Cabe ao usuário a definição de quantas atividades em paralelo serão executadas e o nível do particionamento dos dados por meio da definição do vetor de entrada do operador foreach programaticamente, exigindo que o usuário domine a linguagem de programação do Swift.

O SGWf Pegasus fornece diversas interfaces de acesso para seu uso, permitindo a definição dos workflows de maneira gráfica ou textual (por meio da linguagem DAX). O paralelismo é definido pelo usuário por meio da indicação da dependência de dados entre as atividades na especificação do workflow. Por exemplo, duas atividades ou mais atividades podem ser executadas paralelamente se todos os dados dos quais elas dependem já estão disponíveis. O sistema fornece ainda uma interface para monitoração da execução e análise dos resultados, além de mecanismos para tolerância a falhas. É composto por diversos subsistemas, tais como o DAGMan e o HTCondor, e seu fraco acoplamento permite que seja facilmente integrado a outros motores de execução e sistemas de gerenciamento de dados. Tem sido bem sucedido em projetos de larga escala, tais como o Projeto LIGO [Col], que detectou a existência de ondas gravitacionais em colisões de buracos negros. Diferentemente do SciCumulus, o gerenciamento dos dados de domínio é separado do gerenciamento de dados de controle e proveniência; isso resulta em maior autonomia para a manipulação dos dados de domínio em um workflow, tornando-o independente do SGWf utilizado.

Analisando esses três sistemas, observamos que o uso de um SGWf é viável para o processamento de dados em grande escala. Contudo, a definição das atividades paralelizáveis é feita pelo usuário em tempo de projeto e criar um fluxo de processamento paralelo que faça uso eficiente da plataforma de execução não é uma tarefa trivial. Os SGWfs deveriam fornecer mecanismos que auxiliassem o uso de um ambiente distribuído para análise de dados de diferentes domínios e por isso deveriam ser acessíveis principalmente a usuários não-especialistas em computação [BC14].

A SciWfA é um método interessante para descrição de workflows paralelos, contudo, depende de que todas as atividades estejam descritas como operadores de sua álgebra, o que obriga também que usuário defina em tempo de projeto a relação (cardinalidade) entre o número de tuplas geradas em cada atividade e o número de tuplas consumidas. No caso do Swift/T, é possível aumentar o paralelismo dos dados sem a necessidade de definir a cardinalidade do conjunto de dados a ser produzido por atividade. Entretanto, sua implementação como linguagem de programação limita seu uso a projetistas com conhecimento prévio de programação. Já o Pegasus, fornece interfaces diversificadas para definição de workflows, onde o paralelismo encontra-se na definição de atividades sem dependências de dados entre si. É possível, nesses dois últimos sistemas, modificar apenas o modelo do workflow a fim de se obter maior paralelismo. Contudo, esses SGWfs não são capazes de definir isso automaticamente devido à ausência de semântica na descrição de suas atividades. Nenhuma das três estratégias para paralelização de workflows em que os dados de domínio são mantidos em SGBDs associam a criação de atividades paralelas às funcionalidades de um SGBD distribuído, tais como particionamento, replicação e indexação, importantes para fornecer um maior acesso paralelo e tolerância a falhas em ambientes distribuídos para dados de grande escala [PZ14].

O paralelismo de dados em workflows é explorado também no arcabouço FRIEDA [GR12] que define a fragmentação do processamento a partir da criação de cópias de uma atividade que combina um arquivo de entrada a uma lista de arquivos em um repositório de dados. Esse sistema não permite a decomposição dos arquivos em listas de tuplas, como ocorre no SciCumulus. Além disso, não suporta outros mecanismos existentes em SGWfs, como gerenciamento de dados de proveniência.

No sistema Moteur [GMLP08], o paralelismo é obtido por meio da definição da forma como os vetores de parâmetros - que são os dados de entrada - serão combinados entre si por uma atividade. Uma atividade é modelada como um serviço web, isto é, sua implementação é desconhecida pelo usuário, que utilizará cada serviço de processamento de dados por meio de uma interface de acesso via internet. Esta receberá como entrada conjuntos de vetores, em que é possível definir dois padrões de composição desses elementos de entrada: um-para-um (one-to-one) e todos-para-todos (all-to- 
all). O primeiro padrão indica que o consumo dos itens de dados de cada vetor recebido será combinado com o item de dado pertencente a mesma posição no vetor subsequente, como vemos na Figura 3.1(a). O segundo padrão indica que cada item de dado do primeiro vetor deverá ser associado a todos os itens do segundo vetor (Figura 3.1(b)).
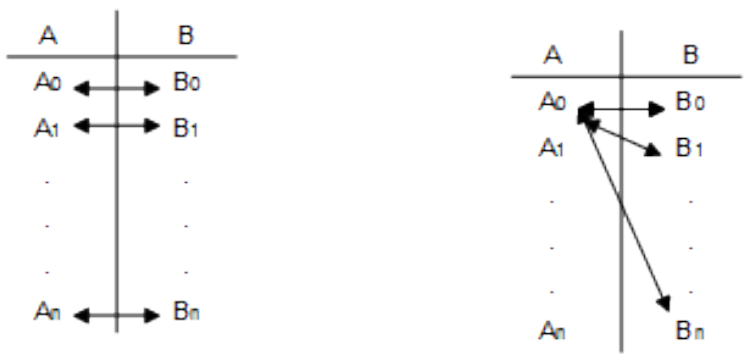

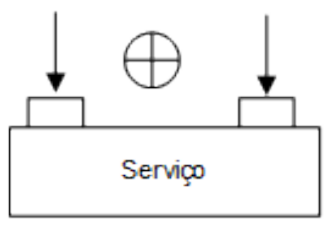

(a)

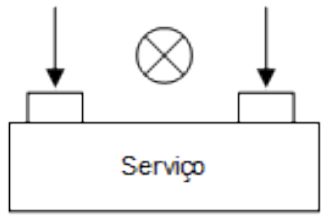

(b)

Figura 3.1: Exemplo da composição dos vetores de entrada de um serviço do Moteur: (a) composição um-para-um; (b) composição todos-para-todos

De acordo com a forma de consumo dos vetores, o serviço (atividade) é capaz de definir o paralelismo aplicável. No entanto, nesse modelo de execução, a atividade é vista como um serviço web a ser utilizado pelo usuário; este não possui controle sobre o processo de transformação dos dados envolvido, apenas utiliza um serviço de processamento de dados existente.

Explorar a granularidade dos conjuntos de dados de entrada permite a criação de estratégias de execução mais paralelas. O uso de arquivos como dados de entrada não possibilita a fragmentação de seus dados sem a realização de um pré-processamento para o particionamento de seu conteúdo. Além disso, não provê mecanismos de controle de acesso ou seleção parcial dos atributos que descrevem seus dados, característica importante para reduzir o custo de comunicação entre o repositório de dados e uma atividade intensiva em dados. Já o uso de sistemas baseados em serviços limitam o tipo de processamento a ser realizado.

\subsection{Gerenciamento de Dados de Workflows}

O gerenciamento de dados é avaliado em diversos trabalhos, incluindo o uso de sistemas de arquivos distribuídos, de objetos e de bancos de dados.

O custo monetário e o desempenho de workflows executados em nuvens computacionais foram avaliados por Juve et.al. [JDB $\left.{ }^{+} 12\right]$. Entretanto, para o armazenamento dos dados manipulados pelos workflows, esses trabalhos consideraram apenas o uso de sistemas de arquivos distribuídos e de armazenamento de objetos de dados (como o do Amazon S3), não considerando bancos de dados relacionais ou NoSQL.

No trabalho de Ferreira et.al. [FJdO14] é apresentado um estudo comparativo do uso dos SGBDs PostgreSQL (relacional) e Cassandra (NoSQL) para o registro de dados de proveniência da execução de workflows científicos no SciCumulus, destacando o bom desempenho do Cassandra em cenários distribuídos. O trabalho não descreveu como os dados de entrada e de saída das atividades dos workflows foram mantidos e nem estratégia de distribuição usada para os dados de proveniência.

O trabalho de Oliveira et.al. [dOBP14] analisou alternativas de armazenamento de grandes volumes de dados que favorecem o processamento paralelo de fluxos de dados. Os autores concluíram 
que o uso de um sistema que privilegie a localidade de dados impacta positivamente no desempenho. No entanto, avaliaram somente cenários com um banco de dados relacional (PostgreSQL) centralizado, particionado ou distribuído, e com os dados armazenados em um sistema de arquivo distribuído (HDFS).

Apesar de usarem mecanismos de gerenciamento de dados escaláveis, esses trabalhos não exploraram o impacto que a configuração desses mecanismos tem na paralelização dos workflows, tais como o número de réplicas ou partições dos conjuntos de dados utilizados.

\subsection{Considerações sobre o Capítulo}

Os trabalhos discutidos neste capítulo apresentam estratégias relacionadas à exploração do paralelismo em aplicações descritas como workflows orientados a dados, relacionadas à definição de um modelo de programação distribuída, à paralelização de atividades em SGWf e ao gerenciamento distribuído dos dados em um workflow, incluindo dados de domínio, de controle e de proveniência. O método proposto neste trabalho difere-se dos demais, pois o paralelismo é promovido por meio de modificações na estrutura do banco de dados e da replicação de atividades, feitos a partir de anotações semânticas no workflow. Apresentamos esta abordagem no Capítulo 4. 


\section{Capítulo 4}

\section{Paralelização Automática de Workflows Intensivos em Dados}

O uso de plataformas de alto desempenho para execução de workflows intensivos em dados tornou-se um requisito para o processamento de grandes volumes de dados de maneira eficiente. Nesse contexto, tais aplicações devem ser capazes de particionar e replicar os conjuntos de dados utilizados por suas atividades a fim de que seja possível o processamento paralelo de seus dados. A ausência de caracterização semântica sobre o tipo de processamento a ser realizado limita a exploração automática do paralelismo desses workflows por parte dos sistemas de gerenciamento de workflows existentes, delegando essa responsabilidade aos projetistas dessas aplicações, que definem o paralelismo de um workflow no seu modelo de descrição e que nem sempre são especialistas em computação paralela e distribuída. A definição de um modelo de execução que faça um uso eficiente da plataforma distribuída, nesses casos, não é uma tarefa trivial.

Apresentamos neste capítulo o método proposto para paralelização de workflows intensivos em dados. Seu objetivo é prover uma execução mais eficiente de workflows intensivos em dados de maneira automática a partir de anotações semânticas fornecidas pelo projetista do workflow sobre seu modelo de descrição. Essas anotações caraterizam as atividades quanto ao tipo de processamento a ser realizado. Com informações adicionais sobre o consumo dos dados de entrada, sobre o ambiente de execução e sobre as dependências entre as atividades, o método é capaz de gerar réplicas das atividades anotadas, associando a elas subconjuntos de seus dados de entrada, além de definir um esquema de indexação e distribuição dos dados que possibilita maior acesso paralelo aos mesmos.

Nas seções a seguir, descrevemos as anotações propostas e a forma como foram implementadas pelo método, isto é, como essas informações são usadas para modificar o modelo de workflow e o banco de dados com o qual ele interage. Apresentamos também a implementação desse método por meio da ferramenta SciWonc-Dataflow, utilizada para avaliar o impacto do método proposto no desempenho de workflows anotados.

\subsection{Considerações Iniciais}

Supomos neste trabalho que um workflow candidato a modificações propostas pelo nosso método é descrito como um $D A G$ (vide Seção 2.1), cujos nós representam as atividades a serem executadas e distribuídas. Supomos também que o conjunto de dados de domínio manipulado pelo workflow é mantido em um SGBD relacional ou em um sistema NoSQL orientado a agregados, devido às funcionalidades desses sistemas para o gerenciamento de acesso concorrente, a otimização de consultas, a persistência dos dados e o controle de acesso de usuários.

Definiremos uma nomenclatura comum para descrever os conjuntos de dados manipulados, uma vez que o modelo de dados adotado pelos SGBDs relacionais difere dos modelos implementados em sistemas NoSQL. Neste trabalho, consideramos que um objeto de dados é equivalente a uma tupla do modelo relacional (vide Seção 2.3.1) ou a um agregado em sistemas NoSQL orientados a agregados (vide Seção 2.3.2). Cada objeto é caracterizado por uma lista de atributos. Cada atributo é definido 
por um nome e um valor. No contexto relacional, um atributo precisa estar associado a um domínio que caracterize o tipo do dado que armazena e deve ser simples, ou seja, deve conter um único valor por tupla. Já em sistemas NoSQL, um atributo pode ser definido como um par chave-valor dentro de um agregado, sendo que o valor pode ser complexo (composto e/ou multivalorado), contendo, por exemplo, uma lista de valores ou um sub-agregado. Podemos considerar um agregado como um objeto em JSON, que é definido por um conjunto de pares chave-valor.

Para que o método proposto seja aplicável a bancos de dados tanto NoSQL quanto relacionais, consideramos que os atributos dos objetos de dados manipulados nos workflows alvos deste trabalho contêm sempre valores simples. Um conjunto de dados é chamado de coleção de objetos de dados e equivale a uma relação no modelo relacional, ou a uma coleção de agregados em um sistema NoSQL. A Figura 4.1 apresenta um exemplo de uma coleção de objetos definidos pelos atributos ID e Nome em um modelo relacional e em um NoSQL orientado a agregados.

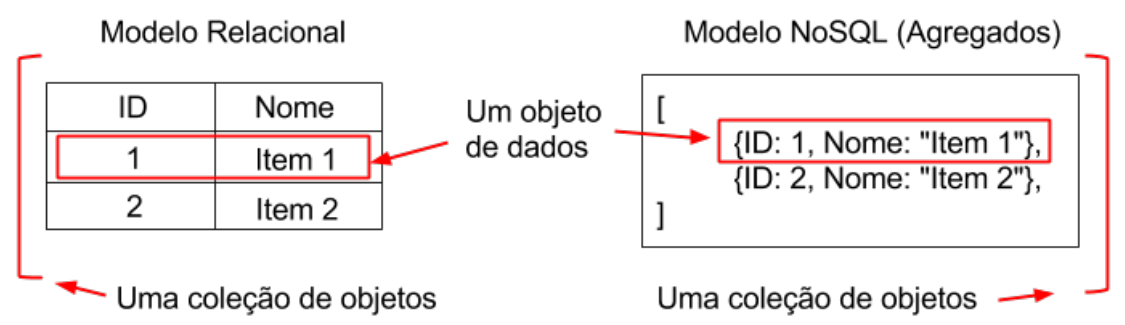

Figura 4.1: Exemplo de uma coleção de objetos definidos pelos atributos ID e Nome em um modelo relacional e em um modelo NoSQL orientado a agregados.

Consideramos também que os atributos de um objeto podem ser indexados por meio de uma chave de indexação e que todo objeto possui uma chave primária para a restrição de integridade.

O método proposto considera que cada atividade de um workflow só pode usar como entrada objetos de dados provenientes de uma única coleção de objetos. Por essa razão, o uso de chaves estrangeiras para referenciar objetos de diferentes coleções não foi definido nem avaliado. Isso possibilita que um workflow que manipula dados mantidos em um sistema NoSQL, que em geral não permite a definição de restrições de integridade referencial entre coleções, possa se beneficiar das estratégias de paralelização propostas aqui.

\subsection{Anotações sobre o Workflow}

Propomos o uso de anotações sobre o modelo de workflow para identificação do tipo de processamento realizado por uma atividade, da forma como ela consome seus objetos de dados de entrada e de como os atributos serão utilizados. A partir dessas informações, definimos como o paralelismo será explorado para essa atividade em um ambiente de execução distribuído. As seções a seguir detalham cada anotação proposta e o processo de paralelização aplicado a cada caso.

\subsubsection{Caracterização das Atividades}

Uma atividade de workflow pode ser caracterizada por meio de nove anotações. As anotações $C E$ e $C S$ descrevem as coleções de objetos de entrada e saída, respectivamente, que são utilizadas pela atividade. As anotações $S A$ e $O O$ descrevem a forma como os atributos são apresentados à atividade e as anotações $P C, P O, P G, P J T$ e $P V D$ indicam o tipo de processamento que a atividade realiza; essas anotações têm como requisito a associação com a anotação $C E$.

Utilizaremos um workflow de exemplo para ilustrar como cada anotação pode ser aplicada e, dessa forma, facilitar a compreensão de seu significado. Esse workflow, que chamaremos de PlayFlow, analisa um log (fictício) de execuções de músicas de um usuário de um serviço digital de streaming. Como entrada, temos uma coleção de objetos descritos por seis atributos referentes à execução 
de uma música: (Horário de Início, Horário de Término, Usuário, Música, Artista, Duração da música). Suponha que os dados sejam referentes a um único mês de serviço e usuário. Como saída, queremos saber qual é o perfil do usuário, analisando: (i) o total de execuções registradas nesse log; (ii) quais são as cinco músicas com maior duração; (iii) como as músicas são executadas por este usuário (para verificar se a maioria é tocada até o final ou apenas parcialmente); (iv) qual é o seu artista preferido; (v) quanto tempo ele passa ouvindo música por dia; (vi) e quantas músicas ele possui em sua playlist.

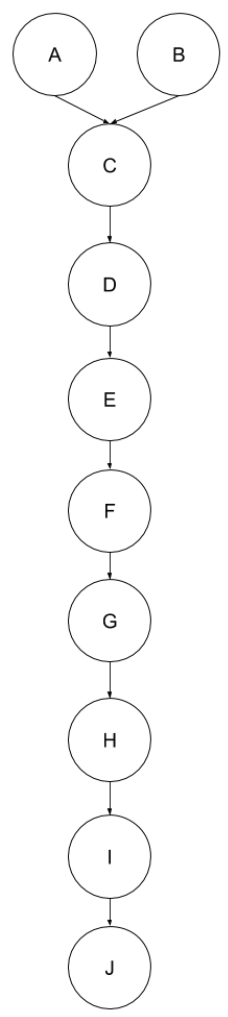

Figura 4.2: Representação do Modelo do Workflow PlayFlow, adotado como exemplo para ilustrar as anotações propostas neste trabalho.

O modelo deste workflow é apresentado na Figura 4.2 e suas atividades são detalhadas a seguir.

- Status (A): atividade que calcula o total de execuções registradas no log analisado.

- Top5MusicasMaisLongas (B): atividade que identifica quais são as cinco músicas com maior tempo de duração.

- CategorizaTipoExecução (C): atividade responsável pela categorização de cada execução de uma música como execução parcial ou completa.

- AnalisaExecuçãoParcialTotal (D): atividade responsável por calcular a porcentagem de músicas executadas por completo ou parcialmente, ambas em relação ao total de músicas executadas (incluindo repetições), baseada na categorização definida pela atividade C.

- CalculaTotalMusicasPorArtista (E): atividade que calcula o total de músicas executadas por artista.

- DefineArtistaPreferido (F): atividade que define qual é o artista preferido do usuário avaliado, com base na análise feita pela atividade E.

- PlaysPorDia (G): atividade que calcula, por dia, quantas músicas foram executadas. 
- MédiaPlaysPorDia (H): atividade responsável pelo cálculo da média de músicas executadas por dia, a partir dos dados obtidos pela execução da atividade G.

- ListaMúsicasÚnicas (I): atividade que identifica unicamente quais são as músicas presentes no $\log$ analisado.

- TotalDeMúsicasÚnicas (J): atividade que contabiliza o total de músicas únicas identificadas pela atividade I.

As atividades $A$ e $B$ referem-se à análise (i) e (ii), respectivamente; conforme o modelo descrito, elas podem ser executadas paralelamente. As atividades $C$ e $D$ compõem o processo para execução da análise (iii) e as atividades $E$ e $F$, fazem parte da análise (iv). A análise (v) é obtida a partir da execução das atividades $G$ e $H$ e, por último, a análise (vi) é efetuada por meio das atividades $I$ e $J$. As análises de (iii) a (vi) ilustram um tipo de processamento distinto que pode ser caracterizado por meio das anotações propostas, como mostrado a seguir.

\section{Anotações sobre as Coleções de Entrada e de Saída: \\ CE (NomeColeção, DadosConexão [, Esquema][, Particionado][, PreferênciaLeitura]) e CS (NomeColeção, DadosConexão/, Esquema][, ConsistênciaEscrita])}

$C E$ e $C S$ são anotações que permitem que o projetista forneça informações de acesso sobre cada coleção de objetos de dados utilizada ou gerada por uma atividade. A anotação $C E$ denota uma coleção de objetos de entrada, enquanto a $C S$ denota uma coleção de objetos de saída da atividade. Cada uma dessas anotações é definida por meio de um conjunto de parâmetros, sendo opcionais os parâmetros delimitados por um par de colchetes.

O parâmetro NomeColeção denota o nome da coleção de objetos a ser acessada ou gerada, enquanto que as informações de conexão com o banco de dados são definidas em DadosConexão no seguinte formato textual:

[usuario:senha@]servidor1[:porta1][,servidor2[:porta2],...[,servidorN[:portaN]]]/bancodedados

sendo possível fornecer uma lista de servidores de acesso a um banco de dados distribuído.

No contexto de SGBD relacionais, é necessária a definição da lista de todos os atributos que serão usados na coleção por meio do parâmetro Esquema. Já em sistemas NoSQL, o esquema pode ser definido dinamicamente e por isso a definição do parâmetro Esquema não é necessária. Ainda referente a coleções de objetos em NoSQL, é possível a definição do nível de consistência desejável em operações de escrita por meio do parâmetro ConsistênciaEscrita, que define o quórum de gravação. O quórum de gravação pode ser um número entre 1 e o total de réplicas de uma coleção, indicando o número de réplicas necessárias para a confirmação de uma escrita. Ele pode também assumir como valor a constante Majoritário, indicando que uma operação de escrita deve ser confirmada pela maioria das réplicas da coleção, ou seja, dado um total de t réplicas, serão necessárias $(t / 2+1)$ confirmações de escrita por operação.

A preferência de acesso aos dados na leitura das coleções mantidas em um sistema NoSQL é definida em PreferênciaLeitura, que pode assumir como valor uma das seguintes constantes: Primária ou Secundária. A constante Primária define que a leitura será realizada apenas de réplicas principais (mestre), enquanto que a constante Secundária define que a leitura das réplicas secundárias (escravas) também será permitida, configuração essencial para que as operações de leitura sejam escaláveis horizontalmente. Tanto o conceito de quórum de gravação quanto o de preferência de leitura são descritos na Seção 2.3.2.

A anotação $C S$ permite que se adote uma estratégia de particionamento no banco de dados (caso este seja distribuído) para os dados intermediários (i.e., dados gerados e consumidos durante a execução do workflow). O parâmetro Particionado, que recebe um valor booleano, quando verdadeiro indica que o banco de dados está particionado e que as novas coleções podem ser distribuídas; 
caso contrário, considera-se que o banco de dados é centralizado ou que não é possível distribuir os objetos das novas coleções criadas durante a execução.

Nas anotações $C E$ e $C S$, os atributos opcionais devem ser nomeados, isto é, devem ser definidos por meio da associação de um valor explicitamente ao nome do parâmetro.

No nosso exemplo, a coleção de entrada do PlayFlow é a LogPlaylist, cujas informações de conexão são indicados pelo valor "user:pwd@localhost:27017/playlist" no parâmetro DadosConexão, onde playlist é nome do banco de dados utilizado. Suponha que uma das atividades desse workflow, a atividade $A$, recebe como entrada a coleção LogPlaylist e gera após a sua execução a coleção Status, referente a primeira análise sobre o total de registros. A Figura 4.3 exemplifica o uso das anotações $C E$ e $C S$ para a atividade $A$ considerando que as coleções são mantidas em um banco de dados NoSQL. Além do nome da coleção e dados de conexão, informamos por meio da anotação que o banco de dados está particionado e que queremos que as leituras sejam efetuadas das réplicas primárias. Como saída, teremos a coleção Status e cada objeto de dados gravado nela necessita ter sua escrita somente em uma única réplica (a primária). No segundo exemplo, Figura 4.4, temos a mesma atividade sendo executada com um banco de dados relacional, em que o esquema é passado explicitamente como valor do parâmetro Esquema. Como os parâmetros Particionada e PreferênciaLeitura não estão definidos, assume-se que o banco de dados é centralizado e que os dados são lidos somente de uma réplica. Na definição da coleção de saída, faz-se necessário definir o esquema para que o método seja capaz de gerar a estrutura da coleção no banco de dados utilizado antes de persistir os dados gerados por $A$.

A anotação $C E$ é obrigatória em atividades que desejam descrever seu processamento por meio das demais anotações propostas (sobre o tipo de processamento e/ou apresentação de atributos), com uma lista de parâmetros definida para cada caso.

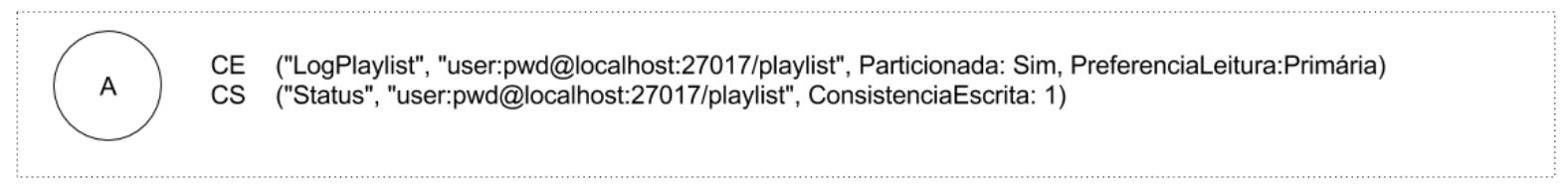

Figura 4.3: Exemplo de uso das anotações CE e CS para um banco de dados NoSQL

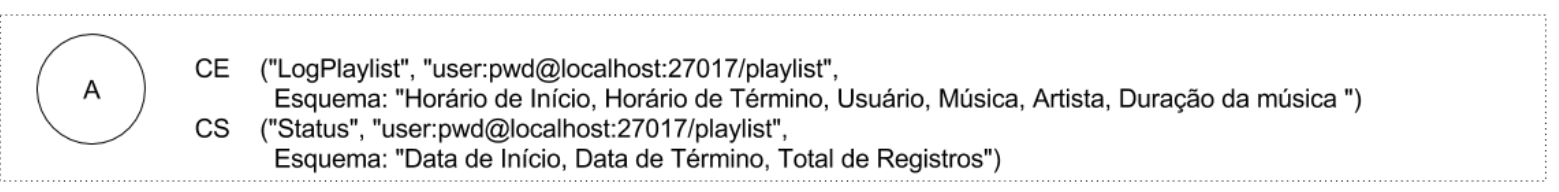

Figura 4.4: Exemplo de uso das anotações CE e CS para um banco de dados relacional

\section{Anotação sobre a Seleção de Atributos: SA(ListaAtributos)}

A recuperação de objetos de dados de uma coleção é realizada por meio de consultas definidas em SQL (linguagem padronizada para consulta e manipulação de dados em SGBDs relacionais) ou a partir de uma API de acesso para o Sistema NoSQL escolhido. O método aqui proposto permite que o usuário defina uma lista de atributos a serem selecionados de todos os objetos de dados recuperados de uma coleção para uma dada atividade. Isso permite que o volume de dados trafegado entre o ambiente de execução e o SGBD escolhido seja reduzido, diminuindo também o tempo de execução.

A anotação de Seleção de Atributos SA define, por meio do parâmetro ListaAtributos, quais atributos da coleção de dados de entrada serão usados por uma atividade. Ou seja, se $\mathcal{A}$ é uma atividade em um workflow e $\mathcal{L}$ é uma lista com nomes de atributos existentes nos objetos da coleção de entrada $C E$ de $\mathcal{A}$, então $S A(\mathcal{L})$ sobre $\mathcal{A}$ denota que apenas os atributos em $\mathcal{L}$ serão 
selecionados de cada objeto da coleção de entrada para que $\mathcal{A}$ possa realizar seu processamento. Em uma atividade não anotada com $S A$, por padrão, todos os atributos pertencentes aos objetos da coleção definida em $C E$ para a atividade serão recuperados do SGBD.

A Figura 4.5 ilustra o uso de $S A$. A atividade $A$, que já recebia uma coleção de entrada definida em $C E$ e gerava uma de saída, definida por $C S$, agora passa a receber somente os atributos (Horário de Início, Horário de Término) dos objetos de LogPlaylist, ao invés de todos os atributos, que incluíam também o Usuário, Música, Artista e Duração da Música.

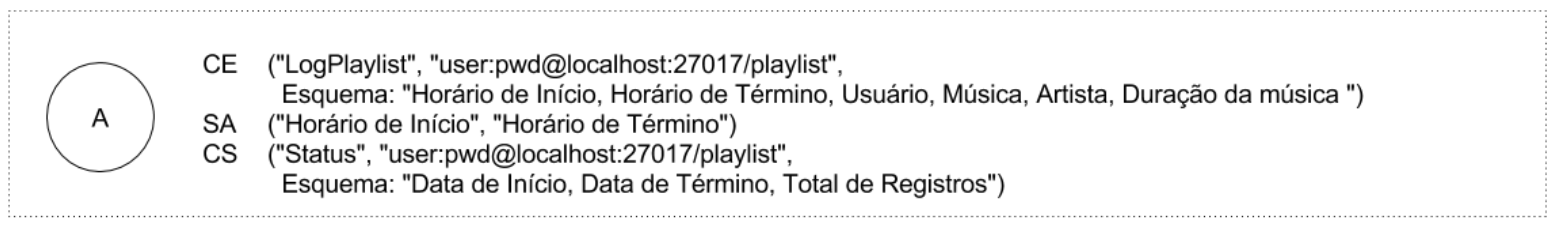

Figura 4.5: Exemplo de uso da anotação SA para um banco de dados relacional

Para manter a anotação aplicável a coleções de objetos em bancos de dados relacionais, supomos que cada atributo da lista definida em ListaAtributos existe no esquema relacional da coleção associada. Em cenários NoSQL, o acesso a um atributo não-existente em um agregado é comumente tratado como ao acesso a um atributo existente mas com valor nulo. Nesse caso, operações de busca que envolvem condições de seleção sobre atributos não-existentes retornam os objetos que satisfazem às demais condições de busca.

\section{Anotação sobre a Ordenação dos Objetos: OO(ListaAtributos)}

Conforme o tipo de processamento a ser realizado, atividades distintas de um workflow que acessam objetos de uma mesma coleção de dados de entrada podem requerer ordenações distintas desses dados. A anotação de Ordenação de Objetos OO(ListaAtributos) especifica para uma atividade, por meio do parâmetro ListaAtributos, os atributos que devem ser usados para a ordenação dos objetos de sua coleção de dados de entrada. Dessa forma, os objetos da coleção indicada pela anotação $C E$ da atividade serão recuperados em ordem crescente, seguindo a ordem de prioridade dos atributos da lista, isto é, ordena-se todos os objetos pelo primeiro atributo da lista, depois pelo segundo atributo e assim sucessivamente. A ausência dessa anotação indica que, por padrão, os dados devem ser recuperados em ordem crescente de valor da chave de identificação (primária).

Utilizando como exemplo duas atividades, $A$ e $B$ do workflow PlayFlow, definimos na Figura 4.6 que a atividade $A$ necessita que os objetos da coleção de entrada LogPlaylist estejam ordenados de modo crescente por seus atributos Horário de Início, Horário de Término respectivamente. Já na Figura 4.7, podemos observar que a atividade $B$, que utiliza a mesma coleção de $A$, requer que os objetos sejam ordenados somente pelo atributo Duração da Música a fim de que seja capaz de gerar um ranking com as cinco músicas de maior duração na lista de músicas processadas.

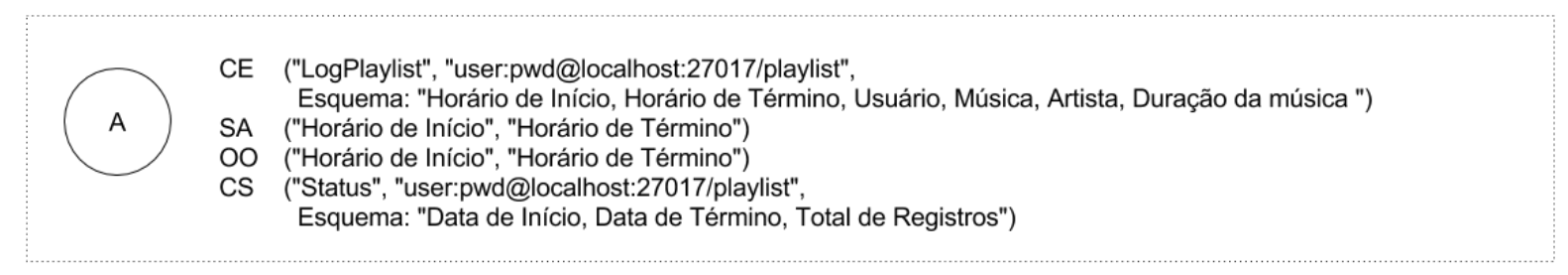

Figura 4.6: Exemplo de uso da anotação $O O$ da atividade A sobre os objetos da coleção LogPlaylist, indicando que tais objetos devem ser ordenados pelo atributo Horário de Início, Horário de Término.

No contexto de processamento de grandes volumes de dados, a criação de índices é essencial, pois permite a ordenação por atributos diferentes da chave primária. Contudo, deve-se considerar 


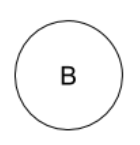

CE ("LogPlaylist", "user:pwd@localhost:27017/playlist",

Esquema: "Horário de Início, Horário de Término, Usuário, Música, Artista, Duração da música ")

SA ("Música", "Duração da música")

OO ("Duração da música")

CS ("Top5MusicasMaisLongas", "user:pwd@localhost:27017/playlist",

Esquema: "Musica, Duração da música, Posição no Ranking")

Figura 4.7: Exemplo de uso da anotação $O O$ da atividade $B$ sobre os objetos da coleção LogPlaylist, indicando que tais objetos devem ser ordenados pelo atributo Duração da Música.

o impacto no desempenho durante o processo de escrita no SGBD.

\section{Anotação sobre o Processamento de uma Coleção:}

\section{$P C$}

A anotação $P C$ associada a uma atividade indica que essa atividade faz um processamento que envolve todos os objetos da coleção de entrada definida pela anotação $C E$ associada a ela. Esse é o tipo de processamento de objetos de dados que o método proposto assume como padrão para as atividades do workflow. Sendo assim, caso não seja indicado um outro tipo de processamento (via anotações $P O, P G, P J T$ ou $P V D$ ) para uma atividade do workflow, a anotação $P C$ (Processamento de todos os objetos da Coleção) é adicionada implicitamente.

Nos exemplos descritos pelas Figuras 4.6 e 4.7, tanto a atividade $A$ quanto a $B$ processam todos os objetos de dados da coleção LogPlaylist, ou seja, ambas possuem uma anotação $P C$ associada.

\section{Anotação sobre o Processamento por Objeto de dados:}

\section{$P O$}

Uma coleção de entrada, definida pela anotação $C E$ associada a uma atividade, contém um ou mais objetos de dados. Caso a atividade processe cada objeto individualmente, isto é, necessite de apenas um objeto de entrada por vez para gerar nenhum, um ou mais objetos de saída, esta atividade pode receber a anotação $P O$ (Processamento por Objeto de dados). Esta anotação indica como a coleção de entrada será consumida, estabelecendo que um mesmo processamento (definido pela atividade) será aplicado para cada um dos objetos de dados.

Por exemplo, suponha que a coleção LogPlaylist, utilizada pelo workflow Playflow, contenha dois objetos de dados, definidos como:

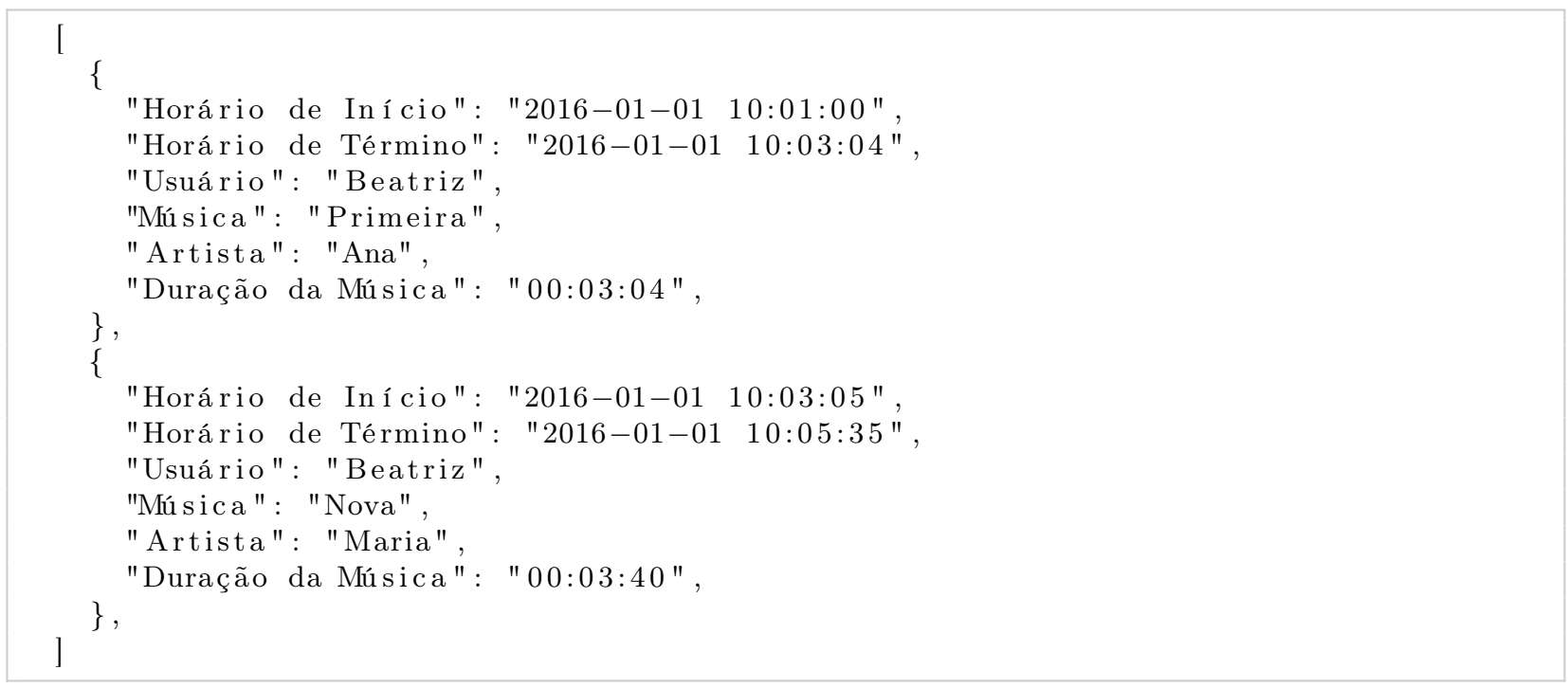

Para que o PlayFlow obtenha a primeira análise do perfil de seu usuário, analisando como as músicas foram executadas ao longo do período analisado, definimos duas atividades: $C$ e $D$. A atividade $C$ é responsável por analisar cada objeto e verificar se o período de execução é igual 
ao tempo de duração de cada música descrita no objeto de dados, classificando-o como "Execução Parcial"ou "Execução Completa". Essa informação é persistida em um novo objeto na coleção de saída NumExecParcialTotal, definido por dois atributos: "Música", "Tipo de Execução". Após a execução de $C$, todos os objetos da coleção NumExecParcialTotal serão fornecidos como entrada a $D$, a fim de que sejam definidas as porcentagens de músicas executadas por completo e parcialmente, em relação ao total de músicas de LogPlaylist. A classificação realizada por $C$ sobre o primeiro objeto de dados é independente da análise feita sobre o segundo objeto de dados da coleção LogPlaylist, o que permitiria que ambos objetos fossem analisados simultaneamente caso existissem duas cópias de $C$, cada uma associada a um dos objetos.

A anotação $P O$ caracteriza um comportamento similar ao operador foreach, implementado na linguagem Swift. Entretanto, diferentemente da nossa anotação, o operador foreach necessita que o usuário especifique programaticamente o vetor de objetos (equivalente a coleção de objetos). Já na abordagem que propomos, a anotação é capaz de acessar a coleção de objetos do SGBD e retornar o vetor a ser consumido pela atividade automaticamente.

No caso da caracterização de atividades pela SciWfA, a anotação $P O$ é equivalente ao operador álgebrico Map. Entretanto, por não exigir que haja uma relação entre o número de objetos consumidos e produzidos, permite que seja equivalente também ao operador Filter e ao operador SplitMap, uma vez que o número de objetos gerados em relação aos objetos consumidos pode ser definido como 0,1 ou $n$ objetos (vide Tabela 3.1).

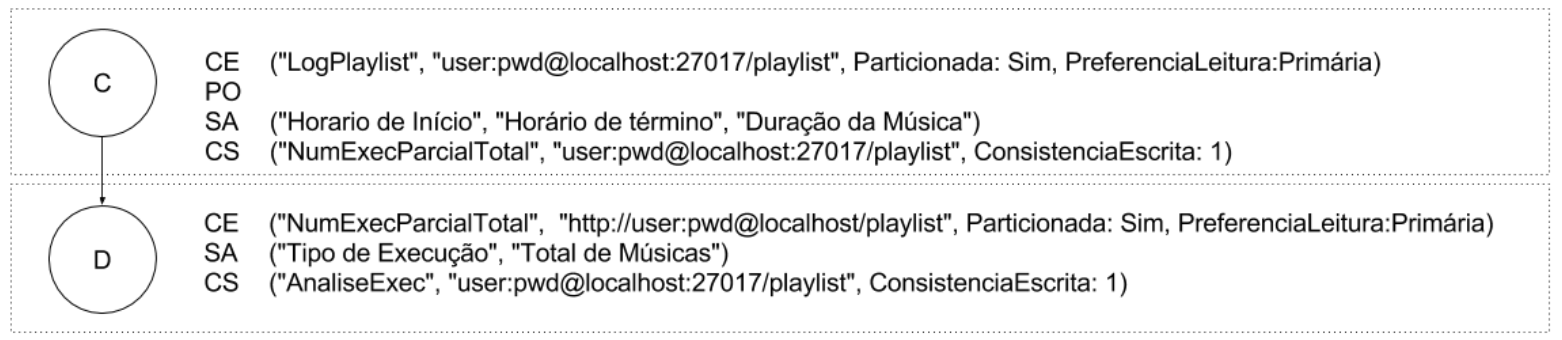

Figura 4.8: Exemplo de duas atividades utilizadas para a análise do perfil de execução das músicas descritas na coleção de entrada LogPlaylist. A atividade $C$ ilustra o uso da anotação PO.

\section{Anotação sobre o Processamento de Grupos de Objetos: PG(ListaAtributosAgrupadores)}

Outro tipo de processamento que pode ser caracterizado por uma anotação é o processamento de grupos de objetos, definido pela anotação $P G$. A anotação recebe como parâmetro uma lista de atributos agrupadores que determinam como os grupos de objetos a serem processados por uma atividade serão definidos e recuperados do banco de dados. Cada combinação distinta de valores observada na coleção de entrada nos atributos agrupadores corresponde a um grupo diferente, que contém todos os objetos de dados que possuem essa combinação de valores. O processamento dos objetos de dados de um grupo deve ser independente dos objetos pertencentes aos demais grupos.

Para ilustrar essa anotação, usaremos novamente duas atividades, $E$ e $F$, do workflow de PlayFlow, que permitem a identificação do artista preferido do usuário avaliado. Descrevemos as atividades e suas anotações na Figura 4.9. Considere agora os quatro objetos da coleção LogPlaylist mostrados a seguir, caracterizados somente pelos atributos Artista, Música. Note que uma música pode ser ouvida mais de uma vez em horários distintos:

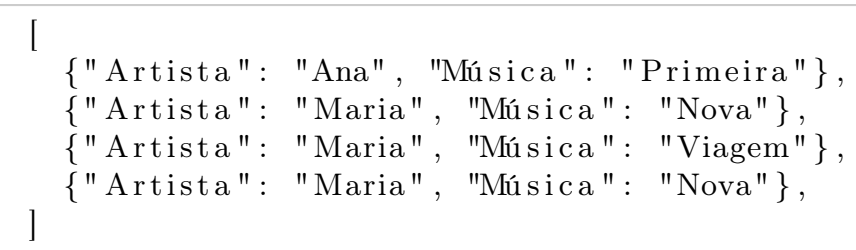


O processamento realizado na atividade $E$ é baseado em grupos definidos por artistas distintos, ou seja, primeiramente serão processados todos os objetos relacionados à artista "Ana"e, posteriormente, todos os objetos com artista = "Maria". Para cada grupo, a atividade $E$ contabilizará o número de execuções (objetos recuperados) e armazenará essa informação na coleção TotalMúsicasPorArtista, por meio de um objeto definido pelos atributos (Total de Plays, Artista). Essa coleção é fornecida como entrada da atividade $F$, cujos objetos serão ordenados pelo atributo TotaldePlays. $F$ definirá o artista preferido como o artista com o maior número de plays. Essa informação será persistida na coleção de saída ArtistaPreferido.

Caso a anotação $P G$ em $E$ recebesse como parâmetro os atributos (Artista, Música), seriam definidos três grupos: (Ana, Primeira), (Maria, Nova), (Maria, Viagem). Assim, o grupo definido pelos valores (Maria, Nova) conteria dois objetos.

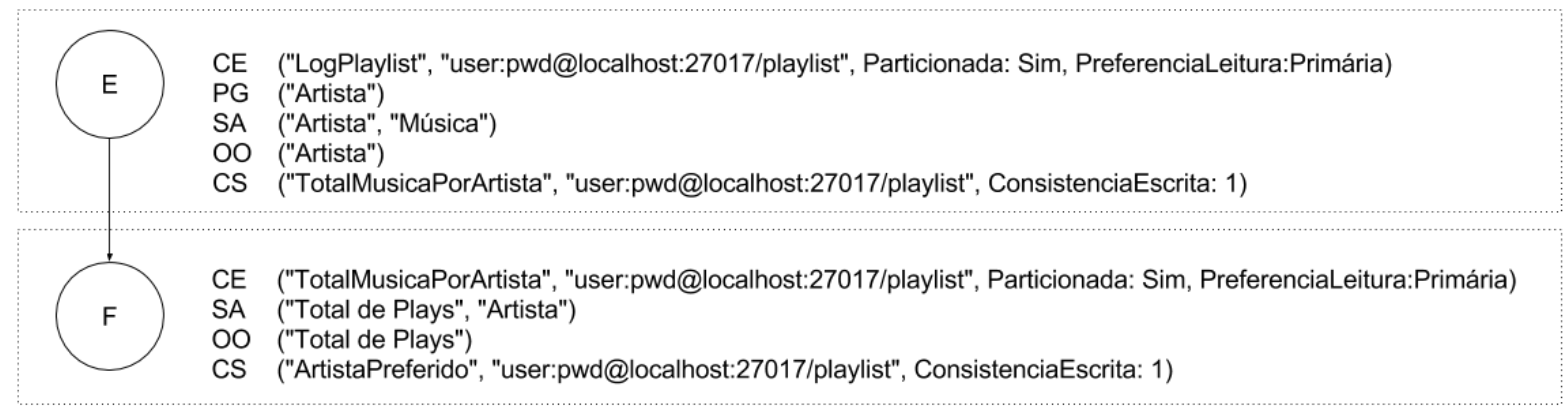

Figura 4.9: Exemplo do uso da anotação $P G$ para analisar o artista preferido de um usuário por meio do workflow PlayFlow

Na álgebra SciWfA, a anotação $P G$ pode ser comparada ao operador Reduce. Entretanto, na abordagem que propomos, não há a restrição de que a cada grupo de objetos processado obrigatoriamente deva ser gerado um único objeto. A anotação $P G$ pode ainda ser relacionada ao construtor de agregação de dados ou ao construtor de redistribuição de dados (vide Seção 2.1.2, considerando cada item de dado consumido como um objeto.

\section{Anotação sobre o Processamento de Janelas de Tempo: PJT(AtributoSeparador, TamanhoJanela, UnidadeTempo)}

Os objetos de dados de uma coleção podem ser processados em grupos definidos por janelas de tempo, caso contenham um atributo do tipo data e hora (timestamp). Esse tipo de operação é comum em atividades que analisam logs de um usuário [SF12, $\left.\mathrm{LMT}^{+} 05\right]$, por exemplo.

Para descrever esse tipo de agrupamento, definimos a anotação PJT com os parâmetros (AtributoSeparador, TamanhoJanela,UnidadeTempo), que permitem a definição de intervalos de tempo (janelas) e a associação de cada objeto de uma coleção a um desses intervalos. Um intervalo é definido pelos parâmetros: AtributoSeparador, referente a um atributo temporal no formato timestamp existente nos objetos da coleção de entrada; UnidadeTempo, que define a unidade de tempo a ser considerada, restrita aos valores \{ "ano", "mes", "dia", "hora", "minuto", "segundo"\}; e TamanhoJanela, que descreve o tamanho do intervalo na unidade de tempo definida, por exemplo, o valor 2 para a unidade "dia", descreverá grupos de 2 em 2 dias.

Retomando o PlayFlow como exemplo, caso fossem criados quatro objetos na coleção LogPlaylist e selecionados seus atributos Horário de Início, Música, poderíamos ter os seguintes objetos:

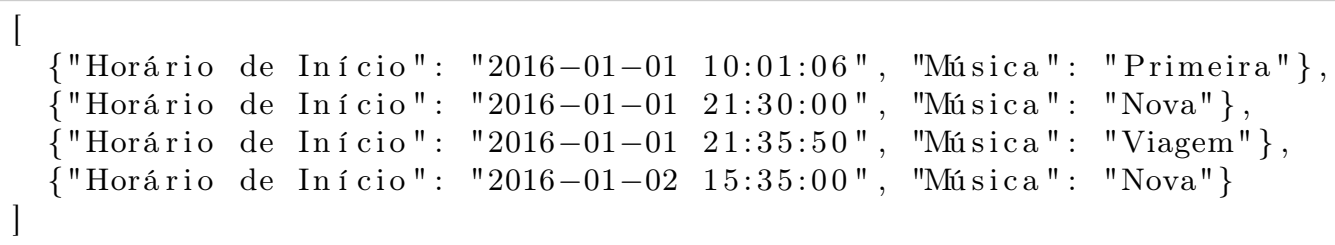


Caso uma anotação PJT fosse associada a uma atividade que recebe como entrada a coleção LogPlaylist, com os seguintes parâmetros ("Horário de Início", 1, dia), teríamos duas janelas temporais definidas, referente aos dias "2016-01-01"e "2016-01-02". No primeiro grupo, teríamos três objetos, referentes às execuções das músicas Primeira, Nova e Viagem e, no segundo grupo, apenas um objeto, referente à execução da música Nova do dia "2016-01-02".

Exemplificando o uso dessa anotação no workflow PlayFlow, definimos as atividades $G$ e $H$ para processar o total de músicas executadas por dia pelo usuário analisado. Para isso, a atividade $G$ recebe os atributos (Horário de Início, Horário de Término) dos objetos de LogPlaylist agrupados em janelas temporais divididas por dia e definidas pelo atributo Horário de Início. Para cada janela, será contabilizado o total de objetos associados. Esse total representará o número de execuções de músicas (plays) por dia e será armazenado na coleção PlaysPorDia por meio de um objeto com dois atributos: Total de Plays e Dia. Os objetos dessa coleção serão passados como entrada para a atividade $H$, responsável pelo cálculo da média de plays por dia, persistindo essa informação como um objeto na coleção MediaPlaysDia.

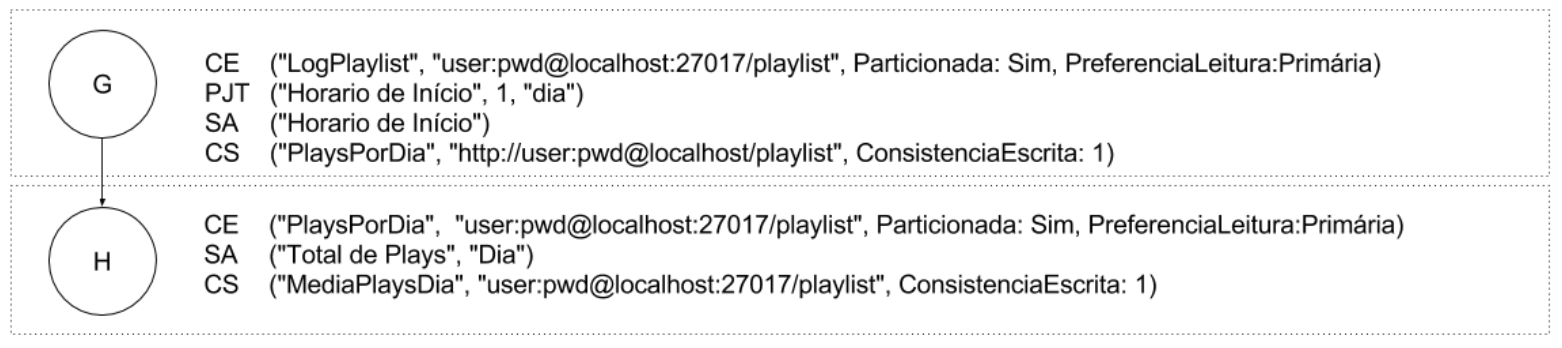

Figura 4.10: Exemplo de uso da anotação PJT para o cálculo da média de execuções de músicas por dia de um usuário no workflow PlayFlow.

\section{Anotação sobre o Processamento por Valor Distinto: $P V D($ Atributo $)$}

O processamento de valores únicos de um atributo não-chave, isto é, um atributo diferente da chave primária, pode requer a varredura de todos os objetos de dados da coleção a fim de se identificar valores distintos desse atributo. Definimos a anotação $P V D$ - Processamento por Valor Distinto - para representar esse tipo de processamento, que recupera uma lista com todos os valores distintos observados para um dado atributo nos objetos de uma coleção de entrada. Desse modo, a lista resultante não contém duplicatas. $\mathrm{O}$ atributo de interesse é definido como parâmetro dessa anotação.

No exemplo descrito no workflow PlayFlow, ilustrado na Figura 4.11, a anotação PVD é adicionada à atividade $I$ para que sejam identificadas todas as músicas existentes na coleção LogPlaylist. $P V D$ recebe como parâmetro, neste caso, o atributo "Música", que define qual atributo deve ter seus valores distintos recuperado dos objetos da coleção. O resultado é persistido na coleção ListaMusicas, que é processada pela atividade $J$, que computa o total de músicas analisadas e armazena este dado em um objeto da coleção TotalMúsicas. Considerando uma lista de objetos como a descrita no exemplo da anotação PJT, teríamos três músicas ("Primeira", "Nova"e "Viagem") identificadas na coleção LogPlaylist.

\subsection{Transformações Baseadas na Semântica da Atividade}

As anotações definidas na Seção 4.2 permitem descrever a forma como os dados são acessados e consumidos nas atividades. Tornam possível também a proposição de estratégias para ampliação do paralelismo do modelo de workflow a partir da semântica definida sobre o tipo de processamento realizado e dos atributos dos objetos manipulados para cada atividade. Assim, é possível modificar a 


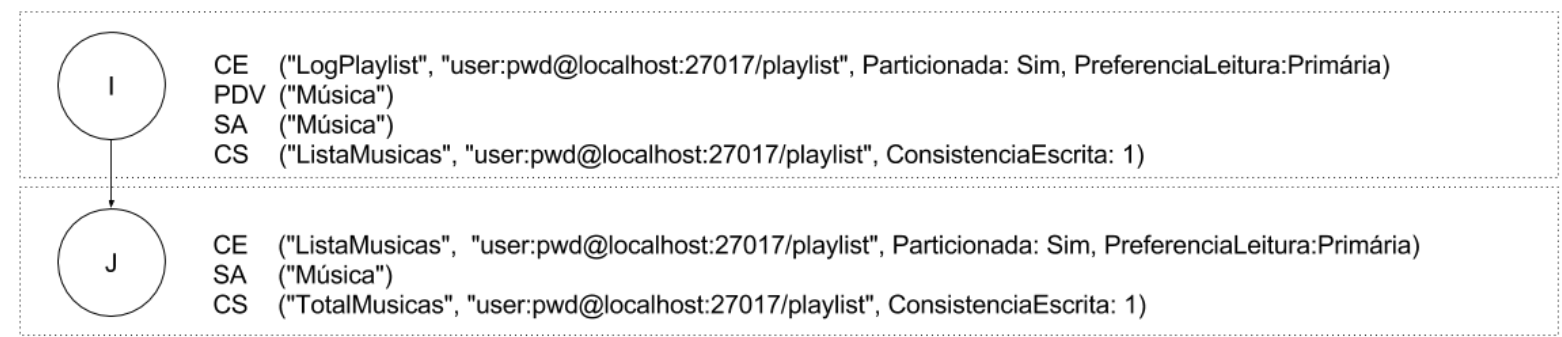

Figura 4.11: Exemplo de uso da anotação PVD para a computação do total de músicas distintas na coleção LogPlaylist, analisada pelo workflow PlayFlow.

estrutura do workflow e do banco de dados de forma automática e tornar a execução mais paralela. Descrevemos cada transformação nas seções a seguir.

\subsubsection{Reestruturação do Workflow}

Os tipos de processamento descritos pelas anotações $P O, P G$ e $P J T$ permitem a paralelização automática de uma atividade $A$, aplicando a técnica de reescrita do DAG (que define o modelo do workflow) com base no total de nós de execução disponíveis. Esse total, denotado por TotalNósExecução, é fornecido como parâmetro para a criação de cada instância do workflow, assim como o nome do SGBD utilizado (por exemplo, "MongoDB"ou "PostgreSQL"), caracterizado como TipoBancoDeDados. Logo, uma atividade $A$, com uma dessas três anotações, pode ser substituída no DAG por $n$ cópias de si mesma, sendo atribuída a cada cópia $A_{i}$ (tal que $1 \leq i \leq n$ ) um subconjunto distinto dos objetos da coleção de entrada definida em $C E$. Consideramos que essas três anotações $(P O, P G, P J T)$ são mutuamente excludentes, ou seja, uma atividade deve ser associada a apenas uma anotação de tipo de processamento dos dados. Assume-se também que, durante a identificação das partições disjuntas, os objetos de dados estão ordenados pela chave primária da coleção definida em $C E$, pelos atributos definidos pelo parâmetro ListaAtributosAgrupadores da anotação $P G$ ou pelo atributo definido pelo parâmetro AtributoSeparador da anotação PJT.

A definição de um subconjunto consiste na divisão de uma lista ordenada $l$ de objetos de entrada de acordo com o critério associado a cada anotação de tipo de processamento, resultando em partições descritas por pares ordenados $(a, b)$, em que $a$ e $b$ indicam a posição de objetos na lista $l$ que definem o início e fim de uma partição de dados. A Figura 4.12 ilustra esse processo de definição de subconjuntos. Dada uma atividade $X$ anotada por $C E$ e $P O$ e os parâmetros de execução de uma instância de workflow que contenha essa atividade, o método criará duas cópias de $X$, devido ao total de nós de execução disponíveis. Associará a primeira cópia ao Subconjunto 1, definido pelo par ordenado (1,3), que representa os objetos de dados com o atributo ID 1, 2 e 4, e a segunda cópia ao Subconjunto 2, indicado pelo par ordenado $(4,5)$, relacionado aos objetos de IDs 6 e 8 . O par $(1,3)$ refere-se aos objetos da primeira e da terceira posição na lista de objetos $l$ da coleção ColeçãoTeste ordenados pela chave primária ID. Já o par $(4,5)$ refere-se aos objetos da quarta e quinta posição da lista $l$.

A anotação $P C$ não permite nenhuma estratégia para paralelização de atividades; apenas descreve que a lista de todos os objetos de dados é recuperada da coleção de entrada da atividade. Também não é possível paralelizar atividades com a anotação $P V D$, que necessita recuperar todos os valores para o atributo definido pelo parâmetro AtributoSeparador de todos os objetos da coleção de entrada.

O Algoritmo 1, ParalelizaAtividadeAnotada, descreve o processo para a criação de réplicas baseado nas informações obtidas por uma anotação $P O, P G$ ou $P J T$ associada a uma atividade $A$. Recebe como parâmetro: (i) as anotações da atividade $A$; (ii) o total de nós disponibilizados por um SGWf para a execução de $A$; (iii) o atributo presente nos objetos de uma coleção, definida em uma anotação $C E$ associada a $A$, que foi utilizado para definir subconjuntos de objetos, (iv) a lista de partições identificadas a partir de um atributo dos objetos da coleção de $C E$, em que cada partição 


\begin{tabular}{|c|c|c|}
\hline & \multicolumn{2}{|c|}{ ColeçãoTeste } \\
\hline \multirow{4}{*}{$\begin{array}{c}\text { Subconjunto } 1 \\
(1,3)\end{array}$} & $\underline{\text { ID }}$ & Nome \\
\hline & 1 & Item 1 \\
\hline & 2 & Item 2 \\
\hline & 4 & Item 4 \\
\hline \multirow{2}{*}{$\begin{array}{c}\text { Subconjunto } 2 \\
(4,5)\end{array}$} & 6 & Item 6 \\
\hline & 8 & Item 8 \\
\hline
\end{tabular}

Anotações de uma Atividade $X$

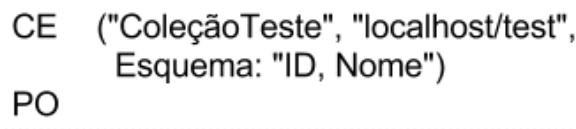

Parâmetros de uma Instância de Workflow

TotalNosExecucao: 2 TipoBancoDeDados: PostgreSQL

Figura 4.12: Subconjuntos de uma coleção de entrada definidos a partir de uma anotação PO sobre uma atividade $X$ e de parâmetros de execução de uma instância de workflow que contém esta atividade. O atributo ID define uma chave primária.

é apresentada como um par ordenado referente ao primeiro e ao último objeto dessa partição.

A partir dessas informações, é calculado o total de partições que podem ser distribuídas. No contexto da anotação $P O$, é o total de objetos de $C E$; para a anotação $P G$, refere-se ao total de grupos identificados pelos valores dos atributos definidos pelo parâmetro ListaAtributosAgrupadores; a respeito da anotação $P J T$, indica o número de janelas a serem processadas.

Ao analisar o parâmetro ListaPartições e TotalNósExecução, o Algoritmo 1 calcula quantas cópias da atividade $A$ serão criadas e associa $m$ partições de ListaPartições para cada réplica de $A$ por meio da função CriaReplicaAtividade. O número de partições a serem processadas por réplica de uma atividade, é calculado por meio da divisão inteira (truncada) do total de partições pelo total de réplicas criadas. Nem sempre é possível atribuir a todas as réplicas uma mesma quantidade de partições. Entretanto, o algoritmo garante que a diferença entre o número de partições atribuídas a quaisquer duas réplicas de uma atividade é no máximo um, a fim de se garantir uma distribuição balanceada.

Após a criação de todas as réplicas, o modelo do workflow é atualizado, ou seja, o $D A G$ que descreve o workflow é reescrito e a atividade $A$ é substituída por suas réplicas.

A seguir descrevemos os critérios adotados nas anotações $P O, P G$ e $P J T$ para a definição dos subconjuntos associados às réplicas.

\section{Criação de Réplicas Baseada na Anotação $P O$}

O Algoritmo 2, ParalelizaAtividadeAnotadaPO descreve como é definido o particionamento dos objetos entre as réplicas da atividade anotada $A$. Primeiramente, é recuperado o nome da chave primária que identifica os objetos dentro da coleção descrita por $C E$ e atribuída a $A$. A seguir, é obtida a lista de todas as chaves primárias ordenadas dos objetos dessa coleção. Por fim, é chamada a função ParalelizaAtividadeAnotada, responsável por associar subconjuntos de objetos de acordo com o total de réplicas a serem criadas.

\section{Criação de Réplicas Baseada na Anotação $P G$}

A criação de réplicas de atividades com a anotação $P G$ é descrita pelo Algoritmo 3, denominado como ParalelizaAtividadeAnotadaPG. Neste, primeiramente, identifica-se os grupos de objetos a serem processados a partir da lista das diferentes combinações de valores para os atributos do parâmetro ListaAtributosAgrupadores observadas nos objetos da coleção de entrada da atividade anotada $A$. Depois, a função ParalelizaAtividadeAnotada distribui esses grupos entre as réplicas de $A$ a serem criadas. 

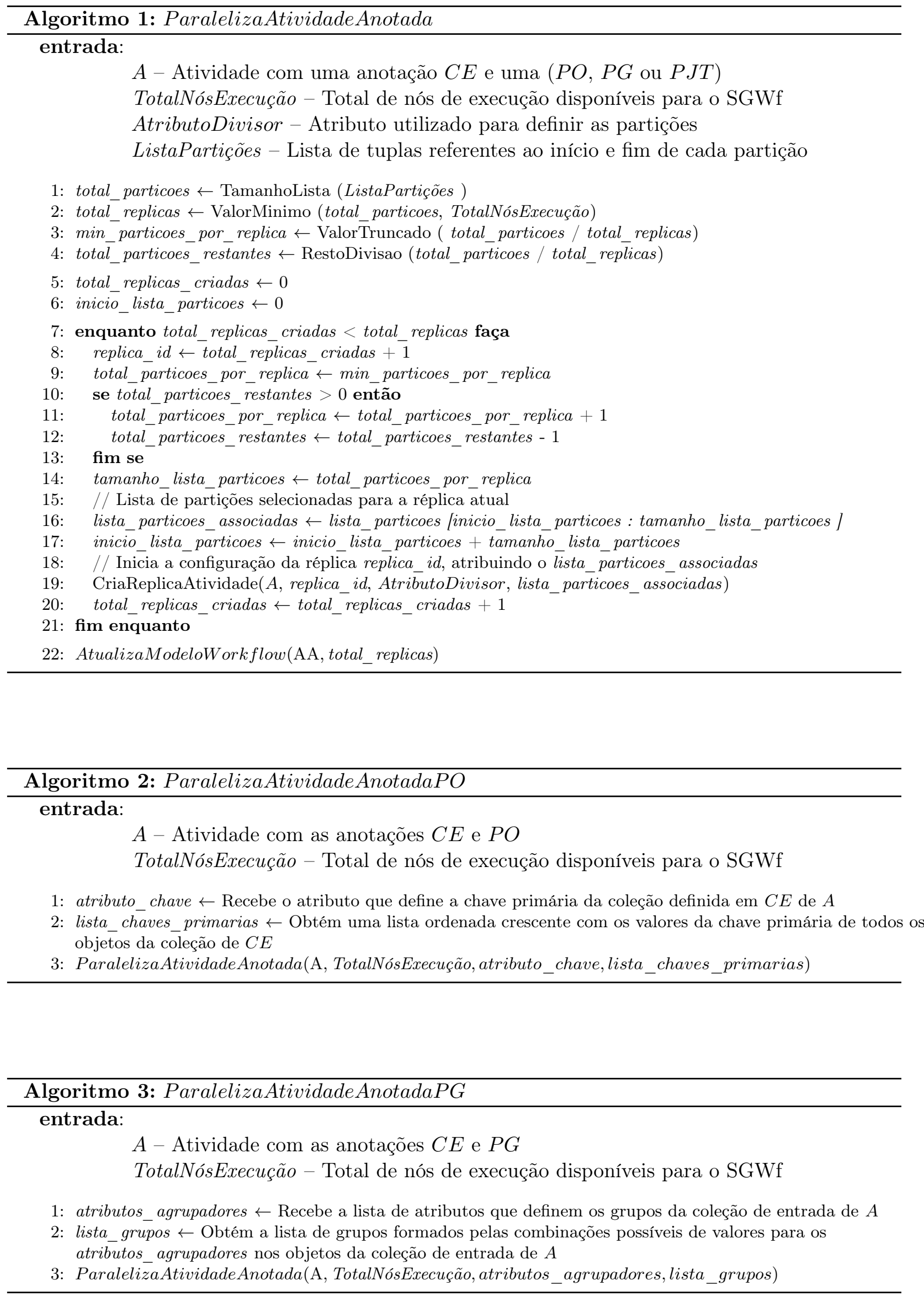


\section{Criação de Réplicas Baseada na Anotação PJT}

O Algoritmo 4 - ParalelizaAtividadeAnotadaPJT - define a lista de janelas temporais a serem processadas pela atividade anotada $A$, por meio de um atributo temporal (relativo a uma data e hora) existente nos objetos da coleção de entrada de $A$, de acordo com os parâmetros UnidadeTempo e TamanhoJanela de PJT. Cada janela é um par ordenado em que o primeiro elemento define o início da janela e o segundo elemento, o seu término. A lista de janelas $l$ é calculada por CalculaIntervalosJanelas e passada como parâmetro da função CriaReplicaAtividadeAnotada, que inicializa cada réplica de $A$ com um subconjunto de janelas de $l$. Os intervalos temporais definidos por cada janela são disjuntos.

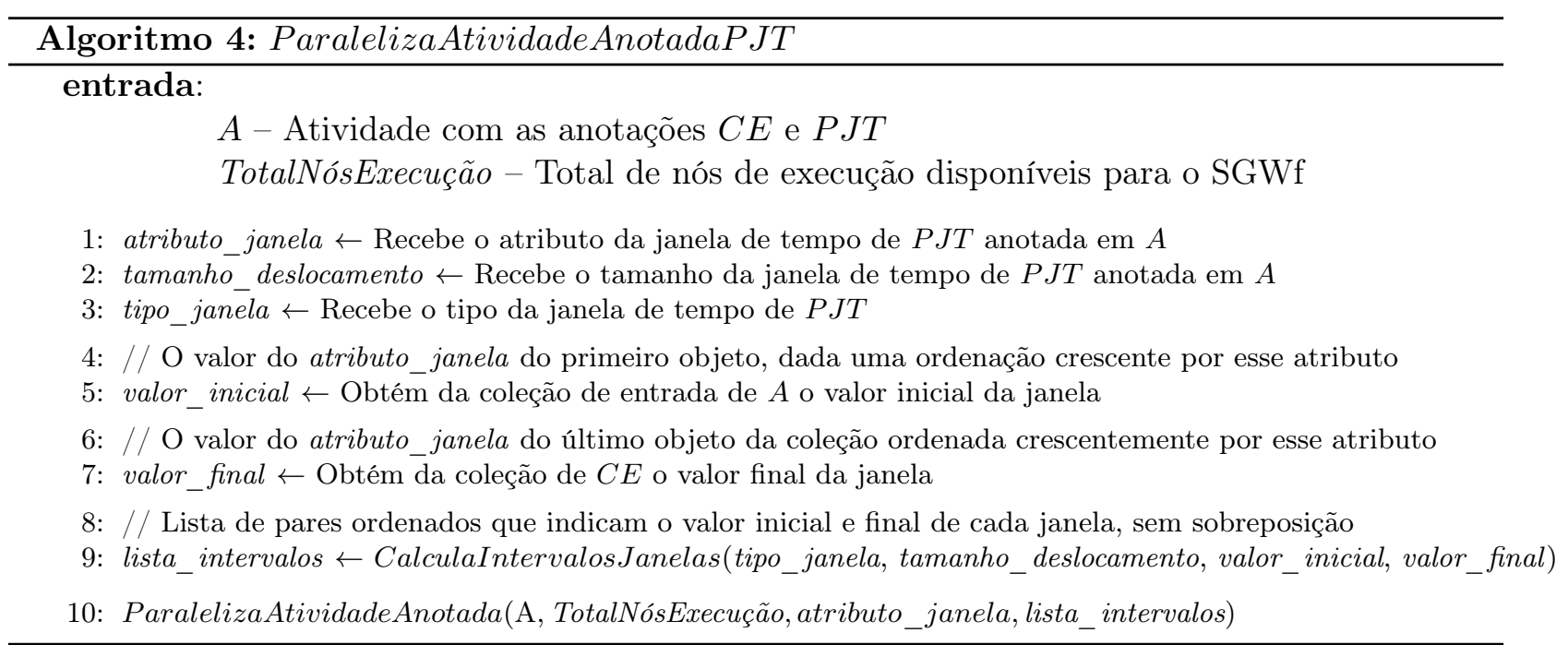

\subsubsection{Modificações no Banco de Dados}

As anotações $O O, P G, P J T$ e $P V D$ permitem a definição de índices de apoio para as consultas a serem realizadas, resultando em operações para modificação das coleções de entrada às quais cada anotação está associada. Além disso, atividades com as anotações $P O, P G$ e $P J T$ combinadas com uma coleção de entrada definida por $C E$ em que o parâmetro Particionada está definido como verdadeiro (indicando o uso de um banco de dados distribuído) permitem a definição de um esquema de distribuição dos objetos de dados desta coleção (durante a sua criação) caso esta seja uma coleção de dados intermediários (gerados previamente por outra atividade do mesmo workflow).

O Algoritmo 5, InicializaBancoDeDados, descreve esse processo. Ele recebe como entrada a lista das atividades, em que cada atividade contém um conjunto definido de anotações. O usuário define qual tipo de estratégia de particionamento (fragmentação) de dados ele deseja aplicar durante a execução do workflow, caso o banco de dados seja distribuído. A estratégia de Hashing resulta em uma distribuição mais aleatória dos dados enquanto a estratégia de Intervalo busca otimizar consultas baseadas em intervalos de valores para um atributo, de modo que o SGBD busque os objetos preferencialmente em uma única partição do banco de dados. Este algoritmo retorna a lista de operações para inicialização do banco de dados e de reinicialização das coleções de entrada após o término da execução, isto é, para remoção de índices criados em coleções de entrada pré-existentes. O operador « usado no algoritmo refere-se ao processo de adição de um item ao final de uma lista.

\subsection{Implementação do Método: Ferramenta SciWonc-Dataflow}

Como prova de conceito, implementamos a ferramenta SciWonc-Dataflow [WGB16] (disponível como software livre), que é um protótipo para interpretação das anotações propostas na Seção 4.2 e criação automática de estratégias de paralelização a partir dessas anotações e do número de nós 


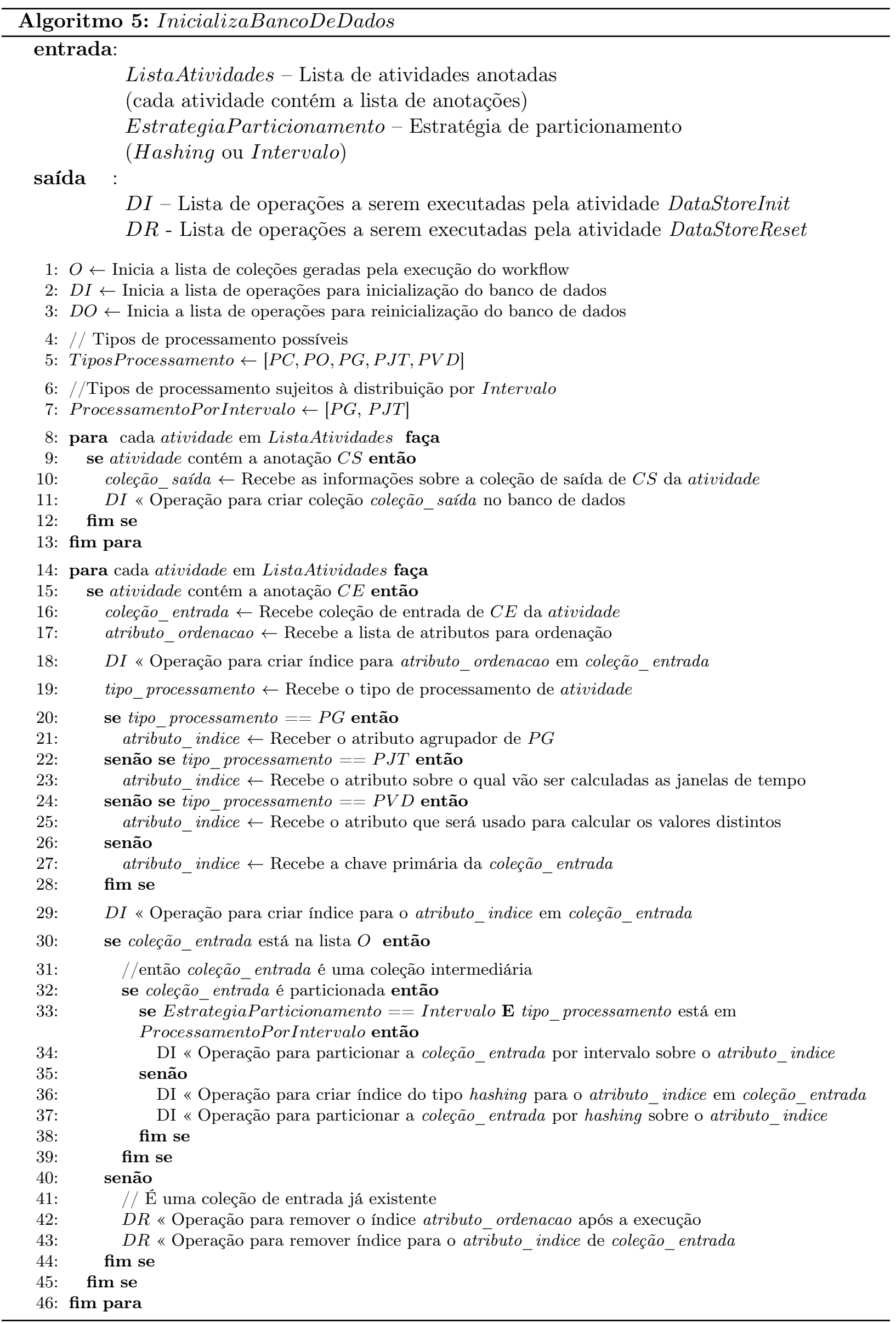


de execução disponível, como descrito na Seção 4.3.1. Para isso, dividimos o funcionamento da ferramenta nas seguintes etapas:

1. Definição da estrutura do workflow no formato JSON, em que o usuário fornece uma lista de atividades (composta por um atributo identificador da atividade e uma lista de anotações) e uma lista de dependências entre essas atividades.

2. A partir desse arquivo de JSON, a ferramenta gera para cada atividade da lista fornecida um arquivo de configuração, que permite converter as anotações associadas à atividade em consultas a um banco de dados, e um arquivo-modelo para implementação da atividade em Python, que inclui a chamada para o arquivo de configuração criado e a estrutura do processamento de listas de objetos por meio de um cursor, que retorna um dicionário para cada objeto de dados (em que cada chave é o nome de um atributo e seu conteúdo é o valor desse atributo). Nessa etapa, a ferramenta associa a anotação $P C$ a cada atividade sem anotação sobre o tipo de processamento, caso a anotação possua a anotação $C E$.

Cada atividade anotada deverá utilizar em sua implementação o módulo (biblioteca) SciWoncDataflow-Connector, responsável por fornecer a interface de conexão com o banco de dados baseada nas anotações propostas.

3. São adicionadas duas atividades artificiais no workflow: DataStoreInit, responsável pela criação das coleções, índices de suporte e estratégia de particionamento; e DataStoreReset, que remove os índices de suporte adicionados aos objetos de entrada do workflow.

4. Após a implementação das atividades, para dar início à criação de um modelo de workflow pronto para ser executado pelo SGWf, o usuário utiliza novamente a ferramenta SciWoncDataflow passando como parâmetro o total de nós de execução disponíveis. Caso o banco de dados seja distribuído, o usuário pode definir o uso de particionamento baseado em Intervalo. Caso não defina, o particionamento, por padrão, será por meio de Hashing. A partir desses parâmetros, a ferramenta se encarrega de aumentar a paralelização do workflow automaticamente, caso o número de nós de execução seja maior que dois e exista anotações do tipo $P O$, $P G$ ou PJT.

5. Por fim, é gerada a descrição do workflow na linguagem DAX, utilizada pelo SGWf Pegasus para gerenciar a execução do workflow.

O protótipo implementado supõe que os dados de entrada para um workflow já estão disponíveis em um SGBD e que o usuário tem permissão de administrador sobre o banco de dados utilizado. Também supõe que o SciWonc-Dataflow-Connector está instalado como um módulo Python em todos os nós de execução do SGWf e que os nós suportam conexões com o MongoDB e com o PostgreSQL via pymongo e psycopg, respectivamente, ambas bibliotecas Python para conexão com SGBDs.

O protótipo tem um arcabouço para criação de workflows nos quais as atividades são implementadas em Python e que, por essa razão, podem ser executadas facilmente em várias plataformas. Outra vantagem do uso de Python neste caso é que a linguagem fornece uma vasta gama de bibliotecas para análise de dados. Entretanto, é importante ressaltar, que o protótipo poderia ser facilmente integrado a workflows já existentes, por meio da geração de arquivos de dados ou definição de subcoleções diretamente no banco de dados utilizado pelo workflow. O esquema de indexação pode ainda ser aplicado independentemente da paralelização das atividades, a fim de proporcionar melhor desempenho às consultas utilizadas.

A criação de réplicas de atividades pela ferramenta pode ser feita segundo duas abordagens uma estática e outra dinâmica - ambas utilizando um número fixo de recursos para a execução do workflow. No primeiro caso, a ferramenta conecta-se ao banco de dados no momento de criação de uma instância do workflow anotado e recupera as informações necessárias para a definição do 
paralelismo. No segundo caso, cria-se tantas réplicas quanto forem os nós para execução e adicionase uma atividade artificial para criação dos arquivos de configuração antes da atividade anotada. Essa atividade artificial, que recebe como parâmetro as anotações da atividade replicada e o total de nós de execução que estão disponíveis, define os intervalos associados a cada réplica em tempo de execução; todas as réplicas são dependentes desta atividade, sendo um ponto de sincronismo das linhas de execução necessárias para iniciar a atividade replicada. Essa abordagem é viável para cenários que manipulam dados intermediários e não permitem saber em tempo de projeto quantos objetos da coleção de entrada serão manipulados.

Para cada consulta realizada por uma atividade, a biblioteca SciWonc-Dataflow-Connector devolve um cursor, para que a atividade possa iterar sobre grandes conjuntos de dados. Além disso, na implementação da biblioteca para o PostgreSQL, usamos cursores nomeados, que são executados diretamente no servidor, mantendo um cache de mil objetos no cliente.

A biblioteca ainda provê uma interface de acesso comum aos bancos de dados PostgreSQL e MongoDB, sendo necessário apenas alterar o tipo e dados de conexão. Um exemplo do arquivo de configuração criado automaticamente pela ferramenta é mostrado a seguir:

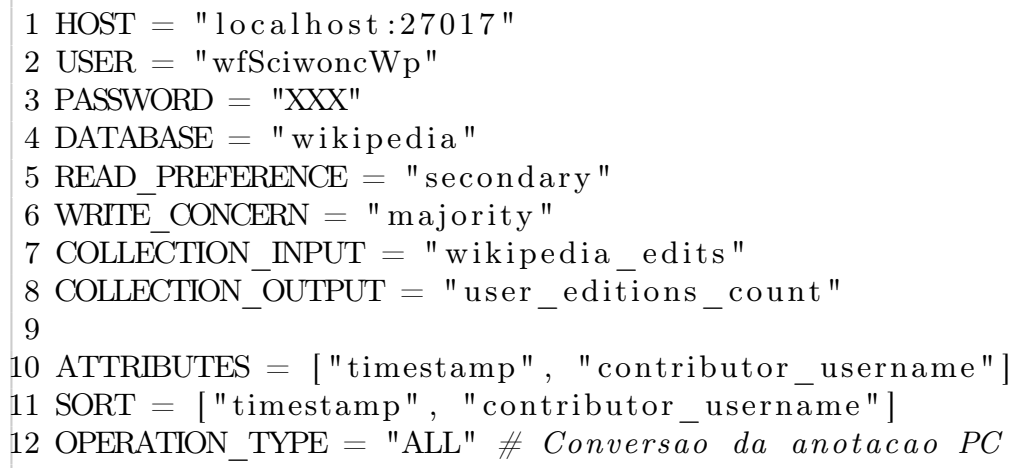

A seguir, é mostrado um exemplo de atividade que o utiliza, criada a partir de um arquivomodelo gerado pela ferramenta:

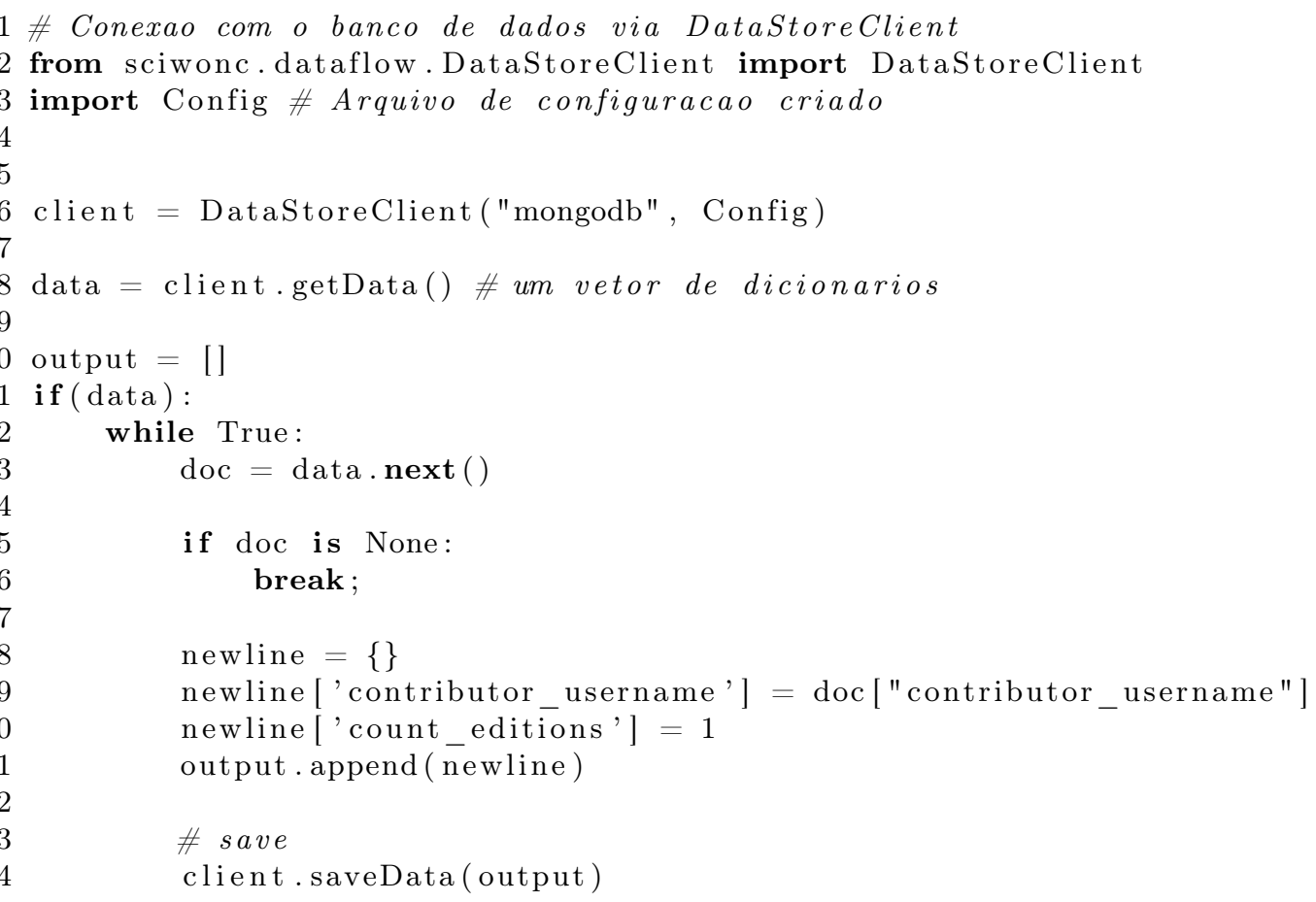

Para alterar o tipo de conexão, basta atualizar as informações de acesso e trocar o conector de "mongodb" para "postgres", na linha 6. Mais informações sobre a implementação estão disponíveis em [WGB16]. 


\subsection{Considerações sobre o Capítulo}

Este capítulo apresenta o método proposto neste trabalho para a paralelização de atividades em workflows intensivos em dados.

O método descrito propõe nove anotações, descritas na Seção 4.2, relacionadas às coleções de objetos de entrada e saída, à apresentação dos atributos às atividades e ao tipo de processamento realizado, permitindo que a semântica das atividades seja incorporada ao modelo do workflow.

Associa ainda processos para a reestruturação do workflow e do banco de dados, descritos na Seção 4.3.1, a partir dessas anotações, capazes de aumentar o paralelismo de uma atividade com uma das anotações $P O, P G$ ou PJT associada e tornar o acesso mais paralelo aos dados consumidos e gerados durante a execução de uma instância de workflow.

Além disso, descreve o protótipo da ferramenta SciWonc-Dataflow, capaz de fornecer uma interface simples de acesso aos dados para a descrição da semântica e a incorporação dessas informações à forma como os dados são acessados e distribuídos. Permite que o usuário escolha a forma de distribuição dos dados, dado que a divisão da coleção de entrada em subconjuntos não garante que o processamento das réplicas possuirá cargas com tamanhos aproximadamente iguais. Sua implementação é feita na linguagem de programação Python, que suporta diversas bibliotecas utilizadas no meio científico para análise de dados, tais como numpy, scipy e pandas, e permite a execução multiplataforma. Esta ferramenta foi usada na criação de dois workflows apresentados nos Capítulos 6 e 7 que manipulam grandes coleções de dados reais. Esses workflows foram executados e avaliados em 21 cenários computacionais diferentes, descritos no capítulo a seguir. 


\section{Capítulo 5}

\section{Ambiente Experimental}

Este capítulo descreve os sistemas e ambientes utilizados para os experimentos apresentados no Capítulo 6 e no Capítulo 7, tais como o SGWf e bancos de dados avaliados, a plataforma de computação em nuvem da Amazon e a configuração de seus recursos durante a execução dos workflows.

\subsection{SGWf Pegasus}

O SGWf Pegasus [DVJ+15] foi o sistema escolhido para controlar a execução dos workflows avaliados neste trabalho, principalmente por sua comunidade ativa e pela possibilidade de integração com novas ferramentas por se tratar de um software livre. Vem sendo utilizado há mais de 12 anos pela comunidade científica em projetos de grande escala tais como o Laser Interferometer Gravitational-Wave Observatory (LIGO) [Col], para identificação de ondas gravitacionais, e o CyberShake [Cen], para a análise de riscos sísmicos. Sua linguagem de declaração, chamada DAX (DAG in XML), permite que o usuário represente um workflow do tipo DAG (Seção 2.1) em um alto nível, no formato XML, indicando as atividades necessárias para o workflow assim como suas dependências e arquivos de entrada e saída esperados. Nessa linguagem, o paralelismo de atividades é representado por meio da ausência de dependências de dados ou de controle entre duas ou mais atividades.

Além do workflow em formato DAX, o usuário fornece para o SGWf Pegasus as informações sobre: (i) a localização dos arquivos de entrada das atividades no Replica Catalog; (ii) a lista de quais recursos computacionais serão utilizados no arquivo Site Catalog; (iii) e, no Transformation Catalog, a localização dos executáveis usados pelas atividades. Por meio desses arquivos, uma instância de workflow é gerada, incluindo atividades, por exemplo, para transferências de arquivos do nó de submissão aos nós de execução que os consumirão. O nó de submissão também é o responsável pelo mapeamento do modelo de workflow (descrição) em uma instância de workflow (executável), relacionando as informações sobre a infraestrutura computacional a ser utilizada. Ele mantém o subsistema de escalonamento de tarefas, responsável pela distribuição das atividades para os nós de execução do ambiente escolhido. É possível executar workflows com o Pegasus em ambientes distribuídos, tais como aglomerados, grades e nuvens computacionais.

O Pegasus ainda monitora a execução das atividades e aciona mecanismos para reexecução de atividades em caso de falha. Mantém também um banco de dados de proveniência para cada execução, fornecendo estatísticas sobre o tempo de execução, consumo dos recursos computacionais e sobre o ambiente de execução.

Nos experimentos realizados, utilizou-se o Pegasus (versão 4.7.0) com o motor de execução HTCondor (versão 8.4.8), que permite compor o ambiente de execução como um aglomerado virtual que pode ser executado em uma grade ou em uma plataforma de computação em nuvem. 


\subsection{SGBDs Avaliados}

A execução em uma nuvem computacional permite o uso de diversos serviços para o armazenamento e compartilhamento de dados, tais como os baseados em objetos (e.g., Amazon S3 [Serd] e Google Cloud Storage [Plac]) e sistemas gerenciadores de bancos de dados relacionais (e.g., Amazon RDS [Serc], Amazon Aurora [Sera] e Google Cloud SQL [Plab]) e não-relacionais (e.g., Amazon DynamoDB [Serb] e Google DataStore [Plaa]). Neste trabalho, entretanto, usou-se SGBDs instalados em instâncias computacionais ao invés de utilizar serviços fornecidos pelos provedores de computação em nuvem para possibilitar maior portabilidade dos experimentos e controle sobre a configuração e escalabilidade dos recursos. Devido à popularidade, ao uso livre e ao suporte a modelos semiestruturados, escolheu-se como SGBD relacional o PostgreSQL e, como NoSQL, o MongoDB.

\subsubsection{PostgreSQL}

O PostgreSQL é um SGBD relacional livre. Além das propriedades ACID, triggers e stored procedures, suporta modelos de dados não-estruturados como JSON e HSTORE (modelo chave-valor), analogamente aos sistemas NoSQL [Cor15]. Entretanto, até a versão avaliada, não possui suporte nativo ao particionamento de dados, que fica a cargo da aplicação de ferramentas de terceiros, como o PgPool II $[\mathrm{PgP}]$.

O PgPool II permite estabelecer um pool de conexões com balanceamento de carga e particionamento de consultas por meio de dblinks e tabelas de sistemas. Quanto à replicação, o Postgres permite a replicação assíncrona no modo Mestre-Escravo, sendo possível atribuir a leitura de dados para os nós escravos. Entretanto, não permite combinar com o particionamento.

Como o suporte à escalabilidade horizontal não é completamente nativo e equivalente ao do MongoDB, optou-se por avaliar somente a sua versão 9.3.14 centralizada. Implementou-se operações simples no módulo Sciwonc-Dataflow, entretanto, o uso do PostgreSQL permite estender a API para recursos mais avançados como manipulação de dados não-estruturados.

Existem iniciativas a respeito de versões NewSQL (baseadas em PostgreSQL, como a Postgres$\mathrm{XC}$ [PXa] e Postgres-XL [PXb]. Entretanto, suas características não foram avaliadas neste trabalho.

\subsubsection{MongoDB}

O MongoDB é um dos mais populares bancos de dados NoSQL orientado a agregados, com vasta documentação, esquema flexível e de fácil escalabilidade horizontal. Seu modelo de dados é baseado em documentos JSON e permite a criação de estruturas aninhadas, além da criação de índices para chaves dentro dos documentos. Seu suporte à replicação segue o modelo Mestre-Escravo, sendo possível configurar o nível do quórum de gravação e a preferência de leitura, que impactam diretamente na consistência dos dados. Além disso, suporta a criação de um aglomerado com particionamento e replicação dos dados, permitindo o balanceamento de carga de acordo com a chave e estratégia de particionamento e tolerância a falhas. A API e drivers de acesso tornam as consultas a dados distribuídos transparentes. Por meio de benchmarks utilizados pela ferramenta YCSB, a eficiência e escalabilidade do MongoDB foi comparada às de dois outros sistemas NoSQL populares (o Cassandra [Foub] e o CouchDB [Foua]). Os resultados mostraram que o MongoDB é capaz de obter um desempenho até 25 vezes superior ao desses sistemas, além de permitir maior flexibilidade na especificação da durabilidade dos dados, definindo-a por operação [Ass15a]. Em relação à escalabilidade, em cenários cujos dados excediam o tamanho da memória RAM e eram particionados e replicados entre diversos servidores, o MongoDB também demonstrou melhor desempenho que os do Cassandra e do CouchDB em cargas de trabalho com operações simples [Ass15b].

Nos experimentos realizados neste trabalho com workflows acessando dados no MongoDB, avaliou-se três níveis de consistência e seu impacto no desempenho. Além disso, as estratégias de particionamento por função de hashing e por intervalo também foram investigadas. As configurações são descritas na Tabela 5.1. A versão do MongoDB utilizada nos experimentos foi a 3.2.10. 


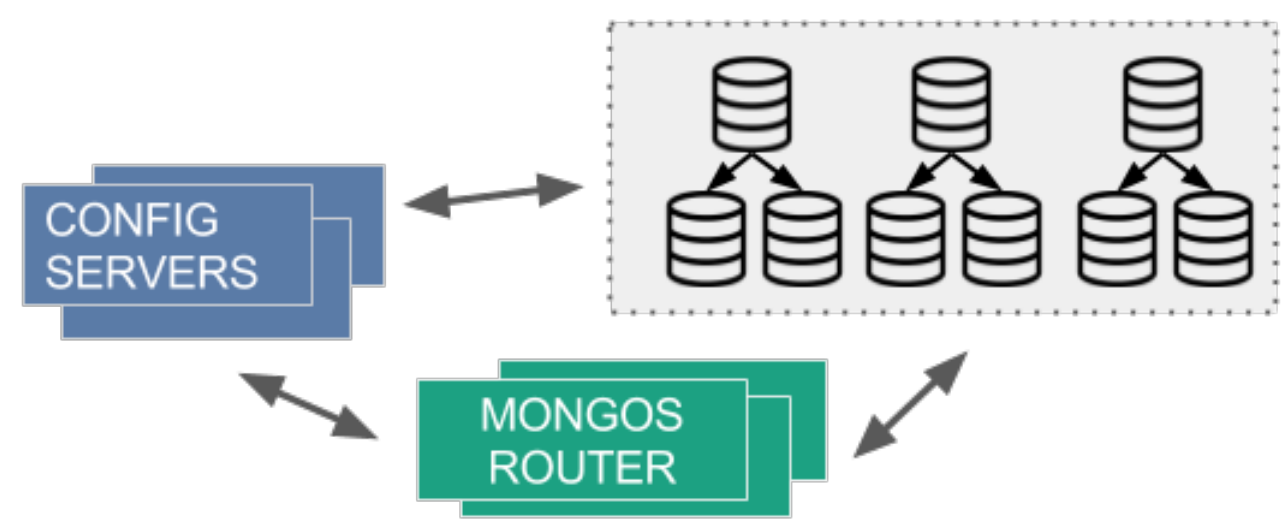

Figura 5.1: Representação de um cluster do MongoDB com três partições de dados (shards) com fator de replicação igual a três, um conjunto de três servidores de configuração (configservers) e serviços de roteamento de consulta (mongos)

\subsection{Plataforma de Computação em Nuvem}

Uma plataforma de computação em nuvem é capaz de prover um ambiente de alto desempenho para execução de workflows intensivos em dados [CBGK13]. Adotamos, para a execução dos experimentos, a plataforma AWS (Amazon Web Service) da Amazon [Amab], no modelo IaaS (Intraestrutura como Serviço, do inglês Intrastructure as a Service ), no qual tem-se o controle sobre o provisionamento de servidores, chamados de instâncias, e a capacidade de definir um aglomerado virtual formado por essas instâncias. O ambiente de execução foi configurado da seguinte maneira: (i) um nó de submissão de workflows, controlado pelo SGWf Pegasus e responsável pela comunicação com o aglomerado virtual HTCondor; (ii) um aglomerado virtual para a execução das atividades dos workflows gerenciado pelo HTCondor, no qual todas as instâncias possuíam o módulo SciWoncDataflow instalado (Seção 4.4); e (iii) uma ou mais instâncias para execução do sistema gerenciador de banco de dados (PostgreSQL ou MongoDB).

O fator de réplica escolhido para os experimentos foi o mínimo recomendado para o MongoDB: 3 réplicas. Baseado neste valor e considerando que a abordagem proposta no Capítulo 4 é estática e o número máximo de instâncias por região na AWS é limitado, definiu-se o número de nós de execução máximo conforme o número total de réplicas existentes. Isso permitiu explorar um maior paralelismo de tarefas. A partir desta relação, o aglomerado do HTCondor foi configurado com base no número de partições do banco de dados.

A Tabela 5.1 descreve os cenários avaliados, incluindo o uso do método proposto para a modificação do modelo do workflow, o SGBD utilizado, o total de partições dos dados, a estratégia de particionamento empregada (quando aplicável ao cenário) e o fator de replicação utilizado por partição. Os cenários distribuídos ainda incluem o quórum de leitura utilizado e a preferência de leitura. O uso do MongoDB distribuído necessita, além das instâncias responsáveis pelas partições (shards) e suas réplicas, instâncias para o servidor de configuração (configurado como um conjunto de réplicas conforme recomendado na documentação do MongoDB) e processos de roteamento de consultas, alocados juntamente com os nós de execução (um para cada nó). Esses processos são os responsáveis pela interpretação das consultas e recuperação dos dados diretamente das partições a partir das informações fornecidas pelo servidor de configuração.

Todos os recursos alugados na AWS eram do tipo m3.medium, com 1vCPU, 3.75GB de RAM e tamanho de disco variável. Os recursos eram do tipo compartilhado. Como a AWS limita o número de recursos que podem ser alugados por região, o nó de submissão ficou alocado na região US West (N. California) e os demais na região US West (Oregon) - nós de execução e dos SGBDs. O acesso ao banco de dados foi realizado por meio do módulo desenvolvido em Python (Sciwonc-DataflowConnector) para interfacear as consultas ao PostgreSQL e ao MongoDB, assim como configurar o nível de consistência requerido. 
O MongoDB foi utilizado na configuração padrão quanto ao consumo de recursos em todos os cenários. O PostgreSQL, nos cenários que manipularam mais de $1 \mathrm{~GB}$, foi modificado com base nas configurações sugeridas pelo PgTune [PgT]. Utilizou-se cursores nomeados (named cursors) para requisições que retornavam um volume de dados superior à memória RAM disponível no nó de execução. O conjunto de dados de entrada utilizado por cada experimento foi definido a partir do tempo de execução obtido nos Experimentos 1 e 2 no cenário W-04. Devido às restrições de orçamento e à necessidade de reproduzir cada cenário da Tabela 5.1 no mínimo três vezes, selecionamos subconjuntos de dados que pudessem ser processados no máximo em uma hora e trinta minutos no cenário de referência escolhido (W-04).

\subsection{Considerações Sobre o Capítulo}

Descrevemos neste capítulo o ambiente experimental utilizado nas avaliações de desempenho de workflows realizadas neste trabalho e cujos resultados são descritos nos Capítulos 6 e 7. Apresentamos os SGBDs e SGWf escolhidos, incluindo suas principais características e recursos. A configuração do aglomerado virtual utilizado também foi descrita, destacando as particularidades na execução em uma plataforma de computação em nuvem.

Foram definidos 21 cenários, conforme o número de nós de execução e características do SGBD utilizado. Tem-se a categoria dos SGBDs centralizados (um relacional e um NoSQL) e dos distribuídos (um NoSQL replicado e outro com particionamento e replicação dos dados). Caracterizamos também a escalabilidade horizontal desejada para a leitura de réplicas de dados e sua relação com a consistência na escrita dos dados, classificando-a em três tipos: (A) leitura somente das réplicas primárias; (B) leitura das réplicas secundárias e quórum de escrita igual a 1; e (C) leitura de réplicas secundárias e quórum majoritário para escrita dos dados.

O Experimento 1, descrito no Capítulo 6, avaliou as anotações $P O$ e $P G$, enquanto o Experimento 2, descrito no Capítulo 7, avaliou as anotações $P V D, P J T$ e $P G$ novamente, mas no contexto de redistribuição de objetos. Uma visão geral dos resultados desses experimentos é apresentada no Capítulo 8. 
Tabela 5.1: Caracterização dos cenários de execução avaliados.

\begin{tabular}{|c|c|c|c|c|c|c|c|c|c|}
\hline Cenário & $\begin{array}{c}\text { Uso do } \\
\text { Mét. Proposto }\end{array}$ & SGBD & $\begin{array}{c}\mathrm{N}^{o} \\
\text { Partições }\end{array}$ & $\begin{array}{c}\text { Estrat. de } \\
\text { Particionamento }\end{array}$ & $\begin{array}{l}\text { Fator de } \\
\text { Replicação }\end{array}$ & $\begin{array}{l}\text { Quórum de } \\
\text { Escrita }\end{array}$ & $\begin{array}{l}\text { Preferência } \\
\text { de Leitura }\end{array}$ & $\begin{array}{l}\text { No Máq. } \\
\text { SGBD }\end{array}$ & $\begin{array}{c}\text { N }^{o} \text { Nós } \\
\text { Execução }\end{array}$ \\
\hline 01 & Não & PostgreSQL & 1 & - & 1 & - & - & 1 & 1 \\
\hline 02 & Não & PostgreSQL & 1 & - & 1 & - & - & 1 & 3 \\
\hline 03 & Sim & PostgreSQL & 1 & - & 1 & - & - & 1 & 3 \\
\hline 04 & Não & MongoDB & 1 & - & 1 & - & - & 1 & 1 \\
\hline 05 & Não & MongoDB & 1 & - & 1 & - & - & 1 & 3 \\
\hline 06 & Sim & MongoDB & 1 & - & 1 & - & - & 1 & 3 \\
\hline $07-\mathrm{A}$ & Não & MongoDB & 1 & - & 3 & 1 & Primária & 6 & $3^{*}$ \\
\hline $07-\mathrm{B}$ & Não & MongoDB & 1 & - & 3 & 1 & Secundária & 6 & $3^{*}$ \\
\hline $07-\mathrm{C}$ & Não & MongoDB & 1 & - & 3 & Majoritário & Secundária & 6 & $3^{*}$ \\
\hline $08-\mathrm{A}$ & Sim & MongoDB & 1 & - & 3 & 1 & Primária & 6 & $3^{*}$ \\
\hline 08-B & Sim & MongoDB & 1 & - & 3 & 1 & Secundária & 6 & $3^{*}$ \\
\hline $08-\mathrm{C}$ & Sim & MongoDB & 1 & - & 3 & Majoritário & Secundária & 6 & $3^{*}$ \\
\hline 09-A & Não & MongoDB & 3 & - & 3 & 1 & Primária & 12 & $9^{*}$ \\
\hline 09-B & Não & MongoDB & 3 & - & 3 & 1 & Secundária & 12 & $9^{*}$ \\
\hline $09-\mathrm{C}$ & Não & MongoDB & 3 & - & 3 & Majoritário & Secundária & 12 & $9 *$ \\
\hline $10-\mathrm{A}$ & Sim & MongoDB & 3 & Intervalo & 3 & 1 & Primária & 12 & $9 *$ \\
\hline $10-\mathrm{B}$ & Sim & MongoDB & 3 & Intervalo & 3 & 1 & Secundária & 12 & $9 *$ \\
\hline $10-\mathrm{C}$ & Sim & MongoDB & 3 & Intervalo & 3 & Majoritário & Secundária & 12 & $9 *$ \\
\hline $11-\mathrm{A}$ & Sim & MongoDB & 3 & Hashing & 3 & 1 & Primária & 12 & $9^{*}$ \\
\hline 11-B & Sim & MongoDB & 3 & Hashing & 3 & 1 & Secundária & 12 & $9^{*}$ \\
\hline $11-\mathrm{C}$ & Sim & MongoDB & 3 & Hashing & 3 & Majoritário & Secundária & 12 & $9^{*}$ \\
\hline
\end{tabular}

*Nó de execução compartilhando a instância da AWS com um serviço de roteamento de consultas do mongo (mongos). 


\section{Capítulo 6}

\section{Experimento 1: Workflow para Análise de Logs de um Aglomerado de Máquinas}

Para a avaliação da eficiência do método proposto no Capítulo 4, fez-se necessária a implementação de um workflow artificial, de modo que a semântica sobre o processamento realizado fosse conhecida e descrita por meio das anotações propostas pela nossa abordagem. Nesse workflow, dividimos as atividades em dois grupos: (i) atividades paralelas independentes, que acessam a mesma coleção de dados de entrada e varrem todos os objetos da coleção seguindo critérios distintos para seleção e ordenação de atributos; (ii) atividades paralelizáveis por anotações sobre o tipo de processamento realizado. O primeiro grupo permite analisar o impacto do SGBD utilizado e sua capacidade nativa de fornecer acesso concorrente aos dados. Já o segundo grupo permite comparar o desempenho obtido pelo processo de transformações do modelo de workflow e do banco de dados, limitadas às anotações $P O$ e $P G$. As demais anotações sobre processamento de dados são avaliadas no Experimento 2, descrito no Capítulo 7.

\subsection{Descrição do Banco de Dados Analisado}

Utilizamos durante a execução o banco de dados disponibilizado por Reiss et. al. [RWH11], com registros de eventos $(\log s)$ referentes à execução de aplicações em um aglomerado de máquinas do Google, composto por 12.500 servidores físicos. Esse banco de dados descreve o ciclo de vida de aplicações submetidas e executadas em um intervalo de 29 dias - um total de 41 GB de dados disponíveis. Nesse banco, existem dados organizados em formato tabular referentes a: (i) eventos sobre o estado atual de servidores (machine_events); (ii) características físicas dos servidores (machine_attributes); (iii) eventos sobre o estado atual da execução de aplicações (job_events); (iv) eventos sobre o estado atual de cada tarefa pertencente a uma aplicação (task_events); (v) restrições para a execução de uma tarefa (task_constraints); e (vi) registros sobre o estado do uso de um recurso físico por uma tarefa medidos a cada 300s (task_usage). Para a criação do workflow de análise de logs, selecionamos a tabela task_events, pois identificamos que seus atributos continham informações suficientes para serem processados individualmente e por grupos. Definimos que o workflow realizaria a análise estatística do perfil das tarefas executadas com sucesso e com falhas, de modo a identificar o tipo de tarefa dominante (uso intensivo de CPU, memória ou balanceado) para cada tipo de evento.

Para a avaliação, selecionamos um subconjunto de dados da tabela task_events referentes a aproximadamente 2,9 milhões de registros. A tabela task_events possui informações sobre as tarefas executadas e sobre os eventos emitidos por cada tarefa durante seu ciclo de vida, incluindo a data e hora (formato timestamp) da inserção do registro do evento no banco de dados. Uma tarefa é identificada pelo par de atributos (job ID, task index). O tipo de evento é identificado pelo atributo event type como um valor inteiro, e sua definição é descrita na Tabela 6.1. Além disso, task_events contém as informações sobre os requisitos para execução de uma tarefa, tais como o máximo de CPU, memória e espaço em disco necessário. O total de tempo de CPU requerido de um recurso é 


\begin{tabular}{|c|c|c|}
\hline Identificador (ID) & Nome & Descrição \\
\hline 0 & SUBMIT & A tarefa está aguardando o escalonamento \\
\hline 1 & SCHEDULE & A tarefa está escalonada em uma máquina \\
\hline 2 & EVICT & $\begin{array}{l}\text { A tarefa foi removida pela existência de outra tarefa com maior prioridade, por } \\
\text { atingir o limite dos recursos requeridos, por manutenção do recurso ou por falha do } \\
\text { disco em uso }\end{array}$ \\
\hline 3 & FAIL & $\begin{array}{l}\text { A tarefa foi removida da execução devido a uma falha } \\
\text { ou a uma modificação dos critérios de escalonamento }\end{array}$ \\
\hline 4 & FINISH & A tarefa terminou a execução normalmente \\
\hline 5 & KILL & $\begin{array}{c}\text { A tarefa foi cancelada pelo usuário ou } \\
\text { por um programa externo ou pelo cancelamento de } \\
\text { uma tarefa da qual dependia }\end{array}$ \\
\hline 6 & LOST & $\begin{array}{l}\text { A tarefa foi considerada como terminada, } \\
\text { no entanto, o registro de seu término } \\
\text { não foi identificado no } \log \text { avaliado }\end{array}$ \\
\hline 7 & UPDATE_PENDING & $\begin{array}{c}\text { Informações sobre o escalonamento } \\
\text { e/ou requisitos foram atualizados enquanto a tarefa aguardava para ser escalonada }\end{array}$ \\
\hline 8 & UPDATE_RUNNING & $\begin{array}{l}\text { Informações sobre o escalonamento } \\
\text { e/ou requisitos foram atualizados enquanto a tarefa estava sendo escalonada }\end{array}$ \\
\hline
\end{tabular}

Tabela 6.1: Descrição dos estados disponíveis para tarefas do cluster avaliado

descrito pelo atributo CPU request e o total de memória por memory request. Todos os dados estão normalizados e/ou ofuscados.

Os eventos indicam a transição entre os estados de uma tarefa durante a execução. A transição de estados mais simples é representada pela submissão de uma tarefa para uma fila de espera (evento $S U B M I T$ ). Em seguida, a tarefa deve ser atribuída (evento SCHEDULE) a uma máquina que atenda os requisitos e começar a sua execução. Caso a execução termine com sucesso, o evento FINISH será registrado e indicará que o ciclo de vida da tarefa foi finalizado corretamente. Entretanto, é possível que uma execução seja interrompida (EVICT, FAIL ou KILL) devido à chegada de uma tarefa com maior prioridade ou quando a tarefa ultrapassa o limite de CPU, memória ou disco definidos no momento de sua submissão ao aglomerado. Ainda sim, o mecanismo de tolerância a falhas tenta reiniciar o processamento, submetendo novamente a tarefa à lista $(S U B M I T)$. É possível ainda que uma tarefa possa ter terminado sua execução mas o registro do evento de término (FINISH) não tenha sido gravado. Para essas tarefas, é atribuído o status LOST.

Segundo os responsáveis por esse banco de dados, não é possível identificar com precisão as causas de todas as falhas registradas, que podem ocorrer devido a programas externos ou por ação do usuário. O Diagrama 6.1 mostra os estados possíveis durante a execução de uma tarefa. Os eventos descritos na tabela task_events indicam a transição entre esses estados.

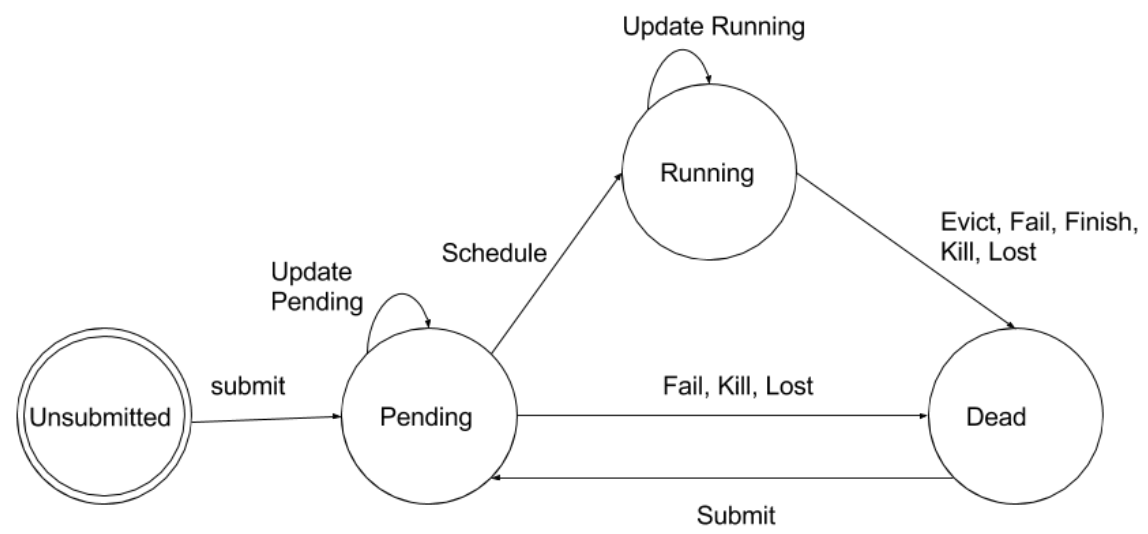

Figura 6.1: Diagrama de estados possiveis durante o ciclo de vida de uma tarefa no arquivo de log analisado

As seções seguintes descrevem como o modelo de workflow foi criado, anotado e executado no ambiente experimental descrito no Capítulo 5. É apresentada também a análise e considerações sobre os resultados obtidos. 


\subsection{Modelo de Workflow}

O workflow implementado visou à avaliação do perfil das tarefas executadas por tipo de evento. A partir da lista de recursos disponíveis ${ }^{1}$, foi possível observar que as máquinas virtuais são distribuídas em 3 grandes grupos: standard (que possuem CPU e memória balanceadas e são as mais utilizadas), high-memory (com grande quantidade de memória) e high-CPU (com grande quantidade de CPU). Assim, delimitou-se o perfil a partir da relação entre a CPU e a memória requerida, considerando como perfil standard os registros da tabela task_events com até 0,5 desvios acima ou abaixo da relação CPU/memória. Registros superiores a 0,5 foram categorizados como tarefas intensivas em CPU e abaixo de 0,5, intensivas em memória. Selecionamos apenas os eventos 2, 3, 4 e 6, para verificarmos se existia alguma relação com o perfil de sucesso ou falha da execução.

Para compor esse workflow, criou-se as seguintes atividades, utilizando a ferramenta SciWoncDataflow:

- DataStoreInit (A): atividade artificial adicionada pela ferramenta para inicialização das coleções intermediárias, criação de índices e regras de particionamento quando aplicáveis.

- GeneralInformation (B): atividade responsável pelo cálculo do período de tempo avaliado durante a execução e do total de itens.

- MedianMemory (C): atividade que calcula a mediana dos valores de memória.

- MedianCPU (D): atividade que calcula a mediana dos valores de CPU.

- StatsCPUMemory (E): atividade responsável pelo cálculo da média e do desvio padrão dos valores de CPU, memória e da relação $\mathrm{CPU} /$ Memória considerando todos os registros, independente do tipo de evento.

- TaskEvent (F): atividade responsável pelo cálculo da média e do desvio padrão dos valores de CPU, memória e da relação CPU/Memória considerando todos os registros, agrupados por tipo de evento. Calcula também a porcentagem de registros de eventos por tipo em relação ao total avaliado.

- RatioCalculation (G): atividade que calcula a relação CPU/Memória por registro e calcula o número de desvios da média geral e por tipo de evento (CPU, memória e CPU/Memória).

- AverageRatioPerEvent (H): atividade que categoriza, por tipo de evento, os registros intensivos em CPU, Memória ou balanceados.

- AnalysisResults (I): atividade que identifica o principal tipo de tarefa por evento e qual é o tipo de tarefa predominante no conjunto de dados avaliado.

- DataStoreReset (J): atividade artificial criada para remover os índices de suporte adicionados aos dados de entrada para a execução do workflow.

A estrutura do workflow é mostrada na Figura 6.2. Pode-se observar que a atividade B poderia ser executada paralelamente às atividades C,D e F, no entanto, optou-se por isolar sua execução a fim de que o workflow tivesse no máximo 3 atividades paralelas nativas, permitindo o balanceamento de carga, dado o fator de criação de nós de execução adotado no experimento (Seção 5.3). As atividades $\mathrm{C}$, D e E poderiam ser agrupadas em uma única atividade pois consomem os mesmos dados de entrada. No entanto, foram projetadas desta forma para que o acesso concorrente ao mesmo conjunto de dados fosse avaliado. É possível observar também que o cálculo da média e desvio padrão das atividades $\mathrm{F}$ e $\mathrm{C}$ são equivalentes, filtradas apenas pelo conjunto de dados de entrada. A atividade $\mathrm{F}$ foi criada a fim de observar o impacto do uso da anotação $P G$. A atividade

\footnotetext{
${ }^{1}$ Lista de tipos de instâncias disponíveis na GCP (último acesso em 20/01/2017) - https://cloud.google.com/ compute/docs/machine-types
} 
$\mathrm{G}$, anotada como $P O$, consome os dados de entrada e relaciona-os com as informações obtidas das atividades E e F. Seus dados de saída são distribuídos conforme o atributo a ser agrupado na atividade $\mathrm{H}$, criada para avaliar o impacto do particionamento dos dados intermediários. A atividade I foi criada para agrupar as informações obtidas pelo processamento de H. Além disso, informações sobre as conexões com o banco de dados, autenticação e número de nós de execução disponíveis também foram fornecidas.

A Figura 6.3 apresenta como o modelo inicial da Figura 6.2 pode ser modificado, a partir das anotações sobre as atividades F, G e H.

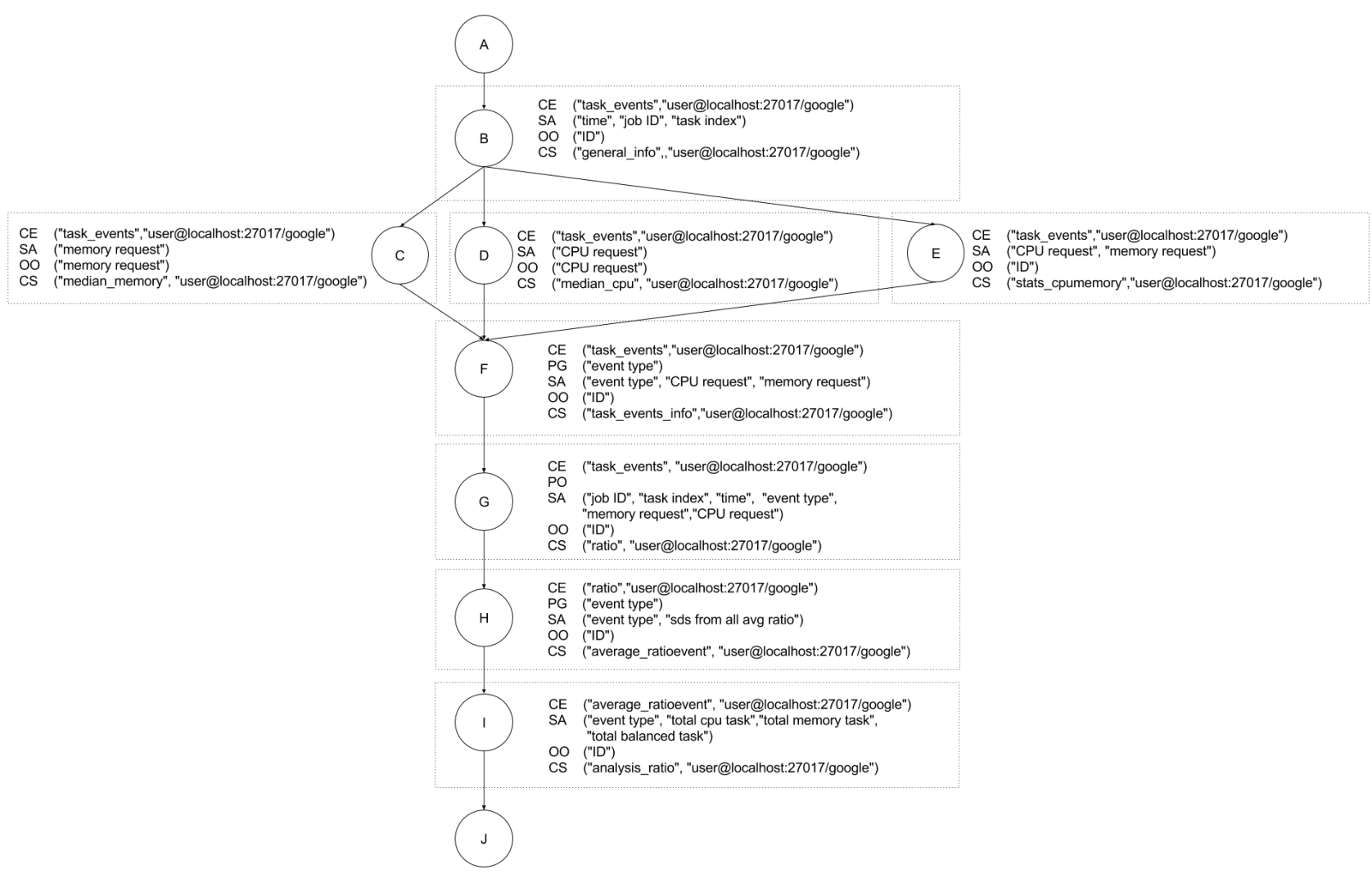

Figura 6.2: Modelo inicial do workflow de análise de logs de um cluster do Google

\subsection{Execução do Modelo de Workflow}

Selecionou-se aproximadamente 335 MB de dados iniciais referentes a 2.892 .970 registros da tabela task_events. Ao todo, foram manipulados aproximadamente $397 \mathrm{MB}$ de dados e, incluindo os índices e replicação de dados, o volume de dados variou de 1,33 GB a 1,6 GB, num total de 3.536.918 objetos.

Avaliou-se, além do tempo total de execução do workflow (makespan), o custo monetário da execução e o nível de consistência obtido nos resultados. Os valores mostrados nos gráficos são apresentados com um intervalo de confiança de $95 \%$ e cinco repetições para cada cenário. A Figura 6.4 apresenta a notação de cores e padrões para representar os cenários avaliados, descritos na Tabela 5.1.

A Figura 6.5 mostra o tempo total (makespan) das execuções do workflow em cada um dos 21 cenários descritos na Tabela 5.1, enquanto a Figura 6.6 mostra o custo financeiro total dessas execuções. O custo é calculado com base no tempo de uso das instâncias da AWS (incluindo os valores de CPU e o tamanho dos discos utilizados para armazenamento de dados) divididos em horas-cheias. Os discos utilizados são todos do tipo ebs-gp2-ssd. As instâncias utilizadas são todas 

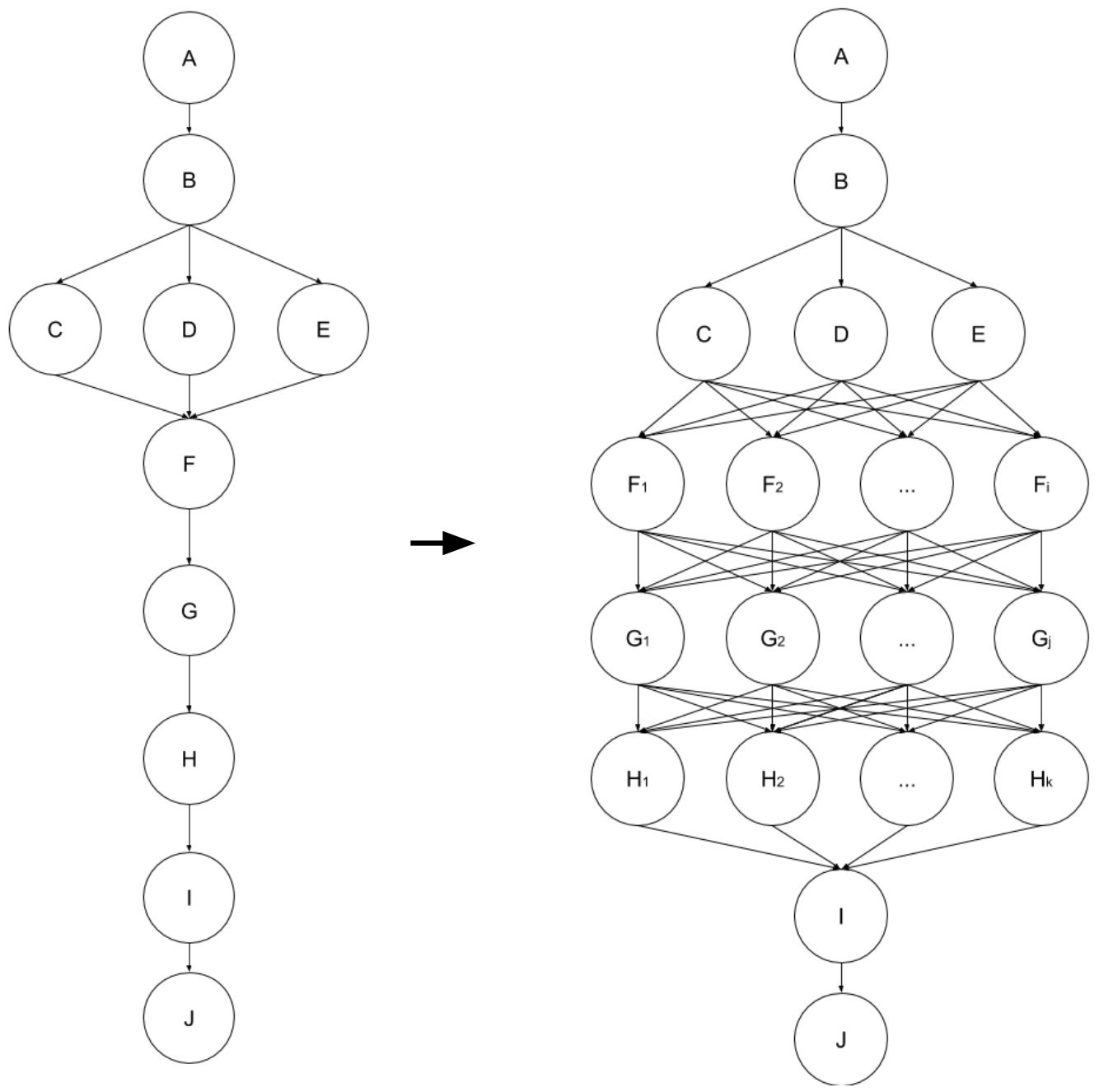

Figura 6.3: Representação da reestruturação aplicável ao modelo de workflow de análise de logs de um cluster do Google gerado a partir das anotações semânticas

do tipo m3.medium, com 1vCPU, 3.75GB de RAM, com 4GB de instance storage ${ }^{2}$. Os valores foram calculados de acordo com a tabela de preços $^{3}$ de janeiro de 2017 para instâncias que executam o sistema operacional Ubuntu 14.04-LTS x64.

A comparação dos tempos de execução das atividades F, G e H, com anotações sobre o tipo de processamento, são mostrados nas Figuras 6.7, 6.8 e 6.9. O tempo de execução das atividades replicadas pelo método proposto neste trabalho foi calculado considerando o início da execução da primeira réplica e o término da execução da última réplica. A Tabela 6.2 mostra a consistência dos dados obtidos conforme a configuração. E os ganhos obtidos em relação ao tempo são descritos na Tabela 6.3 e o custo na Tabela 6.4.

A fim de avaliar o impacto da paralelização do workflow avaliado com um conjunto maior de dados, selecionamos 3,4GB da tabela task_events, referentes a 43.394 .550 objetos de dados. Ao todo, foram manipulados 54.942 .900 objetos de dados, cujo armazenamento variou entre $5,729 \mathrm{~GB}$ a $39 \mathrm{~GB}$ de dados, considerando a replicação dos objetos e a criação de índices de suporte a consultas. Todos os cenários centralizados foram avaliados com o objetivo de ilustrar a degradação do desempenho, mesmo com o uso do método proposto, principalmente no modelo relacional. Avaliamos também os cenários do MongoDB com uma partição e fator de replicação igual a 3 para comparar seu desempenho em relação ao cenário centralizado do MongoDB, uma vez que os processos internos de

\footnotetext{
${ }^{2}$ Instance Storage é um disco local disponível para cada instância. Os dados armazenados não são permanentes, isto é, persistem somente durante o ciclo de vida da instância.

${ }^{3}$ Tabela de preços da AWS (último acesso em 20/01/2017): https://aws.amazon.com/pt/ec2/pricing/on-demand/
} 


\section{Configuração do Banco de Dados}

PostgreSQL

(1 Partição - 1 Réplica)

MongoDB

(1 Partição - 1 Réplica)

MongoDB

(1 Partição - 3 Réplicas)

MongoDB

(3 Partições - 3 Réplicas)

\section{Distribuição de Dados Intermediários}

H Distribuição baseada em Hashing

R Distribuição baseada em Intervalo

\section{Configuração de Leitura e Escrita do Banco de Dados}

Preferência de Leitura: Réplica Primária

Consistência da Escrita: 1 Réplica

Paralelização pelo Método Proposto: Não

Preferência de Leitura: Réplica Secundária

Consistência da Escrita: 1 Réplica

Paralelização pelo Método Proposto: Não

Preferência de Leitura: Réplica Secundária

Consistência da Escrita: Majoritária

Paralelização pelo Método Proposto: Não

Uso do Método Proposto para Paralelização de Atividades

Preferência de Leitura: Réplica Primária

Consistência da Escrita: 1 Réplica

Paralelização pelo Método Proposto: Sim

Preferência de Leitura: Réplica Secundária

Consistência da Escrita: 1 Réplica

Paralelização pelo Método Proposto: Sim

Preferência de Leitura: Réplica Secundária

Consistência da Escrita: Majoritária

Paralelização pelo Método Proposto: Sim

Figura 6.4: Notação gráfica adotada para descrever os cenários apresentados nas Figuras 6.5 a 6.11

gerenciamento do SGBD podem ser distribuídos entre os seus servidores. Em relação aos demais, selecionamos os cenários que realizavam leituras de réplicas primárias ou que liam dados de réplicas secundárias com um quórum de escrita $\mathrm{w}=1$. Descartamos os cenários com quórum majoritário, uma vez que não obtiveram uma consistência superior a 50\%. A Figura 6.10 descreve os tempos de execução do workflow de análise de logs com um segundo conjunto de dados de entrada e a Figura 6.11, apresenta o custo financeiro relacionado a cada execução.

\begin{tabular}{|c|c|c|c|}
\hline Workflow & Consistência obtida & Workflow & Consistência obtida \\
\hline \hline W-01 & $100 \%$ & W-08-C & $100 \%$ \\
\hline W-02 & $100 \%$ & W-09-A & $100 \%$ \\
\hline W-03 & $100 \%$ & W-09-B & $100 \%$ \\
\hline W-04 & $100 \%$ & W-09-C & $100 \%$ \\
\hline W-05 & $100 \%$ & W-10-A & $100 \%$ \\
\hline W-06 & $100 \%$ & W-10-B & $100 \%$ \\
\hline W-07-A & $100 \%$ & W-10-C & $100 \%$ \\
\hline W-07-B & $100 \%$ & W-11-A & $100 \%$ \\
\hline W-07-C & $100 \%$ & W-11-B & $61 \%$ \\
\hline W-08-A & $100 \%$ & W-11-C & $31 \%$ \\
\hline W-08-B & $100 \%$ & & \\
\hline
\end{tabular}

Tabela 6.2: Tabela com o nivel de consistência obtido na execução dos experimentos do workflow para análise de logs. 


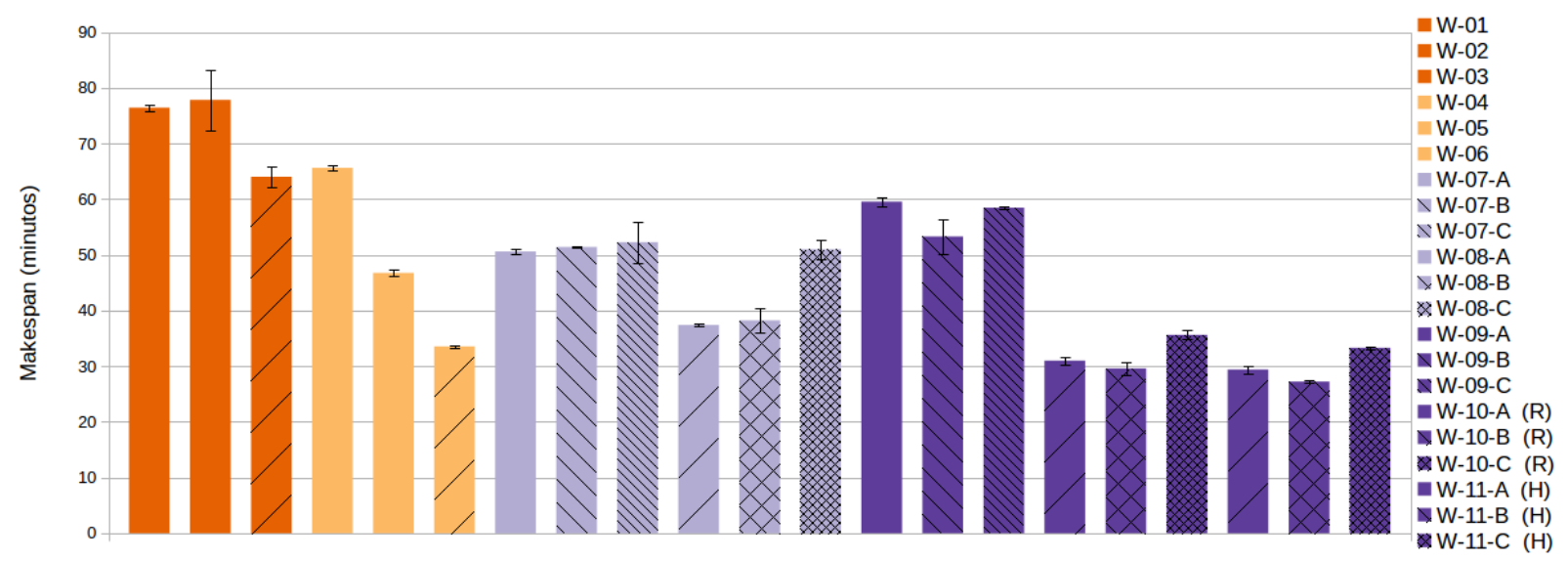

Figura 6.5: Makespans médios das execuções do workflow de análise de logs nos diferentes cenários experimentais

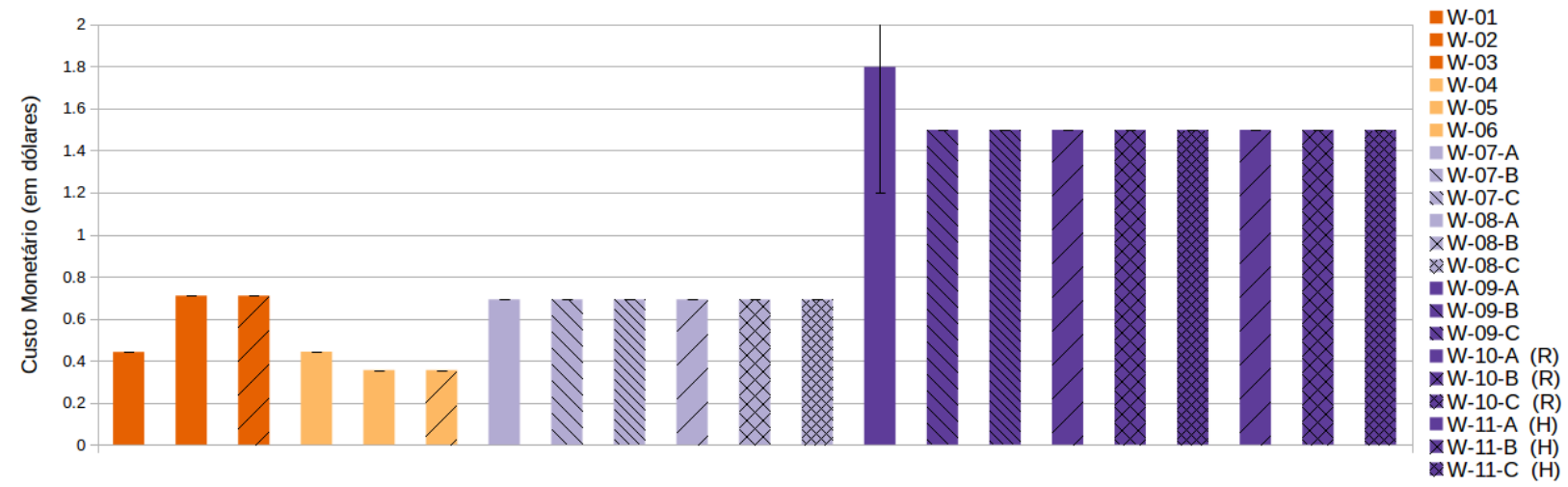

Figura 6.6: Custos financeiros médios das execuções do workflow nos diferentes cenários experimentais, considerando a cobrança por hora-cheia. Os custos incluem o uso das máquinas de execução, submissão e do banco de dados.

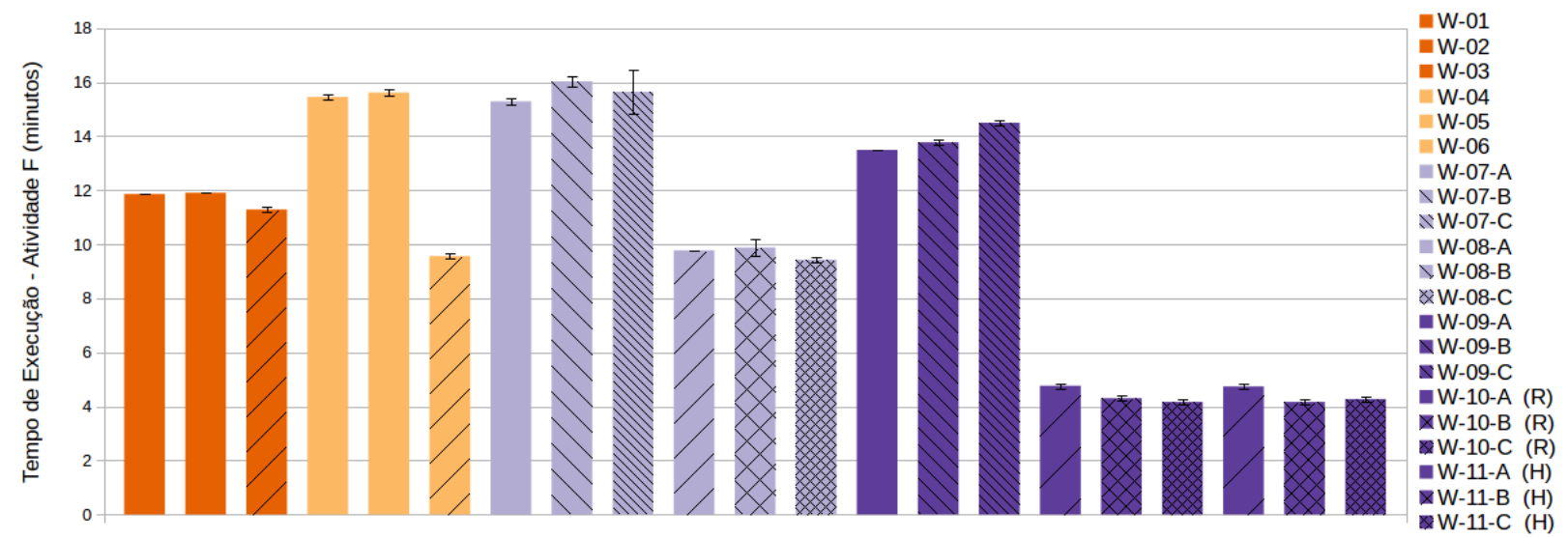

Figura 6.7: Tempos médios das execuções da atividade $F$ do workflow de análise de logs, com a anotação $P G$. 


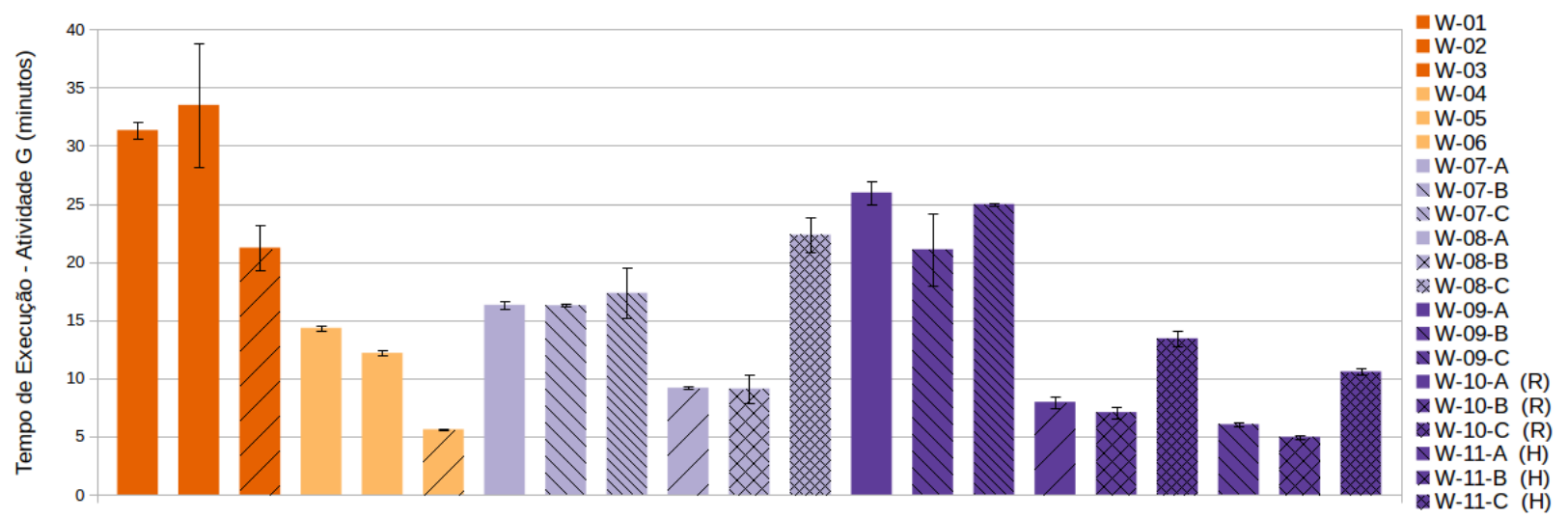

Figura 6.8: Tempos médios das execuções da atividade $G$ do workflow de análise de logs, com a anotação PO.

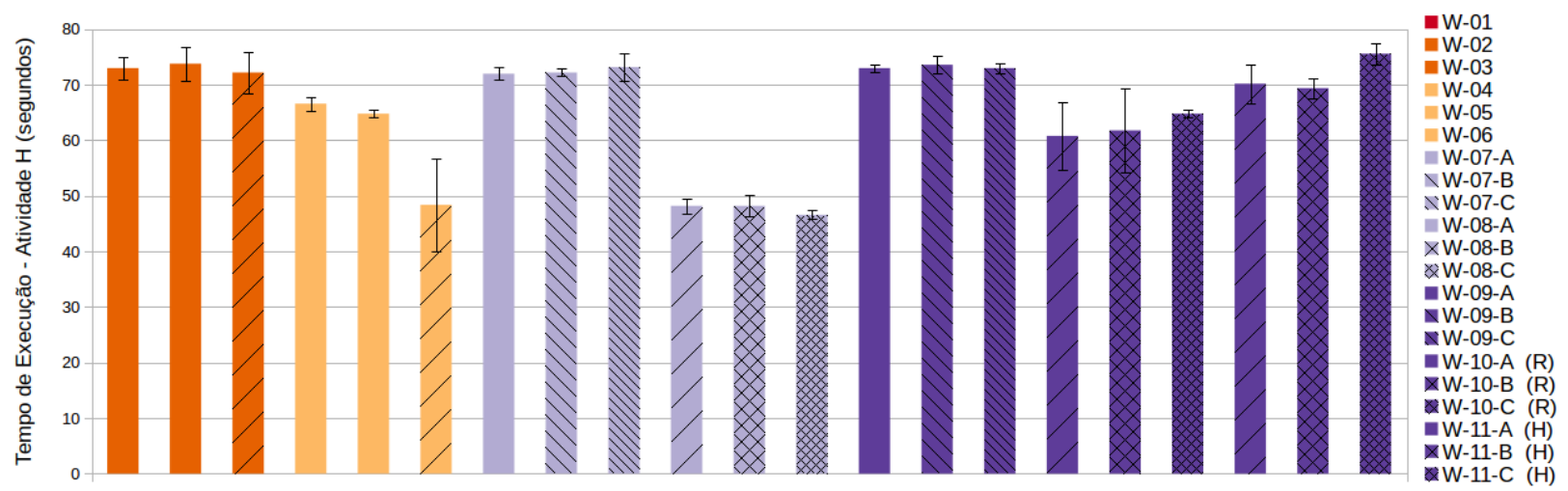

Figura 6.9: Tempos médios das execuções da atividade $H$ do workflow de análise de logs, com a anotação $P G$, que consumiu os dados gerados pela atividade $G$.

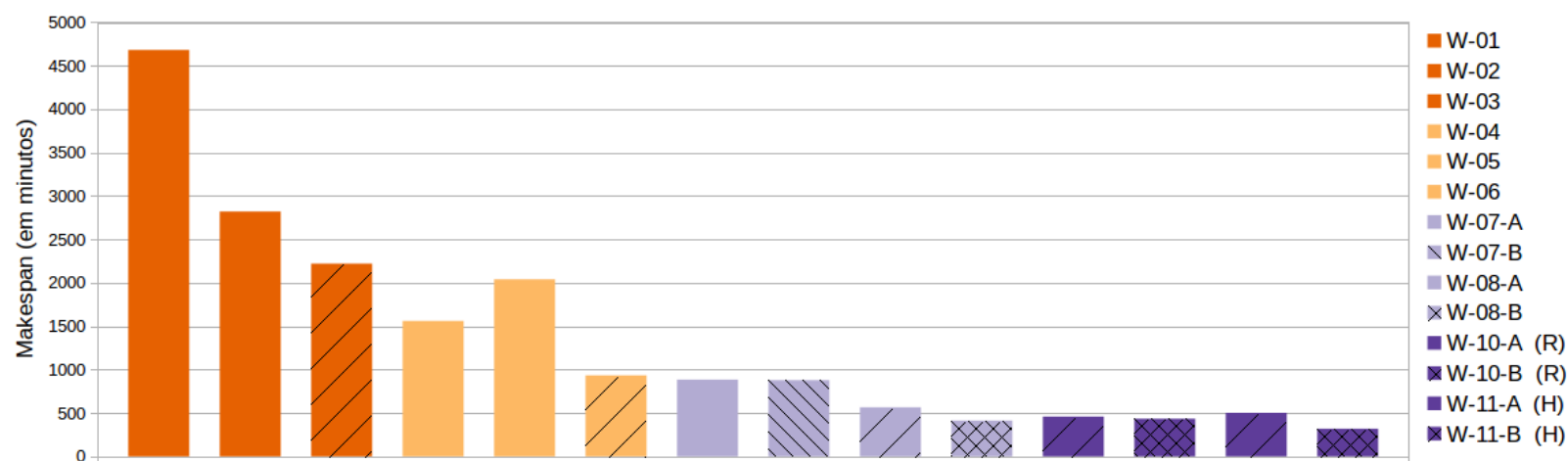

Figura 6.10: Tempos das Execuções do Workflow de Análise de Logs para o processamento de 43,4 milhões de objetos de dados de entrada 


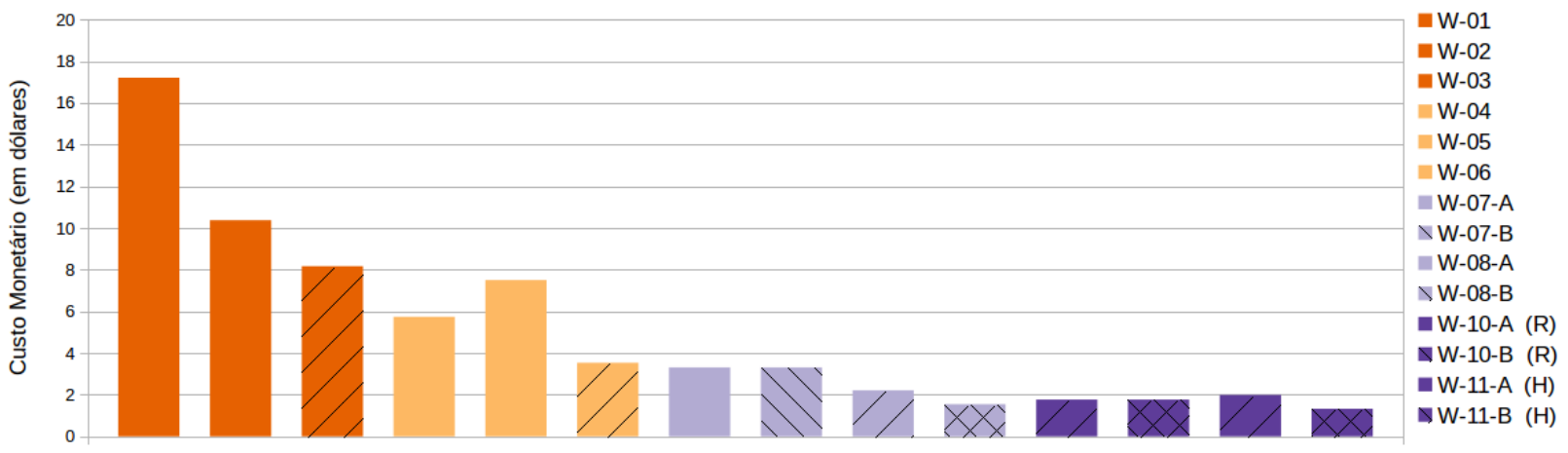

Figura 6.11: Custos Financeiros da Execução do Workflow de Análise de Logs com 43,4 milhões de objetos de dados de entrada 


\begin{tabular}{|c|c|c|c|c|c|c|c|c|c|c|c|c|c|c|c|c|c|c|c|c|c|}
\hline & W-01 & W-02 & W-03 & W-04 & W-05 & W-06 & W-07-A & W-07-B & W-07-C & W-08-A & W-08-B & W-08-C & W-09-A & W-09-B & W-09-C & W-10-A & W-10-B & W-10-C & W-11-A & W-11-B & W-11-C \\
\hline $\mathrm{W}-01$ & $0,0 \%$ & $-1,8 \%$ & $19,4 \%$ & $16,5 \%$ & $63,4 \%$ & \begin{tabular}{|l|l|}
$127,9 \%$ \\
\end{tabular} & $51,0 \%$ & $48,6 \%$ & $46,2 \%$ & $104,4 \%$ & $99,9 \%$ & $49,9 \%$ & $28,3 \%$ & $43,4 \%$ & $30,7 \%$ & $146,5 \%$ & $158,2 \%$ & $114,6 \%$ & $160,0 \%$ & $180,7 \%$ & $129,5 \%$ \\
\hline W-02 & $1,8 \%$ & \begin{tabular}{|l|l|}
$0,0 \%$ \\
\end{tabular} & \begin{tabular}{|l|}
$21,6 \%$ \\
\end{tabular} & $18,6 \%$ & $66,4 \%$ & \begin{tabular}{|l|}
$132,0 \%$ \\
\end{tabular} & \begin{tabular}{|l|}
$53,8 \%$ \\
\end{tabular} & \begin{tabular}{|l|}
$51,4 \%$ \\
\end{tabular} & $48,9 \%$ & $108,2 \%$ & $103,6 \%$ & \begin{tabular}{|l|}
$52,7 \%$ \\
\end{tabular} & $30,7 \%$ & $46,0 \%$ & $33,1 \%$ & $151,0 \%$ & \begin{tabular}{|l}
$162,9 \%$ \\
\end{tabular} & \begin{tabular}{|l}
$118,5 \%$ \\
\end{tabular} & $164,7 \%$ & $185,9 \%$ & $133,7 \%$ \\
\hline W-03 & $-16,2 \%$ & $-17,7 \%$ & $0,0 \%$ & $-2,4 \%$ & $36,9 \%$ & $90,9 \%$ & $26,5 \%$ & $24,5 \%$ & $22,5 \%$ & $71,2 \%$ & $67,5 \%$ & $25,6 \%$ & $7,5 \%$ & $20,1 \%$ & $\begin{array}{l}9,5 \% \\
\end{array}$ & $106,5 \%$ & \begin{tabular}{|l}
$116,3 \%$ \\
\end{tabular} & $79,8 \%$ & $\begin{array}{l}117,8 \% \\
\end{array}$ & $135,2 \%$ & $92,3 \%$ \\
\hline W-04 & $-14,1 \%$ & $-15,7 \%$ & $2,5 \%$ & $0,0 \%$ & $40,3 \%$ & $95,6 \%$ & \begin{tabular}{|l|}
$29,6 \%$ \\
\end{tabular} & $27,6 \%$ & $25,5 \%$ & $75,5 \%$ & $71,7 \%$ & $28,7 \%$ & $10,2 \%$ & $23,1 \%$ & $12,2 \%$ & $111,7 \%$ & \begin{tabular}{|l}
$121,7 \%$ \\
\end{tabular} & $84,3 \%$ & $\begin{array}{l}123,2 \% \\
\end{array}$ & $141,0 \%$ & $97,1 \%$ \\
\hline W-05 & $-38,8 \%$ & $-39,9 \%$ & $-27,0 \%$ & $-28,7 \%$ & $0,0 \%$ & $39,4 \%$ & $-7,6 \%$ & $-9,1 \%$ & $-10,6 \%$ & $25,1 \%$ & $22,3 \%$ & $-8,3 \%$ & $-21,5 \%$ & $-12,3 \%$ & $-20,0 \%$ & $50,8 \%$ & $58,0 \%$ & $31,3 \%$ & $59,1 \%$ & $71,7 \%$ & $40,4 \%$ \\
\hline W-06 & $-56,1 \%$ & $-56,9 \%$ & $-47,6 \%$ & $-48,9 \%$ & $-28,3 \%$ & $0,0 \%$ & $-33,7 \%$ & $-34,8 \%$ & $-35,8 \%$ & $-10,3 \%$ & $-12,3 \%$ & $-34,2 \%$ & $-43,7 \%$ & $-37,1 \%$ & $-42,6 \%$ & $8,2 \%$ & $13,3 \%$ & \begin{tabular}{|l|}
$-5,8 \%$ \\
\end{tabular} & $14,1 \%$ & $23,2 \%$ & $0,7 \%$ \\
\hline W-07-A & $-33,8 \%$ & $-35,0 \%$ & $-20,9 \%$ & $-22,9 \%$ & $8,3 \%$ & $50,9 \%$ & $0,0 \%$ & $-1,6 \%$ & $-3,2 \%$ & $35,4 \%$ & $32,4 \%$ & \begin{tabular}{|l|}
$-0,7 \%$ \\
\end{tabular} & $-15,0 \%$ & $-5,0 \%$ & $-13,4 \%$ & $63,3 \%$ & $71,0 \%$ & $42,1 \%$ & $72,2 \%$ & $85,9 \%$ & $52,0 \%$ \\
\hline W-07-B & $-32,7 \%$ & $-33,9 \%$ & $-19,7 \%$ & $-21,6 \%$ & $10,0 \%$ & $53,3 \%$ & $1,6 \%$ & $0,0 \%$ & $-1,6 \%$ & $37,5 \%$ & $34,5 \%$ & $0,9 \%$ & $-13,7 \%$ & $-3,5 \%$ & $-12,1 \%$ & $65,9 \%$ & $73,7 \%$ & $44,4 \%$ & 74,9\% & $88,9 \%$ & $54,4 \%$ \\
\hline W-07-C & $-31,6 \%$ & $-32,8 \%$ & $-18,3 \%$ & $-20,3 \%$ & $11,8 \%$ & $55,9 \%$ & $3,3 \%$ & $1,7 \%$ & \begin{tabular}{|l|l|} 
& $0,0 \%$ \\
\end{tabular} & $39,8 \%$ & $36,7 \%$ & $2,5 \%$ & $-12,2 \%$ & \begin{tabular}{|l|}
$-1,9 \%$ \\
\end{tabular} & \begin{tabular}{|l|}
$-10,6 \%$ \\
\end{tabular} & $\begin{array}{l}68,6 \% \\
\end{array}$ & $76,6 \%$ & $46,8 \%$ & $77,8 \%$ & $92,0 \%$ & $57,0 \%$ \\
\hline W-08-A & $-51,1 \%$ & $-52,0 \%$ & \begin{tabular}{|l|l|}
$-41,6 \%$ \\
\end{tabular} & $-43,0 \%$ & $-20,0 \%$ & \begin{tabular}{|l}
$11,5 \%$ \\
\end{tabular} & \begin{tabular}{|l}
$, 26,1 \%$ \\
\end{tabular} & $-27,3 \%$ & $-28,5 \%$ & $0,0 \%$ & $-2,2 \%$ & \begin{tabular}{|l}
$-26,7 \%$ \\
\end{tabular} & \begin{tabular}{|l|}
$-37,2 \%$ \\
\end{tabular} & \begin{tabular}{|l|l|}
$-29,8 \%$ \\
\end{tabular} & \begin{tabular}{|l|}
$-36,1 \%$ \\
\end{tabular} & \begin{tabular}{|l|}
$20,6 \%$ \\
\end{tabular} & $26,3 \%$ & $5,0 \%$ & $27,2 \%$ & $37,3 \%$ & $12,3 \%$ \\
\hline W-08-B & $-50,0 \%$ & $-50,9 \%$ & \begin{tabular}{|l|}
$-40,3 \%$ \\
\end{tabular} & $-41,7 \%$ & $-18,2 \%$ & $14,0 \%$ & $-24,5 \%$ & $-25,7 \%$ & \begin{tabular}{|l|}
$-26,9 \%$ \\
\end{tabular} & $2,2 \%$ & $0,0 \%$ & $-25,0 \%$ & \begin{tabular}{|l|}
$-35,8 \%$ \\
\end{tabular} & $-28,3 \%$ & \begin{tabular}{|l|}
$-34,6 \%$ \\
\end{tabular} & \begin{tabular}{|l}
$23,3 \%$ \\
\end{tabular} & $29,1 \%$ & $7,3 \%$ & \begin{tabular}{|l|}
$30,0 \%$ \\
\end{tabular} & $40,4 \%$ & $14,8 \%$ \\
\hline W-08-C & $-33,3 \%$ & $-34,5 \%$ & $-20,4 \%$ & $-22,3 \%$ & \begin{tabular}{|l|}
$9,0 \%$ \\
\end{tabular} & $52,0 \%$ & $0,7 \%$ & \begin{tabular}{|l|}
$-0,8 \%$ \\
\end{tabular} & $-2,5 \%$ & $36,4 \%$ & $33,4 \%$ & $0,0 \%$ & $-14,4 \%$ & $-4,3 \%$ & $-12,8 \%$ & $64,5 \%$ & $72,2 \%$ & $43,2 \%$ & $73,4 \%$ & $87,3 \%$ & $53,1 \%$ \\
\hline W-09-A & $-22,1 \%$ & $-23,5 \%$ & $-7,0 \%$ & $-9,2 \%$ & $27,4 \%$ & $77,6 \%$ & $17,7 \%$ & $15,8 \%$ & $13,9 \%$ & $59,3 \%$ & $55,8 \%$ & $16,8 \%$ & $0,0 \%$ & $11,8 \%$ & $1,9 \%$ & $92,1 \%$ & $\begin{array}{l}101,2 \% \\
\end{array}$ & $67,2 \%$ & $102,6 \%$ & $118,8 \%$ & $78,9 \%$ \\
\hline W-09-B & $-30,3 \%$ & $-31,5 \%$ & $-16,8 \%$ & $-18,8 \%$ & $14,0 \%$ & $58,9 \%$ & $5,3 \%$ & $3,6 \%$ & $1,9 \%$ & $42,5 \%$ & $39,4 \%$ & $4,5 \%$ & $-10,5 \%$ & $0,0 \%$ & $-8,9 \%$ & $71,9 \%$ & $80,0 \%$ & $49,6 \%$ & $81,3 \%$ & $95,7 \%$ & $60,0 \%$ \\
\hline W-09-C & $-23,5 \%$ & $-24,9 \%$ & \begin{tabular}{|l|l|}
$-8,7 \%$ \\
\end{tabular} & $-10,9 \%$ & $25,0 \%$ & $74,3 \%$ & $15,5 \%$ & $13,7 \%$ & $11,9 \%$ & $56,4 \%$ & $53,0 \%$ & $14,7 \%$ & $-1,8 \%$ & $9,7 \%$ & $0,0 \%$ & $88,6 \%$ & $97,5 \%$ & $64,2 \%$ & $98,9 \%$ & $114,8 \%$ & $75,6 \%$ \\
\hline W-10-A & $-59,4 \%$ & $-60,2 \%$ & \begin{tabular}{|l}
$-51,6 \%$ \\
\end{tabular} & $-52,8 \%$ & $-33,7 \%$ & \begin{tabular}{|l|}
$-7,6 \%$ \\
\end{tabular} & \begin{tabular}{|l|l|}
$-38,8 \%$ \\
\end{tabular} & \begin{tabular}{|l|l|}
$-39,7 \%$ \\
\end{tabular} & \begin{tabular}{|l|}
$-40,7 \%$ \\
\end{tabular} & $-17,1 \%$ & $-18,9 \%$ & \begin{tabular}{|l|l|}
$-39,2 \%$ \\
\end{tabular} & \begin{tabular}{|l}
$-47,9 \%$ \\
\end{tabular} & $-41,8 \%$ & $-47,0 \%$ & \begin{tabular}{|l|}
$0,0 \%$ \\
\end{tabular} & \begin{tabular}{|l|}
$4,7 \%$ \\
\end{tabular} & \begin{tabular}{|l|}
$-12,9 \%$ \\
\end{tabular} & $5,5 \%$ & $13,9 \%$ & $-6,9 \%$ \\
\hline W-10-B & $-61,3 \%$ & \begin{tabular}{|l|}
$-62,0 \%$ \\
\end{tabular} & $-53,8 \%$ & $-54,9 \%$ & \begin{tabular}{|l|l|}
$-36,7 \%$ \\
\end{tabular} & $-11,8 \%$ & $-41,5 \%$ & \begin{tabular}{|l|l|}
$-42,4 \%$ \\
\end{tabular} & \begin{tabular}{|l|}
$-43,4 \%$ \\
\end{tabular} & $-20,8 \%$ & $-22,6 \%$ & \begin{tabular}{|l|}
$-41,9 \%$ \\
\end{tabular} & \begin{tabular}{|l|}
$-50,3 \%$ \\
\end{tabular} & \begin{tabular}{|l|}
$-44,5 \%$ \\
\end{tabular} & \begin{tabular}{|l|}
$-49,4 \%$ \\
\end{tabular} & \begin{tabular}{|l|}
$-4,5 \%$ \\
\end{tabular} & \begin{tabular}{|l|}
$0,0 \%$ \\
\end{tabular} & \begin{tabular}{|l|}
$-16,9 \%$ \\
\end{tabular} & \begin{tabular}{|l|}
$0,7 \%$ \\
\end{tabular} & $8,7 \%$ & $-11,1 \%$ \\
\hline W-10-C & $-53,4 \%$ & $-54,2 \%$ & \begin{tabular}{|l}
$-44,4 \%$ \\
\end{tabular} & $-45,7 \%$ & $-23,8 \%$ & $6,2 \%$ & \begin{tabular}{|l|}
$-29,6 \%$ \\
\end{tabular} & \begin{tabular}{|l|}
$-30,7 \%$ \\
\end{tabular} & \begin{tabular}{|l|}
$-31,9 \%$ \\
\end{tabular} & $-4,8 \%$ & $-6,8 \%$ & \begin{tabular}{|l|}
$-30,1 \%$ \\
\end{tabular} & \begin{tabular}{|l|}
$-40,2 \%$ \\
\end{tabular} & \begin{tabular}{|l|}
$-33,2 \%$ \\
\end{tabular} & \begin{tabular}{|l|}
$-39,1 \%$ \\
\end{tabular} & $\begin{array}{l}14,9 \% \\
\end{array}$ & $20,3 \%$ & \begin{tabular}{|l|}
$0,0 \%$ \\
\end{tabular} & $21,1 \%$ & $30,8 \%$ & $6,9 \%$ \\
\hline W-11-A & $-61,5 \%$ & \begin{tabular}{|l}
$-62,2 \%$ \\
\end{tabular} & $\begin{array}{l}-54,1 \% \\
\end{array}$ & $-55,2 \%$ & $-37,1 \%$ & $\begin{array}{l}-12,4 \% \\
\end{array}$ & $-41,9 \%$ & \begin{tabular}{|l|}
$-42,8 \%$ \\
\end{tabular} & $-43,8 \%$ & $-21,4 \%$ & $-23,1 \%$ & \begin{tabular}{|l|}
$-42,3 \%$ \\
\end{tabular} & \begin{tabular}{|l|}
$-50,6 \%$ \\
\end{tabular} & \begin{tabular}{|l|}
$-44,8 \%$ \\
\end{tabular} & \begin{tabular}{|l|}
$-49,7 \%$ \\
\end{tabular} & \begin{tabular}{|l}
$-5,2 \%$ \\
\end{tabular} & \begin{tabular}{|l|}
$-0,7 \%$ \\
\end{tabular} & $-17,5 \%$ & $0,0 \%$ & $8,0 \%$ & $-11,7 \%$ \\
\hline W-11-B & $-64,4 \%$ & $-65,0 \%$ & $-57,5 \%$ & $-58,5 \%$ & $-41,8 \%$ & $-18,8 \%$ & $-46,2 \%$ & \begin{tabular}{|l|l|}
$-47,0 \%$ \\
\end{tabular} & \begin{tabular}{|l|}
$-47,9 \%$ \\
\end{tabular} & $-27,2 \%$ & $-28,8 \%$ & $-46,6 \%$ & $-54,3 \%$ & $-48,9 \%$ & $-53,4 \%$ & $-12,2 \%$ & $-8,0 \%$ & $-23,5 \%$ & $-7,4 \%$ & $0,0 \%$ & $-18,2 \%$ \\
\hline W-11-C & $-56,4 \%$ & $-57,2 \%$ & $-48,0 \%$ & $-49,3 \%$ & $-28,8 \%$ & \begin{tabular}{|l|}
$-0,7 \%$ \\
\end{tabular} & $-34,2 \%$ & $-35,2 \%$ & $-36,3 \%$ & $-10,9 \%$ & $-12,9 \%$ & $-34,7 \%$ & $-44,1 \%$ & $-37,5 \%$ & $-43,1 \%$ & $7,4 \%$ & $12,5 \%$ & $-6,5 \%$ & $13,3 \%$ & $22,3 \%$ & $0,0 \%$ \\
\hline
\end{tabular}

Tabela 6.3: Comparação do makespan médio entre as execuções dos workflows do Experimento 1. 


\begin{tabular}{|c|c|c|c|c|c|c|c|c|c|c|c|c|c|c|c|c|c|c|c|c|c|}
\hline & W-01 & W-02 & W-03 & W-04 & W-05 & W-06 & W-07-A & W-07-B & W-07-C & W-08-A & W-08-B & W-08-C & W-09-A & W-09-B & W-09-C & W-10-A & W-10-B & W-10-C & W-11-A & W-11-B & W-11-C \\
\hline W-01 & $0,00 \%$ & $-37,79 \%$ & $-37,79 \%$ & $-0,25 \%$ & $24,22 \%$ & $24,22 \%$ & $-36,18 \%$ & $-36,18 \%$ & $-36,18 \%$ & $-36,18 \%$ & $-36,18 \%$ & $-36,18 \%$ & $-75,46 \%$ & $-70,55 \%$ & $-70,55 \%$ & $-70,55 \%$ & $-70,55 \%$ & $-70,55 \%$ & $-70,55 \%$ & $-70,55 \%$ & $-70,55 \%$ \\
\hline W-02 & $60,75 \%$ & $0,00 \%$ & $0,00 \%$ & $60,34 \%$ & $99,69 \%$ & $99,69 \%$ & $2,59 \%$ & $2,59 \%$ & $2,59 \%$ & $2,59 \%$ & $2,59 \%$ & $2,59 \%$ & $-60,55$ & $-52,66 \%$ & $-52,66 \%$ & $-52,66 \%$ & $-52,66 \%$ & $-52,66 \%$ & $-52,66 \%$ & $-52,66 \%$ & $-52,66 \%$ \\
\hline W-03 & $60,75 \%$ & $0,00 \%$ & $0,00 \%$ & $60,34 \%$ & $99,69 \%$ & $99,69 \%$ & $2,59 \%$ & $2,59 \%$ & $2,59 \%$ & $2,59 \%$ & $2,59 \%$ & $2,59 \%$ & $-60,55 \%$ & $-52,66 \%$ & $-52,66 \%$ & $-52,66 \%$ & $-52,66 \%$ & $-52,66 \%$ & $\mid-52,66 \%$ & $-52,66 \%$ & $-52,66 \%$ \\
\hline W-04 & $0,25 \%$ & $-37,63 \%$ & $-37,63 \%$ & $0,00 \%$ & $24,54 \%$ & $24,54 \%$ & $-36,02 \%$ & $-36,02 \%$ & $-36,02 \%$ & $-36,02 \%$ & $-36,02 \%$ & $-36,02 \%$ & $-75,40 \%$ & $-70,48 \%$ & $-70,48 \%$ & $-70,48 \%$ & $-70,48 \%$ & $-70,48 \%$ & $-70,48 \%$ & $-70,48 \%$ & $-70,48$ \\
\hline W-05 & $-19,50 \%$ & $-49,92 \%$ & $-49,9$ & $-19,70 \%$ & $0,00 \%$ & $0,00 \%$ & $-48,62$ & $-48,62 \%$ & $-48,62 \%$ & $-48,62 \%$ & $-48,62 \%$ & $-48,62 \%$ & & $-76,30 \%$ & $-76,30$ & $-76,30 \%$ & $-76,30 \%$ & \begin{tabular}{|c|}
-76, \\
\end{tabular} & \begin{tabular}{|l|l}
$-76,30 \%$ \\
\end{tabular} & & $-76,30 \%$ \\
\hline W-06 & $-19,50 \%$ & \begin{tabular}{|l}
$-49,92 \%$ \\
\end{tabular} & $-49,92 \%$ & $-19,70 \%$ & $0,00 \%$ & $0,00 \%$ & $-48,62 \%$ & \begin{tabular}{|l}
$-48,62 \%$ \\
\end{tabular} & $-48,62 \%$ & \begin{tabular}{|l}
$-48,62 \%$ \\
\end{tabular} & $-48,62 \%$ & $-48,62 \%$ & \begin{tabular}{|l}
$-80,25 \%$ \\
\end{tabular} & $-76,30 \%$ & $\begin{array}{l}-76,30 \% \\
\end{array}$ & $-76,30 \%$ & $-76,30 \%$ & \begin{tabular}{|l}
$-76,30 \%$ \\
\end{tabular} & \begin{tabular}{|l}
$-76,30 \%$ \\
\end{tabular} & $-76,30 \%$ & \begin{tabular}{|l}
$-76,30 \%$ \\
\end{tabular} \\
\hline W-07- & $6,69 \%$ & $-2,53 \%$ & $-2,53 \%$ & $56,29 \%$ & $94,64 \%$ & & $0,00 \%$ & $0,00 \%$ & 0,0 & \begin{tabular}{|l|}
0,00 \\
\end{tabular} & $0,00 \%$ & 0,0 & & & & & & & & & \begin{tabular}{|l|}
$-53,86 \%$ \\
\end{tabular} \\
\hline W-07-B & $56,69 \%$ & $-2,53 \%$ & $-2,53 \%$ & $56,29 \%$ & $94,64 \%$ & $94,64 \%$ & $0,00 \%$ & $0,00 \%$ & $0,00 \%$ & $0,00 \%$ & $0,00 \%$ & $0,00 \%$ & $-61,55 \%$ & $-53,86 \%$ & $-53,86 \%$ & $-53,86 \%$ & $-53,86 \%$ & $\mid-53,86 \%$ & $\mid-53,86 \%$ & $\begin{array}{l}-53,86 \% \\
\end{array}$ & $-53,86 \%$ \\
\hline W-07-C & $56,69 \%$ & \begin{tabular}{|l|}
$-2,53 \%$ \\
\end{tabular} & $-2,53 \%$ & $\begin{array}{l}56,29 \% \\
\end{array}$ & $94,64 \%$ & $94,64 \%$ & $0,00 \%$ & \begin{tabular}{|l|}
$0,00 \%$ \\
\end{tabular} & $0,00 \%$ & \begin{tabular}{|l|}
$0,00 \%$ \\
\end{tabular} & $0,00 \%$ & $0,00 \%$ & \begin{tabular}{|l}
$-61,55 \%$ \\
\end{tabular} & $-53,86 \%$ & $-53,86 \%$ & $-53,86 \%$ & $-53,86 \%$ & \begin{tabular}{|l}
$-53,86 \%$ \\
\end{tabular} & \begin{tabular}{|l}
$-53,86 \%$ \\
\end{tabular} & $-53,86 \%$ & \begin{tabular}{|l}
$-53,86 \%$ \\
\end{tabular} \\
\hline W-08-A & $3,69 \%$ & $-2,53 \%$ & $-2,53 \%$ & 56,2 & $94,64 \%$ & $94,64 \%$ & 0,00 & 0,00 & & \begin{tabular}{|l|}
$0,00 \%$ \\
\end{tabular} & 0,0 & 0,0 & & & & $-53,86 \%$ & $-53,86 \%$ & & & & $-53,86 \%$ \\
\hline W-08-B & $56,69 \%$ & $-2,53 \%$ & $-2,53 \%$ & \begin{tabular}{|l|}
$56,29 \%$ \\
\end{tabular} & $94,64 \%$ & $94,64 \%$ & $0,00 \%$ & $0,00 \%$ & $0,00 \%$ & $0,00 \%$ & $0,00 \%$ & 0,00 & $-61,55 \%$ & $-53,86 \%$ & $-53,86 \%$ & $-53,86 \%$ & $-53,86 \%$ & $-53,86 \%$ & $-53,86 \%$ & $\begin{array}{l}-53,86 \% \\
\end{array}$ & $-53,86 \%$ \\
\hline W-08-C & $56,69 \%$ & \begin{tabular}{|l|}
$-2,53 \%$ \\
\end{tabular} & $-2,53 \%$ & $56,29 \%$ & $94,64 \%$ & $94,64 \%$ & $0,00 \%$ & \begin{tabular}{|l|}
$0,00 \%$ \\
\end{tabular} & 0,0 & \begin{tabular}{|l|}
$0,00 \%$ \\
\end{tabular} & $0,00 \%$ & 0,0 & \begin{tabular}{|l}
$-61,55 \%$ \\
\end{tabular} & $-53,86 \%$ & \begin{tabular}{|l}
$-53,86 \%$ \\
\end{tabular} & $-53,86 \%$ & $-53,86 \%$ & \begin{tabular}{|l|}
$-53,86 \%$ \\
\end{tabular} & \begin{tabular}{|l}
$-53,86 \%$ \\
\end{tabular} & \begin{tabular}{|l}
$-53,86 \%$ \\
\end{tabular} & \begin{tabular}{|l}
$-53,86 \%$ \\
\end{tabular} \\
\hline W-09-A & $307,51 \%$ & \begin{tabular}{|l}
$153,51 \%$ \\
\end{tabular} & $153,51 \%$ & $306,49 \%$ & $406,22 \%$ & $406,22 \%$ & $160,08 \%$ & $160,08 \%$ & $160,08^{\circ}$ & \begin{tabular}{|l|l}
160,089 \\
\end{tabular} & $160,08 \%$ & $160,08 \%$ & \begin{tabular}{|l|}
$0,00 \%$ \\
\end{tabular} & $20,00 \%$ & $20,00 \%$ & $20,00 \%$ & $20,00 \%$ & $20,00 \%$ & $20,00 \%$ & $20,00 \%$ & $20,00 \%$ \\
\hline W-09-B & $239,59 \%$ & $111,26 \%$ & $111,26 \%$ & $3874 \%$ & $321,85 \%$ & $321,85 \%$ & 116 & \begin{tabular}{|l}
$116,73 \%$ \\
\end{tabular} & & & & & & 0,0 & 0,0 & 0,0 & 0,00 & 0,0 & 0,0 & $0,00 \%$ & $0,00 \%$ \\
\hline W-09-C & $239,59 \%$ & \begin{tabular}{|l}
$111,26 \%$ \\
\end{tabular} & $\begin{array}{l}111,26 \% \\
\end{array}$ & \begin{tabular}{|l}
$238,74 \%$ \\
\end{tabular} & $321,85 \%$ & $321,85 \%$ & $\begin{array}{l}116,73 \% \\
\end{array}$ & \begin{tabular}{|l}
$116,73 \%$ \\
\end{tabular} & & & 116 , & 116 & \begin{tabular}{|l}
$-16,67 \%$ \\
\end{tabular} & 0,0 & \begin{tabular}{|l|}
0,0 \\
\end{tabular} & $0,00 \%$ & 0,00 & \begin{tabular}{|l|l}
0,00 \\
\end{tabular} & \begin{tabular}{|l|}
0,0 \\
\end{tabular} & \begin{tabular}{|l|}
$0,00 \%$ \\
\end{tabular} & \begin{tabular}{|l|}
$0,00 \%$ \\
\end{tabular} \\
\hline W-10-A & $239,59 \%$ & \begin{tabular}{|l|l}
$111,26 \%$ \\
\end{tabular} & $111,26 \%$ & $238,74 \%$ & $321,85 \%$ & $321,85 \%$ & $116,73 \%$ & $116,73 \%$ & 116 & $\begin{array}{l}116 \\
\end{array}$ & 116 , & & $-16,67 \%$ & 0,0 & 0,0 & $0,00 \%$ & 0,0 & 0,0 & $0, \mathrm{c}$ & $0,00 \%$ & $0,00 \%$ \\
\hline W-10-B & $239,59 \%$ & $111,26 \%$ & 11 & 238,7 & 321,8 & $321,85 \%$ & 116, & 116 & & & & & & & 0,0 & & 0,0 & 0,0 & & 0,0 & $0,00 \%$ \\
\hline W-10-C & $239,59 \%$ & \begin{tabular}{|l}
$111,26 \%$ \\
\end{tabular} & $111,26 \%$ & \begin{tabular}{|l}
$238,74 \%$ \\
\end{tabular} & $321,85 \%$ & $321,85 \%$ & $\begin{array}{l}116,73 \% \\
\end{array}$ & \begin{tabular}{|l}
$116,73 \%$ \\
\end{tabular} & $116,73 \%$ & \begin{tabular}{|l}
$\mid, 73 \%$ \\
116,7
\end{tabular} & $116,73 \%$ & $116,73 \%$ & \begin{tabular}{|l}
$-16,67 \%$ \\
\end{tabular} & $0,00 \%$ & $0,00 \%$ & $0,00 \%$ & $0,00 \%$ & $0,00 \%$ & $0,00 \%$ & \begin{tabular}{|l|l|}
$0,00 \%$ \\
\end{tabular} & \begin{tabular}{|l|}
$0,00 \%$ \\
\end{tabular} \\
\hline W-11-A & $239,59 \%$ & \begin{tabular}{|l|l}
$111,26 \%$ \\
\end{tabular} & $111,26 \%$ & & & & & & & & & & & 0,0 & 0,0 & 0,0 & 0,0 & 0,0 & 0,0 & $0,00 \%$ & $0,00 \%$ \\
\hline W-11-B & $239,59 \%$ & $111,26 \%$ & $111,26 \%$ & $238,74 \%$ & $321,85 \%$ & $321,85 \%$ & $116,73 \%$ & $116,73 \%$ & 116 & 116, & $116,73 \%$ & 116 & -16, & 0,0 & 0,0 & 0,0 & 0,0 & 0,0 & 0,0 & $0,00 \%$ & \begin{tabular}{|l|l|}
$0,00 \%$ \\
\end{tabular} \\
\hline W-11-C & $239,59 \%$ & \begin{tabular}{|l}
$111,26 \%$ \\
\end{tabular} & $111,26 \%$ & $238.74 \%$ & $321,85 \%$ & $321.85 \%$ & $116.73 \%$ & $116.73 \%$ & $116.73 \%$ & $116.73 \%$ & $116.73 \%$ & $116.73 \%$ & $-16.67 \%$ & $0,00 \%$ & $0.00 \%$ & $0,00 \%$ & $0,00 \%$ & $0,00 \%$ & \begin{tabular}{|l|}
$0,00 \%$ \\
\end{tabular} & $0,00 \%$ & $0,00 \%$ \\
\hline
\end{tabular}

Tabela 6.4: Comparação do custo monetário entre as execuções dos workflows do Experimento 1 


\subsection{Análise dos Resultados}

Os resultados para os cenários W-01, W-02, W-04 e W-05 mostram o desempenho obtido sem o uso das anotações, considerando como execução paralela apenas a definida pelas atividades $C$, $D$ e $E$, que acessam a mesma coleção de dados e recuperam todos os objetos, com ordenações distintas. Avaliamos o impacto do acesso paralelo aos dados em um workflow que utiliza um SGBD centralizado relacional e um NoSQL orientado a agregados.

Apesar de possuir 3 nós para execução (que permite a execução paralela de $C, D$ e $E$ ), o cenário W-02 não apresenta diferença significativa em relação ao cenário W-01, que executa sequencialmente as atividades $C, D$ e $E$. Isso deve-se ao fato de que, por haver apenas 1 nó de execução, não houve concorrência no acesso ao PostgreSQL em W-01. Em W-02, o acesso concorrente (com 3 nós de execução) resultou em bloqueios no banco de dados relacional que oneraram o desempenho. Entretanto, o custo da execução de W-02 foi superior ao de W-01 devido ao uso de mais nós de execução (em média, $60 \%$ a mais).

No MongoDB, nos cenários W-04 e W-05, observamos uma redução média de 28,7\% do tempo total de execução do segundo cenário em relação ao primeiro, indicando que o SGBD NoSQL neste caso, mesmo centralizado, suportou melhor o acesso concorrente aos dados de uma mesma coleção. Isso resultou também em uma redução do custo monetário da execução (cerca de 19,70\% a menos).

Em relação aos seus cenários equivalentes, que utilizam o SGBD PostgreSQL (W-01 e W-02), é possível observar a redução do tempo de execução, de 14,1\% a 39,9\%, devido a adoção do SGBD MongoDB e da execução paralela das atividades $C, D$ e $E$. A respeito do custo, a execução de $\mathrm{W}-04$ foi em média 0,25\% mais cara que a de W-01, pois o MongoDB utilizou maior espaço em disco. Contudo, apesar disso, o cenário W-05 obteve uma redução de 19,50\% em relação a W-04 e de 49,9\% em relação a W-02, devido à redução do tempo de execução e à cobrança por hora-cheia da AWS. Os ganhos obtidos refletem os benefícios do uso de um SGBD com interfaces de acesso mais simples e controle de concorrência menos rígido para operações de consultas que não necessitam de junções entre coleções de dados, como é o caso dos workflows que trabalham com dados semiestruturados e não-estruturados. Em relação à consistência dos dados, esta não foi impactada pois ambos os cenários são centralizados, ou seja, com garantia de consistência e desempenho, no entanto, menos tolerantes a falhas e partições de rede.

Considerando cenários que utilizaram as anotações $P O$ e $P G$ para explorar o paralelismo de dados, foi possível obter uma redução de 17,7\% do makespan com o PostgreSQL (cenários W-03 $\times \mathrm{W}-02$ ) e de 28,3\% do makespan no cenário mais básico de uso do MongoDB (cenários W-06 × W-05). No entanto, em ambos os casos, não houve redução do custo monetário, devido à política de cobrança de recursos da AWS. É importante observar que, com uma mesma quantidade de máquinas com mesma configuração de hardware, obteve-se uma diminuição de 56,9\% no makespan e de 49,92\% do custo do workflow devido ao uso do MongoDB e das anotações em substituição ao uso do PostgreSQL (cenários W-06 × W-02). Os cenários W-03 e W-04 obtiveram desempenho equivalente, indicando que o uso do MongoDB em um ambiente centralizado, ainda foi melhor do que o cenário do PostgreSQL que obteve melhor desempenho. O custo de W-04 manteve-se superior a W-03 (2,5\%) devido novamente à necessidade de mais espaço em disco para o MongoDB.

O uso de réplicas dos dados por partição do MongoDB foi avaliado em três configurações: (A) para prover tolerância a falhas; (B) para prover escalabilidade horizontal com quórum mínimo de um recurso para confirmação da escrita; (C) para prover escalabilidade horizontal com quórum definido pela confirmação da escrita da maioria das réplicas (vide Seção 2.3.2). No cenário A, a consistência é garantida pois todas as atividades realizam operações de escrita e leitura do mesmo nó mestre de cada partição. O particionamento dos dados proporciona nesse caso a escalabilidade horizontal para escrita.

O uso do MongoDB, em relação ao PostgreSQL, obteve melhor desempenho em todos os cenários. O caso mais básico do MongoDB, o cenário W-04, obteve o pior desempenho em relação aos demais cenários que também utilizaram o MongoDB.

A adição de réplicas dos dados no MongoDB gerou um aumento de 8,3 a 55,9\% no makespan e de 94,64\% no custo monetário (cenários [W-07-A, W-07-B, W-07-C] × W-05), (cenários [W-07-A, 
W-07-B, W-07-C] × W-06), (cenários [W-08-A, W-08-B, W-08-C] × W-05) e (cenários [W-08-A, W08-B, W-08-C] $\times$ W-06). Isso deve-se ao tempo de sincronização e a necessidade de mais servidores para manutenção das réplicas.

O tempo de execução do workflow W-07-A foi em média 1,6\% menor que o tempo de execução de W-07-B pois o tempo para escolha do nó secundário a ser lido (em que uma partição era composta por um nó primário e dois secundários) aumentou o tempo de cada operação e, devido à quantidade de objetos por operação, impactou o tempo total de execução. Observamos também uma grande variância no tempo obtido por W-07-C, que não apresentou diferença significativa em comparação a W-07-A ou a W-07-B.

Os cenários W-07-A, W-07-B, W-07-C obtiveram desempenho inferior a W-05, devido ao custo da sincronização das réplicas dos objetos de dados. Entretanto, com o uso das anotações, W-08-A e W-08-B mostraram-se mais eficientes que W-05, mesmo com o uso de um SGBD com fator de replicação igual a 3. O quórum majoritário definido para W-08-C impactou no desempenho mesmo com o uso das anotações, obtendo desempenho inferior a W-05.

Em comparação a W-06, todos os cenários com o MongoDB replicado (W-07-A, W-07-B, W07-C, W-08-A, W-08-B, W-08-C) sofreram com o impacto do sincronismo das réplicas.

Analisando o intervalo de confiança de W-08-A e W-08-B, observamos que as anotações resultaram em uma redução do tempo de execução, respectivamente: de $26,1 \%$ e $24,5 \%$, em relação a W-07-A; de $27,3 \%$ e $25,7 \%$, comparado a W-07-B; e de $28,5 \%$ e $26,9 \%$, em relação a W-07-C. Entretanto, novamente devido ao quórum de escrita majoritário, O cenário W-08-C não apresentou diferença significativa no desempenho em nenhum caso, devido à grande variância em seu tempo de execução.

O desempenho de W-08-B em relação a W-08-A também não apresentou diferença significativa, entretanto, ambos obtiveram melhor desempenho em relação a W-08-C. Em relação ao custo, não houve diferença entre os cenários W-07-A, W-07-B, W-07-C, W-08-A, W-08-B e W-08-C devido ao uso do mesmo número de instâncias e à forma de cobrança da AWS. Em relação à consistência obtida com a leitura das réplicas do MongoDB, observamos que o quórum composto por uma única réplica (primária) foi suficiente para se obter dados consistentes durante a leitura das réplicas.

Os cenários W-09-A, W-09-B, W-09-C, W-10-A, W-10-B, W-10-C, W-11-A, W-11-B e W-11-C permitem a escalabilidade horizontal das operações de escrita, por meio do uso de um banco de dados do MongoDB dividido em três partições, com fator de replicação igual a 3. Os cenários do tipo B e C permitem a análise da escalabilidade horizontal para leitura. Os cenários do tipo W-10 adotaram como estratégia de particionamento dos dados intermediários a distribuição baseada em intervalos (nas anotações em que fosse aplicável). Já para os cenários do tipo W-11 foi escolhida a distribuição de dados sempre baseada em hashing.

Como podemos observar, o cenário W-09-A obteve desempenho inferior em relação aos cenários W-05, W-06, W-07-A, W-07-B, W-07-C, W-08-A, W-08-B, W-08-C e não se diferenciou de forma estatisticamente significativa de W-09-C.

O cenário W-09-B, que habilita a leitura das réplicas com um quórum igual a 1, não obteve melhora de desempenho significativa em relação a W-07-A, W-07-B, W-07-C e W-08-C; seu desempenho foi inferior ao obtido nos cenários W-08-A e W-08-B (modificados pelo método proposto) e melhor apenas do que W-09-A e W-09-C, devido à leitura das réplicas e menor quórum de escrita. O desempenho de W-09-C foi pior que o obtido por W-08-C, apesar do uso do mesmo quórum de escrita. Todos os cenários do tipo W-09 obtiveram melhor desempenho que W-04, devido a execução do workflow em mais nós e à leitura das réplicas.

O desempenho dos cenários do tipo W-10 e W-11, modificados pelo método, obtiveram a redução de 0,7\% a 58,5\% do tempo total de execução em comparação aos cenários do MongoDB, W-04, W-05, W-07-A, W-07-B, W-07-C, W-09-A, W-09-B, W-09-B que não se beneficiam do uso das anotações e uma redução de 4,8\% a 39,2\% nos cenários W-08-A, W-08-B e W-08-C, que são modificadas pelo método. Em relação ao cenário W-06, apenas os cenários que não utilizaram o quórum majoritário (tipo A e B) obtiveram maior desempenho, com ganhos médios variando entre 7,6\% a 18,8\%.

Os ganhos obtidos pelos cenários W-10-A, W-10-B, W-11-A e W-11-B indicam o ganho obtido 
pelo uso do método proposto para paralelização de workflows para processamentos do tipo $P O$ e $P G$, em que a execução é paralela tanto no nível do SGWf quanto no acesso aos dados de um SGBD, em que a replicação e particionamento garante a escalabilidade horizontal das operações e tolerância a falhas, com o uso de um quórum de escrita igual a 1.

A leitura das réplicas não causou diferença significativa no desempenho de W-10-B em relação a W-10-A. O cenário W-10-A obteve um aumento do tempo de execução, em relação a W-11-A e W-11-B de 5,5\% e 13,9\%, respectivamente, e redução de 6,9\% em comparação a W-11-C. O cenário W-10-B não mostrou diferença significativa em relação a W-11-A e obteve desempenho melhor que W-10-C e W-11-C. W-10-C obteve o pior desempenho no uso das anotações em ambiente distribuído, pois aumentou o makespan em até 30,8\% em comparação a W-06, W-10-A, W-10-B, W-11-A, W11-B e mesmo com W-11-C, que possui o mesmo quórum de escrita. Em relação a W-06, W-11-C não apresentou diferença significativa.

O cenário com maior redução do tempo total de execução foi W-11-B (considerando todas as execuções), que reduziu, em média, o tempo de execução de 7,4\% a 64,4\%. Entretanto, devido ao tempo necessário para sincronização das réplicas, os dados gerados foram apenas $61 \%$ consistentes em relação aos valores esperados para a execução.

Considerando a consistência e o desempenho obtido, o melhor cenário foi o W-11-A, que manteve a consistência dos dados e, ainda assim, foi capaz de prover maior escalabilidade para o SGWf e para o banco de dados, reduzindo o tempo médio de execução de $5,2 \%$ a $62,2 \%$. A estratégia de particionamento adotada gera uma melhor distribuição dos dados entre as partições.

Em relação ao custo financeiro, apesar do custo ter aumentado ao compararmos o uso de um cenário centralizado e um distribuído, foi possível observar que o uso do método proposto não impactou no custo da execução em cenários com as mesmas configurações de ambiente. Ressaltamos ainda que, caso a cobrança fosse por minuto, o custo poderia ser reduzido também.

A respeito do resultado obtido por anotação, observamos na Figura 6.7 que, em todos os cenários cuja atividade $\mathrm{F}$ foi modificada devido à anotação $P G$, o makespan sofreu uma redução, se comparado aos workflows que executaram no mesmo ambiente de execução sem a aplicação do método, considerando o acesso a dados pré-existentes antes da execução, ou seja, que não usufruíram das estratégias de particionamento propostas. Essa atividade permite observar o perfil das operações do tipo $P G$, em que um conjunto de objetos com o mesmo atributo é recuperado de uma coleção. Os cenários que utilizaram o MongoDB e não foram modificados pelo método foram piores que os casos que utilizam o PostgreSQL pois o modelo relacional é otimizado para esse tipo de consulta. Entretanto, ao analisarmos o uso do método, observamos que conseguimos a redução do tempo de até $65 \%$ para os casos do MongoDB em relação ao PostgreSQL $(\mathrm{W}-11-\mathrm{B} \times \mathrm{W}-02)$ e de $74 \%$ em comparação com o pior caso do MongoDB $(\mathrm{W}-11-\mathrm{B} \times \mathrm{W}-07-\mathrm{B})$.

Entretanto, na avaliação do desempenho da Atividade $H$ na Figura 6.9, que também possui a anotação $P G$ e, no entanto, consome dados intermediários, gerados por $G$, observamos que as anotações não tiveram impacto significativo no caso do PostgreSQL e que o desempenho dos casos do PostgreSQL (com e sem anotações) em relação ao MongoDB distribuído e/ou replicado sem anotações não teve diferença significativa (como ocorreu com a atividade $\mathrm{F}$ ). Isso deve-se ao fato de que a atividade $\mathrm{F}$ manipulou 2.892 .970 objetos e a atividade $\mathrm{H}$, apenas 643.930 objetos. Além disso, apenas os cenários do tipo W-06, W-08 e W-10, e os W-11-A e W-11-B obtiveram redução do tempo de execução em relação ao seu caso base (com o mesmo ambiente de execução). Os cenários com o MongoDB distribuído não obtiveram a maior redução do tempo de execução pois sofreram impacto do balanceador de carga, que estava em execução para distribuição dos dados intermediários gerados por $G$. Ainda assim, reduziram o tempo de execução de $4 \%$ a $17 \%$ em relação aos cenários do tipo W-09. O melhor resultado foi obtido nos cenários em que o banco de dados estava apenas replicado (não particionado), não sendo impactado pelo balanceador de carga, com redução de até $36 \%$ (W-08-C x W-07-C).

A definição da distribuição por intervalo obteve melhor desempenho do que a distribuição por hashing. O quórum majoritário para escrita obteve o pior desempenho pois precisava esperar o balanceador de carga executar para confirmar a escrita. 
A consistência dos dados foi afetada também pela execução do balanceador de carga nativo do MongoDB, que efetua a migração de objetos entre as partições: enquanto uma migração está em andamento, os resultados obtidos pelas réplicas estão sujeitos à inconsistência, como pode ser observado na Tabela 6.2.

A respeito das operações por objeto descritas na Figura 6.8 referente à execução da Atividade G, é possível observar que o PostgreSQL obteve o pior desempenho sem o uso da anotação, devido ao alto número de escritas realizadas. O MongoDB lidou melhor com esse perfil de processamento, apesar do impacto que podemos observar nos cenários distribuídos. O quórum majoritário de escrita aumentou o tempo de execução dos cenários que utilizaram o método proposto. Entretanto, nos demais casos em que a anotação foi utilizada, observamos a redução de até $81 \%(\mathrm{~W}-11-\mathrm{B} \times \mathrm{W}$ 09-A). Destacamos ainda que o uso de um SGBD distribuído em relação ao centralizado reduziu o desempenho em $12 \%$ (W-11-B x W-06), invertendo o resultado obtido para os casos-base de cada cenário, em que o MongoDB centralizado executou em menos tempo que no MongoDB distribuído $(\mathrm{W}-04 \times[\mathrm{W}-09-\mathrm{A}, \mathrm{W}-09-\mathrm{B}, \mathrm{W}-09-\mathrm{C}])$.

A execução de um cenário com um volume maior de dados mostra que todos os cenários distribuídos avaliados são mais eficientes que os centralizados por serem mais escaláveis, mesmo nos quais o método proposto de paralelização não era aplicado. O SGBD relacional (PostgreSQL) obteve o pior desempenho, apesar do uso do método reduzir sua execução de 3 dias e 6 horas para 1 dia e 13 horas. Podemos observar que o cenário que obteve melhor desempenho foi o W-11-B, que executou o workflow em 5 horas e 19 minutos. Entretanto, como demonstrado anteriormente na avaliação da consistência dos dados, o cenário W-11-B não consegue obter um alto nível de consistência, sendo mais interessante o uso dos cenários W-10-A e W-11-B, que executaram suas instâncias em 7 horas e 38 minutos e 8 horas e 21 minutos, respectivamente. Observa-se também que o cenário W-08-B obteve o segundo menor tempo de execução, 6 horas e 52 mins; contudo, como ele possui uma configuração equivalente à W-11-B em relação o seu nível de consistência, W-08-A mostra-se com um desempenho mais relevante ( 9 horas e 25 minutos).

Em relação ao custo, é possível observar que um tempo de execução maior resultou em um custo maior, mesmo com o uso de um número reduzido de máquinas virtuais. À medida que o volume de dados cresce, a adoção de um ambiente mais distribuído em um workflow modificado pela nossa proposta mostra-se mais eficiente, tanto em relação ao tempo de execução quanto ao seu custo monetário.

\subsection{Considerações sobre o Capítulo}

A consistência torna-se um requisito importante para a validação de uma análise. Incluímos neste estudo operações que efetuavam análises estatísticas sobre todos os objetos de uma coleção, tanto pré-existente quanto gerada durante a execução e foi possível observar que a leitura das réplicas tem impacto negativo na consistência dos dados, mesmo quando é definido um quórum majoritário para escrita. Neste último caso, o processo de escrita é oneroso e a execução sujeita a bloqueios do balanceador de carga.

Nos demais casos, foi possível observar que o uso do método proposto foi capaz de obter o melhor desempenho em um ambiente distribuído, com maior escalabilidade horizontal no acesso ao banco de dados e tolerância a falhas, obtendo redução de makespan de até $62,3 \%$ em cenários com consistência forte e de até $65 \%$ em cenários com consistência relaxada. Além disso, o método não impactou o custo da execução em relação ao cenários com o mesmo ambiente. Em especial, o método aliado ao ambiente distribuído reduziu o tempo de execução das operações $P G$ que processavam dados de entrada já existentes em até $81 \%$ (comparando-se o MongoDB com o PostgreSQL) e de até $74 \%$ (comparando-se o MongoDB distribuído com a versão centralizada).

No entanto, observamos que esse desempenho não é equivalente em cenários que processam coleções de dados intermediários, como o descrito pela Atividade H. O balanceador de carga afetou o desempenho da atividade, que se beneficiou da escalabilidade horizontal somente nos cenários com dados replicados, sem particionamento (redução de até 36\%). No cenário distribuído, apenas 
o particionamento por intervalo foi melhor que seu caso base (redução de $4 \%$ a $17 \%$ ).

As operações $P O$ foram as que mais se beneficiaram do método: houve uma redução de até 85\% na comparação do uso do PostgreSQL com o MongoDB particionado e replicado, de até $81 \%$ comparando o cenário distribuído com seu caso base e de até $12 \%$ na comparação do cenário distribuído com o centralizado.

No Capítulo 7 avaliamos as anotações $P G$ para redistribuição de dados, a $P V D$ e $P J T$. 


\section{Capítulo 7}

\section{Experimento 2: Workflow para Análise de Edições da Wikipédia}

O método proposto no Capítulo 4 define quatro anotações sobre o tipo de processamento de dados: $P O, P G, P V D$ e $P J T$. No Capítulo 6, avaliamos o uso das anotações $P O$ e $P G$ em um modelo de processamento de dados similar ao MapReduce. Neste capítulo, avaliamos a anotação PJT e descrevemos o uso da anotação $P V D$ e da $P G$ para redistribuição de dados. Para isso, implementamos um workflow para análise de edições da Wikipédia ${ }^{1}$ baseado no processamento descrito pelo pipeline Top WikipediaSessions ${ }^{2}$ do Google Cloud Dataflow ${ }^{3}$.

Esse pipeline utiliza o arcabouço Apache Beam para descrição do seu processamento por meio de classes que fornecem a semântica sobre as operações a serem realizadas. O Apache Beam foi desenvolvido a partir do modelo de programação de dataflows, criado por Akidau et al. [ABC $\left.{ }^{+} 15\right]$ e difere-se de modelos como o MapReduce por permitir a descrição de operadores baseados em janelas temporais $\left[\mathrm{LMT}^{+} 05\right]$, além de fornecer um modelo capaz de processar paralelamente dados em fluxos contínuos (streamings) e em lotes (batch).

TopWikipediaSessions é um pipeline de análise em lote que processa os dados de edições de páginas da Wikipédia ${ }^{4}$ armazenados no Google Cloud Storage em arquivos no formato JSON. Cada arquivo contém uma lista de registros, caracterizados pelo nome do usuário, data e hora (no formato timestamp) em que a edição foi salva, o conteúdo adicionado, o nome da página modificada, o identificador do usuário que revisou o conteúdo, entre outros dados. Por meio de agregações de dados baseadas em janelas de tempo, esse pipeline tem como proposta identificar o usuário com o maior número de edições em uma única sessão.

Define-se neste cenário uma sessão como um conjunto de edições de um usuário que ocorreram em um intervalo de tempo inferior a uma hora. Considere um usuário A, por exemplo, que realizou, em um mesmo dia, 4 edições na Wikipédia, com intervalo de 20 minutos entre cada uma e, dois dias depois, realizou mais 1 edição. Sua maior sessão contém 4 edições (não 5). Considere também um usuário B, que realizou 10 edições em um mesmo dia, com um intervalo de 2 horas entre cada registro. Sua maior sessão contém apenas uma edição. O usuário A seria o usuário com a sessão com o maior número de edições.

O pipeline é definido basicamente por quatro etapas: (i) Extração dos atributos username (nome do usuário) e timestamp (data e hora) de cada edição realizada dos arquivos JSON utilizados como entrada e indexação da lista de usuários únicos com a lista de edições realizadas; (ii) Seleção do período máximo de registros a serem processados a partir de um limite definido pelo usuário; (iii) Computação de todas as sessões de cada usuário e o número de edições realizadas em cada uma;

\footnotetext{
${ }^{1}$ A Wikipédia é uma enciclopédia online multilíngue de licença livre que permite a criação de conteúdo de maneira colaborativa (último acesso em 20/01/2017) - https://pt.wikipedia.org/wiki/Wikipédia

${ }^{2}$ TopWikipediaSessions (último acesso em 20/01/2017): https://cloud.google.com/dataflow/examples/ all-examples \#top-wikipedia-sessions

${ }^{3}$ Google Cloud Dataflow (último acesso em 20/01/2017) - https://cloud.google.com/dataflow/

${ }^{4}$ Dados de edições da Wikipédia disponíveis no Google Storage (último acesso em 20/01/2017): gs:// apache-beam-samples/wikipedia_edits/
} 
e (iv) Cálculo do usuário com maior número de edições em uma única sessão para cada mês do período avaliado (30 dias).

A criação do modelo, adição das anotações e execução seguindo os critérios apresentados no Capítulo 5 são descritos nas seções a seguir. Incluímos também a análise dos resultados e conclusões sobre os resultados obtidos.

\subsection{Modelo de Workflow}

Em nossa implementação, supomos que os registros de edições já estavam disponíveis em um banco de dados, a fim de que não fosse necessário realizar a extração dos atributos como parte do workflow, sendo necessária apenas a identificação dos usuários únicos, uma vez que um usuário pode estar associado a mais de um registro de edição. Definimos também que o workflow não precisaria identificar o período máximo a ser computado pois a delimitação estaria no total de registros armazenados no banco de dados utilizado. Assim, o workflow foi definido como a composição de cinco atividades e implementado com o auxílio da ferramenta SciWonc-Dataflow [WGB16]. Essas atividades são:

- DataStoreInit (A): atividade artificial criada pela ferramenta para configuração do banco de dados e suas coleções, o que inclui criação de coleções de dados intermediários, índices e regras de particionamento quando aplicáveis.

- IdentifyUniqueUsernames (B): atividade que identifica a lista de usuários que aparecem nos registros de edições da Wikipédia e gera dinamicamente os arquivos de configuração referentes às listas de usuários a serem processadas pela Atividade C;

- ComputeSessionsPerUsername (C): atividade responsável pelo cálculo do número de edições por sessão para cada usuário;

- ComputeLongestSession (D): atividade que processa janelas temporais de 30 dias e identifica o usuário que editou mais páginas da Wikipédia em uma única sessão;

- DataStoreReset (E): atividade artificial adicionada pela ferramenta para remover índices de suporte criados nas coleções de dados de entrada durante a execução do workflow.

A estrutura do workflow pode ser observada na Figura 7.1. O modelo inicial não define a execução de nenhuma atividade paralela. A atividade B utiliza a anotação $P V D$ para recuperar a lista de usuários únicos, fornecida pela biblioteca SciWonc-Dataflow e definir os arquivos de configuração a serem utilizados pelas réplicas da atividade C. Nessa implementação, a atividade B recebe o número de arquivos que deve gerar assim como um modelo para geração do arquivo e definição de seu nome. A atividade $\mathrm{C}$ processa o conjunto de entrada, referente aos registros de edições, agrupando-os pelo nome do usuário (contributor_username) e salva as informações sobre cada sessão como a data e hora de início e fim da sessão e o número de edições computados. Todo usuário tem no mínimo uma sessão de uma hora. Caso tenha efetuado diversas edições com um intervalo inferior ao tempo limite da sessão (1 hora), o término da sessão é calculado a partir do último registro desta sessão. E caso o intervalo ultrapasse o tempo limite, uma nova sessão é armazenada seguindo os mesmos critérios. A partir da lista de sessões, a atividade D identifica o usuário com maior número de edições em uma única sessão dentro de janelas de intervalo de 30 dias calculadas a partir da data de término de cada sessão. A Figura 7.2 apresenta como o modelo inicial descrito pela Figura 7.1 pode ser modificado, a partir das anotações sobre as atividades C e D.

\subsection{Execução do Modelo de Workflow}

Selecionamos aproximadamente 2 GB de dados iniciais referentes a 19.449.715 edições de páginas da Wikipédia. Definimos também que seriam selecionados 10.000 usuários da lista de usuários únicos 


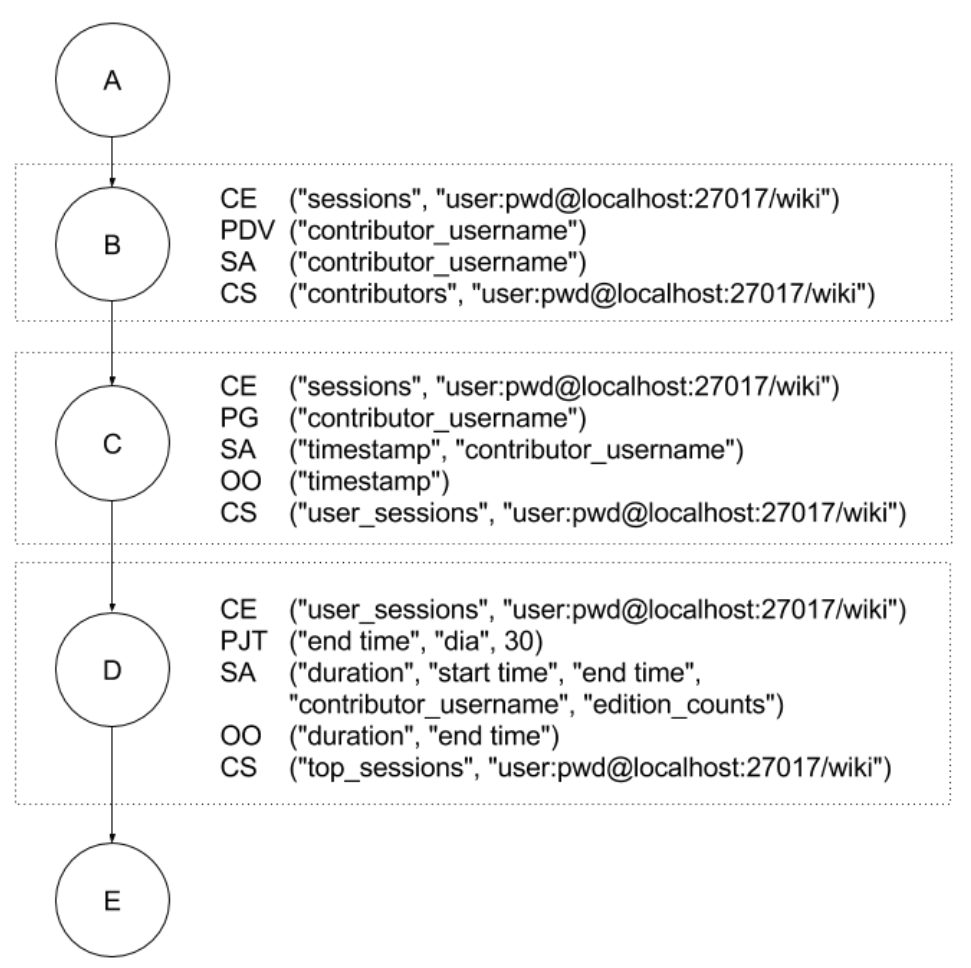

Figura 7.1: Modelo inicial do workflow para análise de edições da Wikipédia. As atividades A e E representam atividades artificiais criadas pelo método.

para a análise das sessões e definições dos grupos consumidos pela atividade $\mathrm{C}$ para que o tempo total de execução do workflow variasse entre uma e três horas, viabilizando que a execução do workflow fosse feita repetidas vezes, em diferentes cenários experimentais. A partir dessas sessões, foram identificadas 100 janelas de 30 dias a serem processadas pela atividade D. Ao todo, foram manipulados aproximadamente $2,65 \mathrm{~GB}$ de dados e, incluindo os índices e replicação de dados, o volume de dados variou entre 5,94 GB e 15,21 GB, num total de 20.481 .222 objetos. Não executamos esse workflow nos cenários 02 e 05 descritos no ambiente experimental apresentado no Capítulo 5 pois o modelo de workflow deste experimento não apresentava atividades paralelas originalmente definidas em seu modelo.
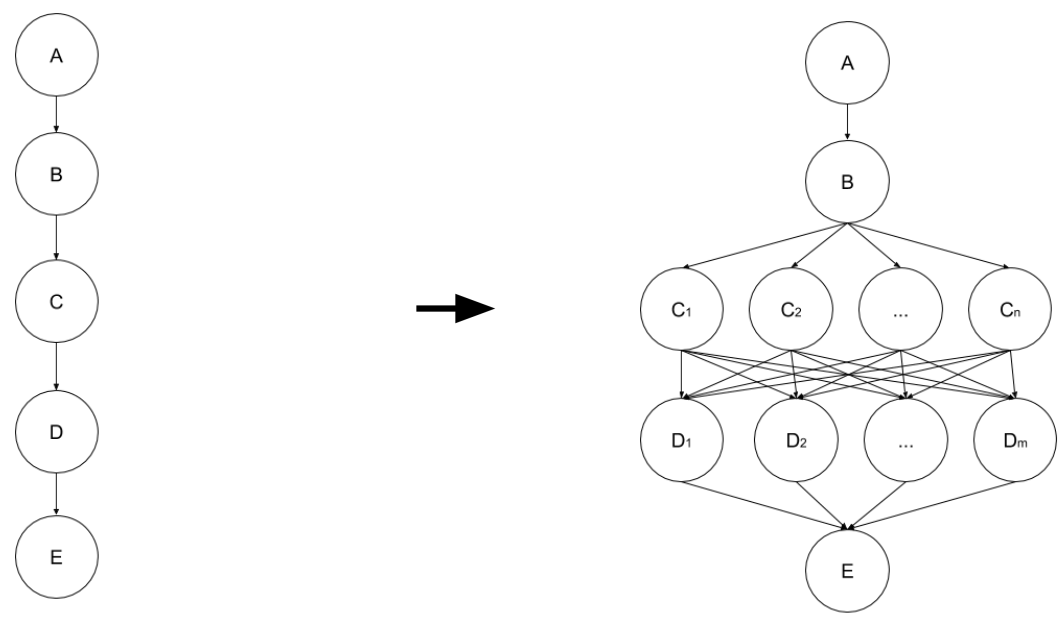

Figura 7.2: Representação da reestruturação aplicável ao modelo de workflow para análise de edições da Wikipédia, gerada a partir das suas anotações semânticas 
A Figura 7.4 mostra o tempo total médio de execução obtido nos experimentos e a Figura 7.5, o custo financeiro total médio de execução nos respectivos cenários. O custo é calculado com base no tempo de uso das instâncias da AWS (incluindo os valores gastos com as CPUs e discos utilizados). Os discos utilizados foram todos do tipo ebs-gp2-ssd, enquanto as instâncias foram todas do tipo m3.medium, com 1vCPU, 3.75GB de RAM, com 4GB de instance storage. Os valores foram calculados de acordo com a tabela de preços $^{5}$ de janeiro/2017 para instâncias que executam o sistema operacional Ubuntu 14.04-LTS x64.

A Figura 7.3 descreve a notação de cores e padrões adotada para representar os cenários avaliados neste capítulo, referentes às Figuras 7.4 a 7.8.

A comparação do tempo total médio de execução das atividades $\mathrm{B}, \mathrm{C}$ e D, com e sem anotações sobre o tipo de processamento, é mostrada nas Figuras 7.6, 7.7 e 7.8. O tempo médio de execução das atividades replicadas pelo método proposto foi calculado considerando o início da execução da primeira réplica e o término da execução da última réplica.

Não avaliamos o nível de consistência dos dados pois o Experimento 1 foi suficiente para demonstrar que a leitura das réplicas impacta na consistência e desempenho de acordo com a estratégia para distribuição de dados intermediários. Os ganhos obtidos em relação ao tempo são descritos na Tabela 7.1 e o custo na Tabela 7.2.

\section{Configuração do Banco de Dados}

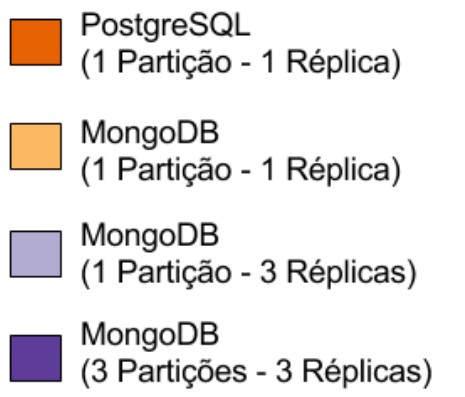

Distribuição de Dados Intermediários

H Distribuição baseada em Hashing

R Distribuição baseada em Intervalo

\section{Configuração de Leitura e Escrita do Banco de Dados}

Preferência de Leitura: Réplica Primária

Consistência da Escrita: 1 Réplica

Paralelização pelo Método Proposto: Não

Preferência de Leitura: Réplica Secundária

Consistência da Escrita: 1 Réplica

Paralelização pelo Método Proposto: Não

Preferência de Leitura: Réplica Secundária

Consistência da Escrita: Majoritária

Paralelização pelo Método Proposto: Não

Uso do Método Proposto para Paralelização de Atividades

Preferência de Leitura: Réplica Primária

Consistência da Escrita: 1 Réplica

Paralelização pelo Método Proposto: Sim

Preferência de Leitura: Réplica Secundária

Consistência da Escrita: 1 Réplica

Paralelização pelo Método Proposto: Sim

Preferência de Leitura: Réplica Secundária

Consistência da Escrita: Majoritária

Paralelização pelo Método Proposto: Sim

Figura 7.3: Notação gráfica adotada para descrever os cenários apresentados nas Figuras $7.4 \quad$ a 7.8

\footnotetext{
${ }^{5}$ Tabela de preços de instâncias da AWS (último acesso em 20/01/2017): https://aws.amazon.com/pt/ec2/pricing/ on-demand/
} 


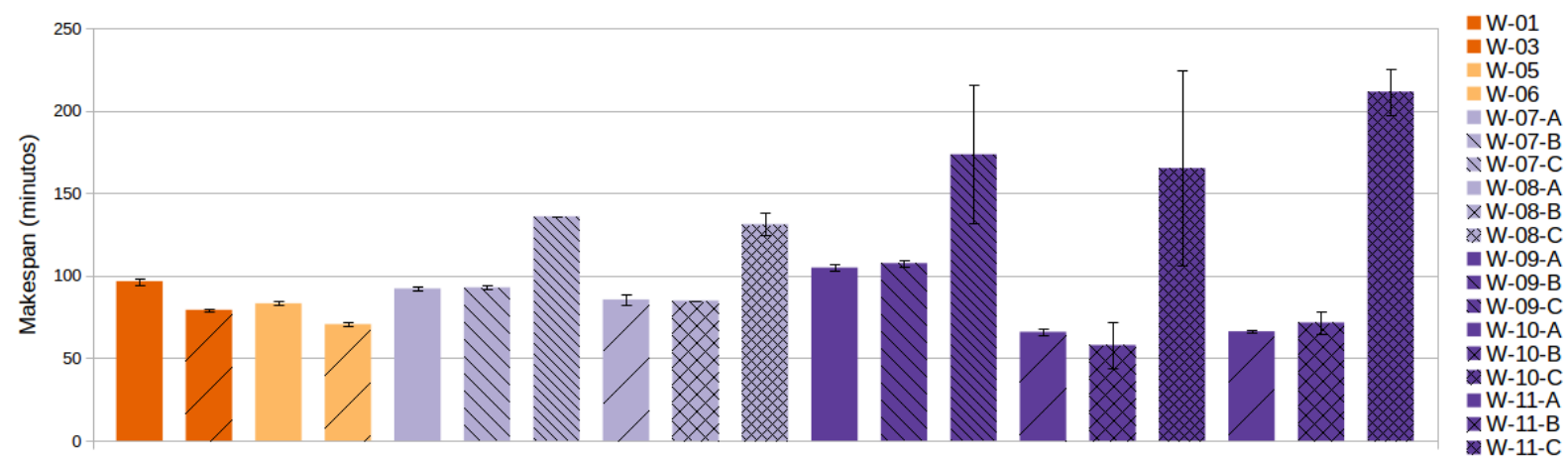

Figura 7.4: Makespans médios das execuções do workflow de análise de edições da Wikipédia

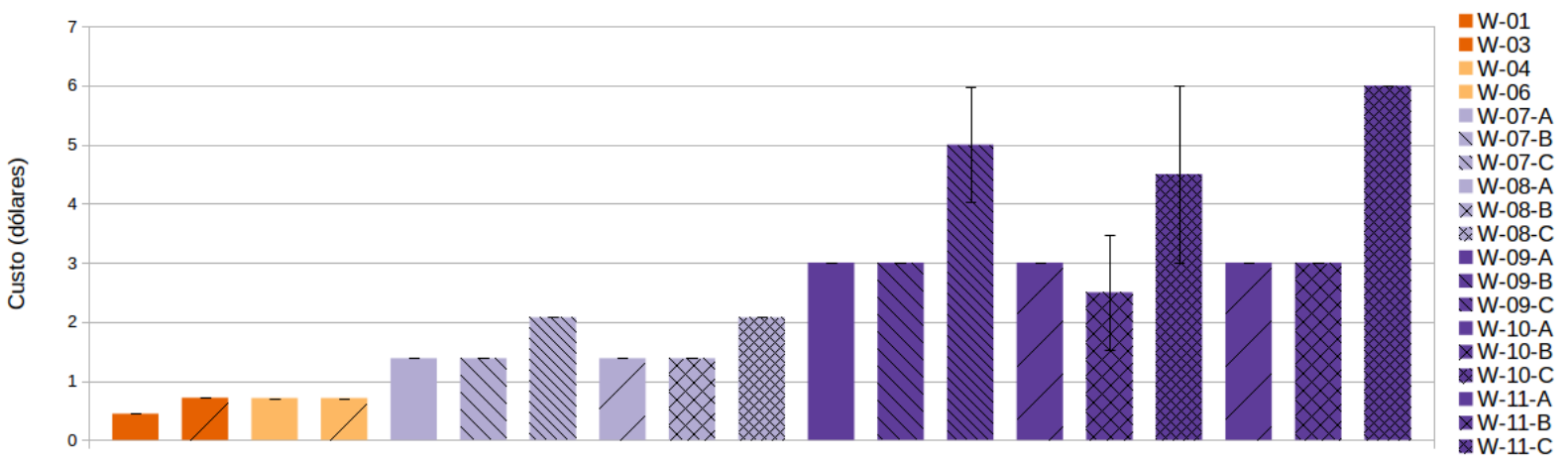

Figura 7.5: Custos financeiros médios das execuções do workflow de análise de edições da Wikipédia

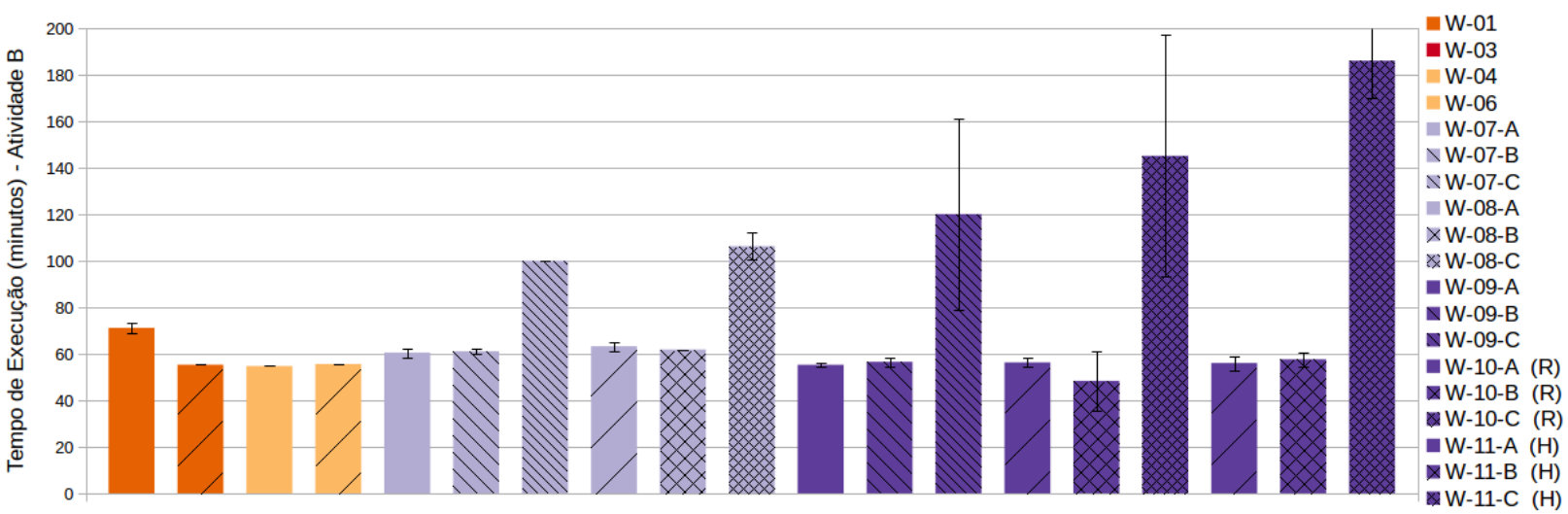

Figura 7.6: Tempos médios de execução da Atividade $B$ do workflow de análise de edições da Wikipédia

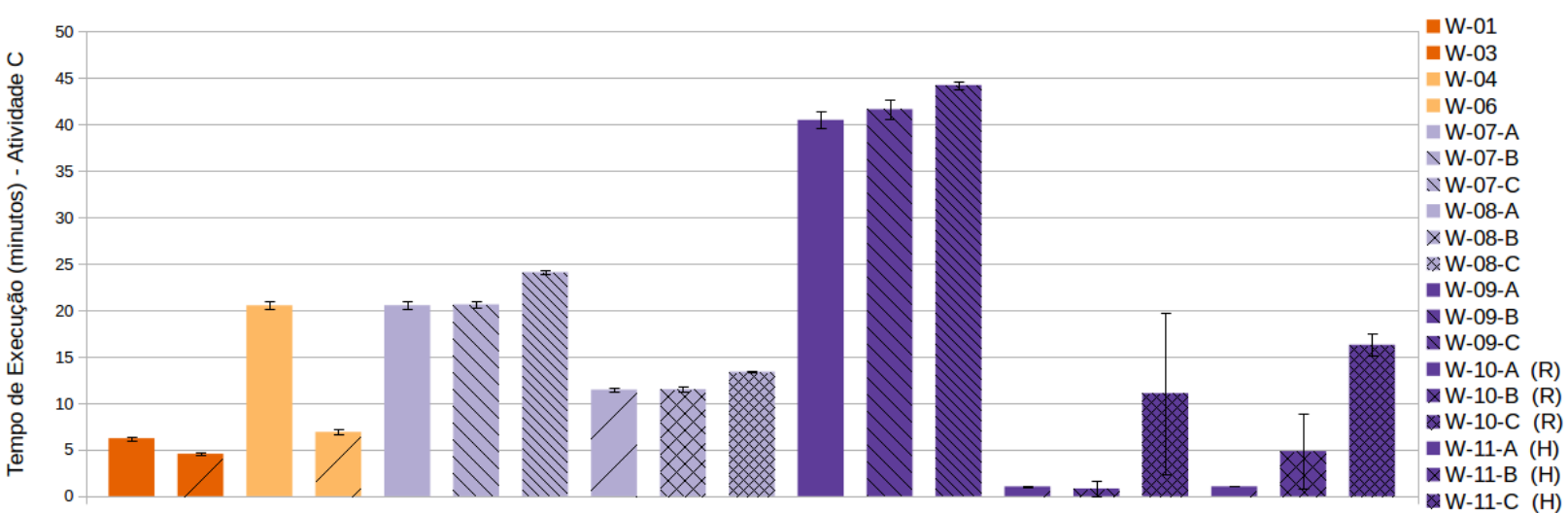

Figura 7.7: Tempos médios de execução da Atividade $C$ do workflow de análise de edições da Wikipédia 


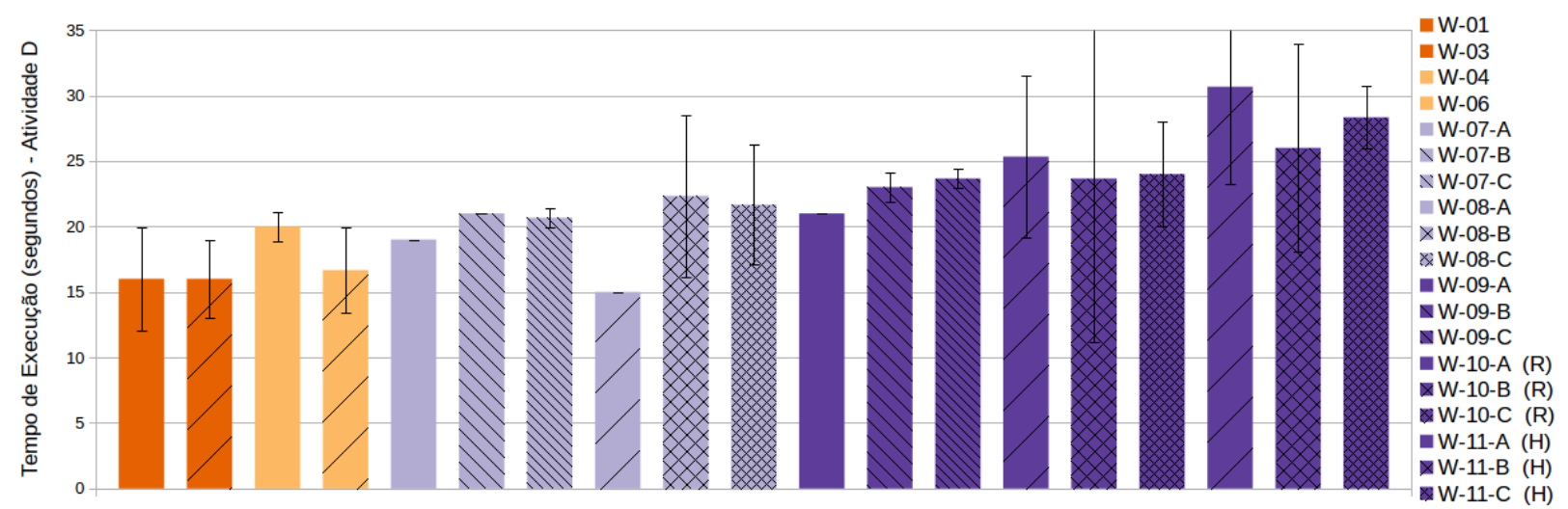

Figura 7.8: Tempos médios de execução da Atividade D do workflow de análise de edições da Wikipédia 


\begin{tabular}{|c|c|c|c|c|c|c|c|c|c|c|c|c|c|c|c|c|c|c|c|}
\hline & W-01 & W-03 & W-04 & W-06 & W-07-A & W-07-B & V-07-C & W-08-A & W-08-B & V-08-C & W-09-A & W-09-B & W-09-C & W-10-A & W-10-B & W-10-C & W-11-A & W-11-B & W-11-C \\
\hline $\mathrm{W}-01$ & $0,0 \%$ & $21,8 \%$ & $16,0 \%$ & $36,8 \%$ & $4,7 \%$ & $3,9 \%$ & $-28,9 \%$ & $12,8 \%$ & $13,7 \%$ & $-26,4 \%$ & $-7,9 \%$ & $-10,2 \%$ & $-44,3 \%$ & $46,5 \%$ & $66,7 \%$ & $-41,5 \%$ & $45,7 \%$ & $34,9 \%$ & $-54,3 \%$ \\
\hline W-03 & $-17,9 \%$ & $0,0 \%$ & $-4,8 \%$ & $12,3 \%$ & $-14,1 \%$ & $-14,7 \%$ & $41,7 \%$ & $-7,4 \%$ & $-6,7 \%$ & $-39,6 \%$ & $-24,4 \%$ & $-26,3 \%$ & $-54,3 \%$ & $20,2 \%$ & $36,8 \%$ & $-52,0 \%$ & $19,6 \%$ & $10,7 \%$ & $-62,5 \%$ \\
\hline W-04 & $3,8 \%$ & $5,0 \%$ & $0,0 \%$ & $17,9 \%$ & $-9,7 \%$ & $0,4 \%$ & $38,7 \%$ & $-2,7 \%$ & $-2,0 \%$ & $-36,5 \%$ & $-20,6 \%$ & $-22,6 \%$ & $-52,0 \%$ & $26,3 \%$ & $43,7 \%$ & $-49,6 \%$ & $25,6 \%$ & $16,3 \%$ & $-60,6 \%$ \\
\hline W-06 & $5,9 \%$ & $-10,9 \%$ & $5,2 \%$ & $0 \%$ & $3,5 \%$ & $4,0 \%$ & $8,0 \%$ & $7,5 \%$ & $16,9 \%$ & $6,2 \%$ & $2,7 \%$ & $-34,4 \%$ & $9,3 \%$ & & $21,9 \%$ & $7,3 \%$ & $6,5 \%$ & $-1,4 \%$ & $-66,6 \%$ \\
\hline W-07-A & $-4,5 \%$ & $16,4 \%$ & $10,8 \%$ & $30,7 \%$ & $0,0 \%$ & $-0,7 \%$ & $32,1 \%$ & $7,8 \%$ & $8,6 \%$ & $-29,7 \%$ & $-12,1 \%$ & $-14,2 \%$ & $-46,8 \%$ & $39,9 \%$ & $59,2 \%$ & $-44,2 \%$ & $39,2 \%$ & $28,8 \%$ & $-56,4 \%$ \\
\hline W-07-B & $-3,8 \%$ & $17,2 \%$ & $11,6 \%$ & $31,6 \%$ & $0,7 \%$ & & $1,6 \%$ & $6 \%$ & 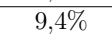 & $-29,2 \%$ & & $-13,6 \%$ & $-46,4 \%$ & $40,9 \%$ & $60,4 \%$ & $-43,8 \%$ & $40,2 \%$ & $29,8 \%$ & $-56,1 \%$ \\
\hline W-07-C & $40,7 \%$ & $71,4 \%$ & $63,2^{\circ}$ & $92,5 \%$ & & & & &, $0 \%$ & & & & & $106,1 \%$ & $34,5 \%$ & & $105,0 \%$ & $89,8 \%$ & $-35,7 \%$ \\
\hline W-08-A & $-11,4 \%$ & $8,0 \%$ & $2,8 \%$ & $21,2 \%$ & $2 \%$ & $\%$ & & & & & & & & $29,8 \%$ & $47,7 \%$ & $2 \%$ & $29,1 \%$ & $19,5 \%$ & $-59,5 \%$ \\
\hline W-08-B & $-12,1 \%$ & $7,1 \%$ & $2,0 \%$ & $20,3 \%$ & $9 \%$ & & & $\%$ & & $3 \%$ & & $1 \%$ & $1 \%$ & $28,8 \%$ & $46,6 \%$ & $-48,6 \%$ & $28,1 \%$ & $18,6 \%$ & $-59,8 \%$ \\
\hline $\mathrm{W}-08-\mathrm{C}$ & $35,9 \%$ & $65,5 \%$ & $57,6 \%$ & $85,8 \%$ & $2 \%$ & $2 \%$ & $4 \%$ & $3 \%$ &, $5 \%$ & & & $\%$ & $4 \%$ & $99,0 \%$ & $126,5 \%$ & $-20,6 \%$ & $98,0 \%$ & $83,3 \%$ & $-38,0 \%$ \\
\hline W-09-A & $8,6 \%$ & $32,4 \%$ & $26,0 \%$ & $48,6 \%$ & $7 \%$ & $9 \%$ & $3 \%$ & & $5 \%$ & $1 \%$ & & $\%$ &, $5 \%$ & $59,1 \%$ & $81,1 \%$ &, $5 \%$ & $58,3 \%$ & $46,5 \%$ & $-50,4 \%$ \\
\hline W-09-B & $11,4 \%$ & $35,7 \%$ & $9,2 \%$ & $1 \%$ & & & $3 \%$ & & & $\%$ & & $\%$ & $8,0 \%$ & $63,1 \%$ & $85,6 \%$ & $-34,9 \%$ & $62,3 \%$ & $50,2 \%$ & $-49,1 \%$ \\
\hline W-09-C & $79,7 \%$ & $8,9 \%$ & $8,4 \%$ & $145,8 \%$ & $1 \%$ & $7 \%$ & & $7 \%$ & $3 \%$ & $2 \%$ & $65,4 \%$ & $3 \%$ & $0,0 \%$ & $163,1 \%$ & $199,5 \%$ & $5,0 \%$ & $161,8 \%$ & $142,3 \%$ & $-18,0 \%$ \\
\hline W-10-A & $-31,7 \%$ & $6,8 \%$ & $0,8 \%$ & $-6,6 \%$ & $5 \%$ & $\%$ & $\%$ & $\%$ & & & & & $0 \%$ & $0,0 \%$ & $13,8 \%$ & $1 \%$ & $-0,5 \%$ & $-7,9 \%$ & $-68,8 \%$ \\
\hline W-10-B & $-40,0 \%$ & $-26,9 \%$ & $0,4 \%$ & $2 \%$ & & & & & & & & & $6 \%$ & $1 \%$ & $0^{0}$ & $9 \%$ & $12,6 \%$ & $19,1 \%$ & $-72,6 \%$ \\
\hline W-10-C & $71,0 \%$ & $108,4 \%$ & $98,4 \%$ & $134,0 \%$ & $79,1 \%$ & $77,8 \%$ & $21,6 \%$ & $93,0 \%$ & $94,5 \%$ & $25,9 \%$ & $57,5 \%$ & $53,6 \%$ & $-4,8 \%$ & $150,5 \%$ & $185,1 \%$ & $0,0 \%$ & $149,2 \%$ & $130,7 \%$ & $-21,9 \%$ \\
\hline W-11-A & $-31,4 \%$ & $-16,4 \%$ & $-20,4 \%$ & $-6,1 \%$ & & $28,7 \%$ & & & & & & & & $0,5 \%$ & $14,4 \%$ & $9 \%$ & $0,0 \%$ & $-7,4 \%$ & $-68,7 \%$ \\
\hline W-11-B & $-25,9 \%$ & $-9,7 \%$ & $-14,0 \%$ & $1,4 \%$ & & & & & & & & & & & $23,6 \%$ & & $8,0 \%$ & $0,0 \%$ & $-66,1 \%$ \\
\hline W-11-C & $119,0 \%$ & $166,8 \%$ & $154,0 \%$ & $199,5 \%$ & $129,2 \%$ & $127,6 \%$ & $55,6 \%$ & $147,1 \%$ & $149,0 \%$ & $61,2 \%$ & $101,6 \%$ & $96,6 \%$ & $21,9 \%$ & $220,7 \%$ & $265,0 \%$ & $28,0 \%$ & $219,1 \%$ & $195,3 \%$ & $0,0 \%$ \\
\hline
\end{tabular}

Tabela 7.1: Comparação do makespan entre as execuções das instâncias do Experimento 2 


\begin{tabular}{|c|c|c|c|c|c|c|c|c|c|c|c|c|c|c|c|c|c|c|c|}
\hline & W-01 & W-03 & W-04 & W-06 & W-07-A & W-07-B & W-07-C & W-08-A & W-08-B & W-08-C & W-09-A & W-09-B & W-09-C & W-10-A & W-10-B & W-10-C & W-11-A & W-11-B & W-11-C \\
\hline W-01 & $0,0 \%$ & $-37,6 \%$ & $-37,3 \%$ & $-37,3 \%$ & $-67,8 \%$ & $-67,8 \%$ & $-78,5 \%$ & $-67,8 \%$ & $-67,8 \%$ & $-78,5 \%$ & $-85,1 \%$ & $-85,1 \%$ & $-91,1 \%$ & $-85,1 \%$ & $-82,2 \%$ & $-90,1 \%$ & $-85,1 \%$ & $-85,1 \%$ & $-92,6 \%$ \\
\hline W-03 & $60,1 \%$ & $0,0 \%$ & $0,4 \%$ & $0,4 \%$ & $-48,4 \%$ & $-48,4 \%$ & $-65,6 \%$ & $-48,4 \%$ & $-48,4 \%$ & $-65,6 \%$ & $-76,2 \%$ & $-76,2 \%$ & $-85,7 \%$ & $-76,2 \%$ & $-71,5 \%$ & $-84,1 \%$ & $-76,2 \%$ & $-76,2 \%$ & $-88,1 \%$ \\
\hline W-04 & $59,5 \%$ & $-0,4 \%$ & $0,0 \%$ & $0,0 \%$ & $-48,6 \%$ & $-48,6 \%$ & $-65,7 \%$ & $-48,6 \%$ & $-48,6 \%$ & $-65,7 \%$ & $-76,3 \%$ & $-76,3 \%$ & $-85,8 \%$ & $-76,3 \%$ & $-71,6 \%$ & $-84,2 \%$ & $-76,3 \%$ & $-76,3 \%$ & $-88,2 \%$ \\
\hline W-06 & $59,5 \%$ & $-0,4 \%$ & $0,0 \%$ & $0,0 \%$ & $-48,6 \%$ & $8,6 \%$ & $55,7 \%$ & $-48,6 \%$ & $-48,6 \%$ & $-65,7 \%$ & $-76,3 \%$ & $76,3 \%$ & $-85,8 \%$ & $-76,3 \%$ & $-71,6 \%$ & $-84,2 \%$ & $-76,3 \%$ & $-76,3 \%$ & $-88,2 \%$ \\
\hline W-07-A & $210,4 \%$ & $93,8 \%$ & $94,6 \%$ & $94,6 \%$ & $0,0 \%$ & $0,0 \%$ & $-33,3 \%$ & $0,0 \%$ & $0,0 \%$ & $-33,3 \%$ & $-53,9 \%$ & $-53,9 \%$ & $-72,3 \%$ & $-53,9 \%$ & $-44,7 \%$ & $-69,3 \%$ & $-53,9 \%$ & $-53,9 \%$ & $-76,9 \%$ \\
\hline W-07-B & $210,4 \%$ & $93,8 \%$ & $94,6 \%$ & $94,6 \%$ & $0,0 \%$ & $0,0 \%$ & $-33,3 \%$ & $0,0 \%$ & $0,0 \%$ & $-33,3 \%$ & $-53,9 \%$ & $-53,9 \%$ & $-72,3 \%$ & $-53,9 \%$ & $-44,7 \%$ & $-69,3 \%$ & $-53,9 \%$ & $-53,9 \%$ & $-76,9 \%$ \\
\hline W-07-C & $365,6 \%$ & $190,7 \%$ & $191,9 \%$ & $191,9 \%$ & $50,0 \%$ & $0,0 \%$ & $0,0 \%$ & $0 \%$ & $50,0 \%$ & $0,0 \%$ & $-30,8 \%$ & $-30,8 \%$ & $-58,5 \%$ & $-30,8 \%$ & $-17,0 \%$ & $-53,9 \%$ & $-30,8 \%$ & $-30,8 \%$ & $-65,4 \%$ \\
\hline W-08-A & $210,4 \%$ & $93,8 \%$ & $94,6 \%$ & $94,6 \%$ & $0,0 \%$ & $0,0 \%$ & $-33,3 \%$ & $0,0 \%$ & $0,0 \%$ & $-33,3 \%$ & $-53,9 \%$ & $-53,9 \%$ & $-72,3 \%$ & $-53,9 \%$ & $-44,7 \%$ & $-69,3 \%$ & $-53,9 \%$ & $-53,9 \%$ & $-76,9 \%$ \\
\hline W-08-B & $210,4 \%$ & $93,8 \%$ & $94,6 \%$ & $94,6 \%$ & $0,0 \%$ & $0,0 \%$ & $-33,3 \%$ & $\%$ & $0 \%$ & $-33,3 \%$ & $-53,9 \%$ & $-53,9 \%$ & $-72,3 \%$ & $-53,9 \%$ & $-44,7 \%$ & $-69,3 \%$ & $-53,9 \%$ & $-53,9 \%$ & $-76,9 \%$ \\
\hline W-08-C & $365,6 \%$ & $190,7 \%$ & $191,9 \%$ & $191,9 \%$ & $50,0 \%$ & $50,0 \%$ & $0,0 \%$ & $50,0 \%$ & $50,0 \%$ & $0,0 \%$ & $-30,8 \%$ & $-30,8 \%$ & $-58,5 \%$ & $-30,8 \%$ & $-17,0 \%$ & $-53,9 \%$ & $-30,8 \%$ & $-30,8 \%$ & $-65,4 \%$ \\
\hline W-09-A & $573,3 \%$ & $320,4 \%$ & $322,1 \%$ & $322,1 \%$ & $116,9 \%$ & $116,9 \%$ & $44,6 \%$ & $116,9 \%$ & $116,9 \%$ & $44,6 \%$ & $0,0 \%$ & $0,0 \%$ & $-40,0 \%$ & $0,0 \%$ & $20,0 \%$ & $-33,3 \%$ & $0,0 \%$ & $0,0 \%$ & $-50,0 \%$ \\
\hline W-09-B & $573,3 \%$ & $320,4 \%$ & $322,1 \%$ & $322,1 \%$ & $116,9 \%$ & $16,9 \%$ & $44,6 \%$ & $9 \%$ & $116,9 \%$ & $44,6 \%$ & $0,0 \%$ & $0,0 \%$ & $-40,0 \%$ & $0,0 \%$ & $20,0 \%$ & $-33,3 \%$ & $0,0 \%$ & $0,0 \%$ & $-50,0 \%$ \\
\hline W-09-C & $1022,1 \%$ & $600,7 \%$ & $603,6 \%$ & $603,6 \%$ & $261,5 \%$ & $261,5 \%$ & $141,0 \%$ & $261,5 \%$ & $261,5 \%$ & $141,0 \%$ & $66,7 \%$ & $66,7 \%$ & $0,0 \%$ & $66,7 \%$ & $100,0 \%$ & $11,1 \%$ & $66,7 \%$ & $66,7 \%$ & $-16,7 \%$ \\
\hline W-10-A & $573,3 \%$ & $320,4 \%$ & $322,1 \%$ & $322,1 \%$ & $116,9 \%$ & $16,9 \%$ & & $116,9 \%$ & & & $0,0 \%$ & & $-40,0 \%$ & $0,0 \%$ & $20,0 \%$ & $-33,3 \%$ & $0,0 \%$ & $0,0 \%$ & $-50,0 \%$ \\
\hline W-10-B & $461,1 \%$ & $250,3 \%$ & $251,8 \%$ & $251,8 \%$ & $80,7 \%$ & $80,7 \%$ & $20,5 \%$ & $\%$ & $\%$ & $20,5 \%$ & $-16,7 \%$ & $-16,7 \%$ & $-50,0 \%$ & $-16,7 \%$ & $0,0 \%$ & $-44,4 \%$ & $-16,7 \%$ & $-16,7 \%$ & $-58,3 \%$ \\
\hline W-10-C & $909,9 \%$ & $530,6 \%$ & $533,2 \%$ & $533,2 \%$ & $225,3 \%$ & $225,3 \%$ & $116,9 \%$ & $225,3 \%$ & $225,3 \%$ & $116,9 \%$ & $50,0 \%$ & $50,0 \%$ & $-10,0 \%$ & $50,0 \%$ & $80,0 \%$ & $0,0 \%$ & $50,0 \%$ & $50,0 \%$ & $-25,0 \%$ \\
\hline & $573,3 \%$ & $320,4 \%$ & $322,1 \%$ & $322,1 \%$ & & & & & & & & & & 0,0 &, $0 \%$ & $-33,5 \%$ & 0,0 & $0,0 \%$ & $50,0 \%$ \\
\hline W-11-B & $573,3 \%$ & $320,4 \%$ & $322,1 \%$ & $322,1 \%$ & $116,9 \%$ & $116,9 \%$ & $44,6 \%$ & $116,9 \%$ & $116,9 \%$ & $44,6 \%$ & $0,0 \%$ & $0,0 \%$ & $-40,0 \%$ & $0,0 \%$ & $20,0 \%$ & $-33,3 \%$ & $0,0 \%$ & $0,0 \%$ & $-50,0 \%$ \\
\hline W-11-C & $1246,5 \%$ & $740,8 \%$ & $744,3 \%$ & $744,3 \%$ & $333,8 \%$ & $333,8 \%$ & $189,2 \%$ & $333,8 \%$ & $333,8 \%$ & $189,2 \%$ & $100,0 \%$ & $100,0 \%$ & $20,0 \%$ & $100,0 \%$ & $140,0 \%$ & $33,3 \%$ & $100,0 \%$ & $100,0 \%$ & $0,0 \%$ \\
\hline
\end{tabular}

Tabela 7.2: Comparação do custo entre as execuções das instâncias do Experimento 2 


\subsection{Análise dos Resultados}

De maneira análoga ao Experimento 1, observamos na Figura 7.4 que a aplicação do método baseado nas anotações de tipo de processamento e a execução em um ambiente distribuído (tanto em relação ao SGWf quanto ao SGBD) são capazes de reduzir o tempo total de execução do workflow, caso o quórum de escrita não seja majoritário. O método obtém bom desempenho também se compararmos os cenários que utilizam a mesma configuração do banco de dados.

Observamos que a distribuição dos objetos tanto por intervalo quanto por hashing resultaram em melhora no desempenho (para um quórum igual a 1). Elas reduziram o makespan em até $66,6 \%$ (W-10-B $\times$ W-09-C) em relação ao seu caso base e em até 40,0\%, ao compararmos a execução com o PostgreSQL $(\mathrm{W}-10-\mathrm{B} \times \mathrm{W}-01)$.

A aplicação do método obteve bom desempenho ao compararmos: (W-03 $\times$ W-01), com redução de 17,9\%; (W-06 × W-04) com redução de 15,2\%; ([W-08-A, W-08-B] × [W-07-A,W-07-B] $)$, com redução de 7,2\% a 8,6\%; e ( [W-10-A, W-10-B,W-11-A, W-11-B] × [W-09-A, W-09-B]), com redução de $31,7 \%$ a 46,1\%. O quórum majoritário para escrita apenas onerou o desempenho e aumentou o custo da execução, não apresentando diferença significativa dos casos em que o método foi aplicado com o caso-base de cada cenário.

Não houve diferença significativa entre os resultados obtidos com o uso da distribuição por hashing e os obtidos com o uso da distribuição por intervalo. Entretanto, para se ter resultados mais conclusivos sobre isso, seria necessário realizar uma avaliação com um volume maior de dados.

Os tempos de execução no PostgreSQL quando comparados aos do MongoDB replicado (W-01 $\mathrm{x}$ [W-07-A, W-07-B]) não apresentaram diferença significativa também devido ao volume de dados analisado e aos tipos de processamento realizados pelas atividades. Entretanto, no segundo caso, há maior resiliência dos dados. Em relação à versão centralizada do MongoDB, observamos uma redução de 13,8\% do tempo total de execução $(\mathrm{W}-04 \times \mathrm{W}-01)$. Em relação ao cenário base do MongoDB replicado e particionado, os desempenhos de (W-09-A, W-09-B, W-09-C) foram piores que o do cenário W-01, referente ao PostgreSQL centralizado. O uso de um SGBD com replicação dos dados onerou o desempenho em relação a sua versão centralizada ([W-07-A, W-07-B, W-07-C, $\mathrm{W}-08-\mathrm{A}, \mathrm{W}-08-\mathrm{B}, \mathrm{W}-08-\mathrm{C}] \times[\mathrm{W}-04, \mathrm{~W}-06])$.

A leitura das réplicas nos cenários do tipo B não resultou em diferença significativa no desempenho em relação aos cenários equivalentes do tipo A. [W-08-A,W-08-B] resultaram em um aumento do tempo de execução de até $21,2 \%$ em relação a W-06; entretanto, foi capaz de prover maior resiliência ao dados e de reduzir o tempo de execução em comparação ao seu caso base. [W-10-A, W-10-B, W-11-A, W-11-B] não apresentaram diferença significativa entre si. Em relação a W-06, obtiveram redução de até $6,6 \%$. Em relação ao cenários [W-08-A, W-08-B], a redução chegou a $32,3 \%$. A utilização do método novamente não impactou no custo financeiro em cenários com a mesma configuração de ambiente de execução.

Em relação à redução do tempo de execução obtida por cada anotação, na Figura 7.6, observamos, primeiramente o tempo de execução da atividade $\mathrm{B}$, descrita pela anotação $P V D$. Essa anotação não permite que a atividade anotada seja replicada e, por isso, a diferença no desempenho com o uso da anotação não foi significativa.

A implementação dessa anotação para o MongoDB, por meio da ferramenta SciWonc-Dataflow (descrita na Seção 4.4) permite que seja possível a busca de valores distintos para atributos de um objeto em grandes coleções por meio da definição de uma função MapReduce. Esta função é gerada pela ferramenta e executada internamente pelo MongoDB. Adota-se esta estratégia uma vez que este sistema de banco de dados limita seu operador distinct $(<$ atributo $\rangle$ ) - que realiza buscas por valores distintos, dado um atributo como parâmetro - a coleções de até $16 \mathrm{MB}$.

É possível observar que, apesar da limitação do sistema NoSQL avaliado (MongoDB) em relação à busca de valores distintos em grandes volumes de dados, o tempo de execução da atividade $B$ em cenários distribuídos manteve-se constante em relação a seus casos-base ([W-07-A, W-07-B]x[W-08A, W-08-B], [W-09-A,W-09-B]x[W-10-A, W-10-B, W-11-A,W-11-B]), exceto nos cenários em que o quórum era majoritário, devido ao maior tempo de escrita dos dados (W-08-C, W-10-C e W-11-C). 
Avaliando a execução da Atividade C, anotada com $P G$ e responsável pela definição de 0 a $n$ objetos por grupo, todos os workflows nos quais o método de paralelização foi aplicado obtiveram redução do tempo total de execução. Novamente, como ocorreu no Experimento 1, o método não só foi capaz de melhorar o desempenho de operações que fazem varredura de objetos baseada em um atributo no MongoDB distribuído como também possibilitou que esse ambiente obtivesse o melhor desempenho, mesmo em relação ao SGBD relacional; houve redução de 59,8\% a 98,1\% no tempo de execução na comparação de cenários ([W-10-A, W-10-B, W-10-C, W-11-A, W-11-A, W-11-C] $\times$ [W-09-A, W-09-B, W-09-C]) e de 83,0\% a 86,8\% comparando os cenários ([W-10-A, W-10-B, $\mathrm{W}-11-\mathrm{A}] \times \mathrm{W}-06)$.

Em relação ao processamento por janela de tempo, o desempenho, mostrado na Figura 7.8 não apresentou diferença significativa em ambientes particionados e replicados ([W-09-A, W-09-B, W-09C,W-10-A, W-10-B, W-10-C, W-11-A, W-11-A, W-11-C] ) e nos cenários com dados replicados e com leitura das réplicas ([W-08-B, W-08-C]). O método aplicado a [W-08-A] gerou uma redução do tempo de execução de até 52,5\% em relação a [W-07-A, W-07-B,W-07-C]. Entretanto, ao compararmos com o cenário W-03 do PostgreSQL ou com o cenário W-06 do MongoDB, notamos que o tempo obtido por W-08-A não apresenta diferença significativa em relação a esses casos. O número de janelas fixas manipuladas em relação ao número de objetos distribuídos (100 janelas para 85.585 objetos de dados) mostrou-se insuficiente para demostrar redução do tempo médio de execução dos cenários básicos (sem aplicação do método) com os cenários anotados (modificados pelo método proposto).

Destacamos também que o tempo de execução dos cenários W-01 e W-03 necessita de melhor investigação, uma vez que o tempo de execução total de W-03 foi superior a W-01, apesar dos tempos médios inferiores obtidos nas atividades $B, C$ e $D$. Essa diferença indica que o controle de execução do SGWf, obtido por meio de atividades artificiais adicionadas a todas as instâncias, pode ter sido penalizada pelo número maior de atividades do cenário W-03. Experimentos com um volume maior de dados devem ser efetuados para verificar se há a redução deste impacto no tempo total, como ocorreu no Experimento 1, descrito no Capítulo 6.

\subsection{Considerações sobre o Capítulo}

O experimento reportado neste capítulo permitiu a avaliação do uso do método aplicado às anotações $P V D, P G$ e $P J T$. Observamos que a anotação $P V D$ foi capaz de obter um desempenho equivalente no PostgreSQL e no MongoDB, mesmo em cenários distribuídos (com quórum de escrita igual a 1). Isso indica a viabilidade desse tipo de consulta em um sistema NoSQL, mesmo com o uso de funções MapReduce adicionadas pela biblioteca SciWonc-Dataflow. A anotação $P G$ foi avaliada em um cenário em que há uma redistribuição dos objetos e mostrou novamente a vantagem do método para ambientes distribuídos (SGBD replicado e particionado).

Entretanto, o desempenho obtido pela anotação $P J T$ indica a necessidade de maior investigação do método proposto para o cenário de janelas temporais fixas, em que intervalos são recuperados de objetos distribuídos em diferentes partições. O número pequeno de objetos por janela sugere que a atividade está sofrendo impacto no desempenho devido ao custo de comunicação com o banco de dados e ao balanceamento de carga de sua coleção de entrada.

Verificou-se que a utilização do método novamente não impactou no custo em cenários com as mesmas configurações de ambiente de execução.

No capítulo seguinte, apresentamos uma visão geral sobre o método apresentado neste trabalho e os resultados obtidos em sua avaliação. O capítulo também discute possíveis extensões para o trabalho. 


\section{Capítulo 8}

\section{Considerações Finais}

Este trabalho aborda o problema da execução eficiente de workflows intensivos em dados em plataformas de alto desempenho. Apresenta a descrição das principais técnicas que visam contornar esse problema, destacando a exploração do paralelismo de dados como alternativa para redução do makespan e sua dependência de um projetista de workflows especializado em computação paralela e distribuída para que seja definido um modelo de workflow capaz de fazer uso do ambiente de execução de maneira eficiente. Argumenta também que este não é o perfil comum dos projetistas dos workflows, que conhecem os processos envolvidos na manipulação dos dados de domínio dessas aplicações. E, a fim de eliminar essa limitação, propõe o uso da semântica do próprio processamento realizado pelo workflow para a criação de estratégias de execução paralela automaticamente.

As principais contribuições deste trabalho foram a proposta de: (i) nove anotações aplicáveis a modelos de workflows, para a caracterização do tipo de processamento de suas atividades, baseadas somente na forma como os dados são consumidos e acessados; e (ii) um método para execução mais eficiente de workflows por meio da paralelização automática baseada na semântica do processamento realizado por eles e no total de nós computacionais disponíveis para cada execução.

As anotações semânticas definem o processamento baseado na seleção de atributos, em critérios de busca e na forma como serão consumidos os dados pelas atividades do workflow, indicando, por exemplo, o agrupamento em intervalos ou subgrupos. Essas informações são adicionadas ao modelo do workflow pelo próprio projetista.

O método proposto é responsável, principalmente, por mapear o tipo de processamento realizado em uma atividade em uma estratégia para a criação de suas réplicas e seus respectivos subconjuntos de dados. Define como o modelo de workflow se beneficiará do ambiente de execução e como a estratégia escolhida pode obter um melhor acesso paralelo aos dados.

Diferentemente do que ocorre em outras abordagens para a paralelização de workflows, o método avaliado não depende de conhecimento específico sobre programação paralela. O próprio projetista do workflow, conhecedor do domínio modelado, é capaz de associar as anotações semânticas às atividades e, assim, obter um melhor desempenho na execução em uma plataforma de computação distribuída.

Por fim, mostramos por meio de experimentos de grande escala que a adoção de um sistema distribuído NoSQL aliado a um ambiente de execução de alto desempenho, por meio do método proposto, pode melhorar a eficiência da execução em workflows orientados a fluxos de dados.

\subsection{Pesquisas Futuras}

Possíveis expansões do trabalho apresentado neste texto incluem: a avaliação de outros modelos de workflows anotados e sistemas NoSQL; a investigação do ganho obtido pelo método conforme o volume de dados manipulados; a comparação entre os usos de um sistema NoSQL e um relacional escalável (NewSQL); a definição de novas anotações e experimentos para identificar como o número de partições no banco pode ser definido em função do número de nós usados para a execução do workflow. 
A avaliação em ambientes heterogêneos para execução das atividades e manutenção do banco de dados sugere também a criação de estratégias capazes de definir cargas de trabalho distintas para cada réplica, associando essa informação ao processo de escalonamento. O uso de nuvens federadas permitiria a distribuição das partições de um banco de dados conforme um requisito de localidade desejado para cada réplica de uma atividade.

Em relação ao tipo de processamento, heurísticas para detecção automática da semântica de uma atividade permitiriam remover a necessidade de anotações explícitas no modelo; características como a elasticidade de uma plataforma de computação em nuvem poderiam ser investigadas de modo a aumentar dinamicamente a escalabilidade horizontal ou vertical do banco de dados conforme o nível de paralelismo explorado. 


\section{Referências Bibliográficas}

$\left[\mathrm{ABC}^{+} 15\right]$ Tyler Akidau, Robert Bradshaw, Craig Chambers, Slava Chernyak, Rafael J. Fernández-Moctezuma, Reuven Lax, Sam McVeety, Daniel Mills, Frances Perry, Eric Schmidt e Sam Whittle. The dataflow model: A practical approach to balancing correctness, latency, and cost in massive-scale, unbounded, out-of-order data processing. Proceedings of the VLDB Endowment, 8(12):1792-1803, Agosto 2015. 65

[Amaa] Amazon. SimpleDB. https://aws.amazon.com/pt/simpledb/. Último acesso em 18/01/2017. 14

[Amab] Amazon Web Services. Amazon Web Services. http://aws.amazon.com/. Último acesso em 10/1/2017. 45

[Ass15a] United Software Associates. High performance benchmarking: MongoDB and NoSQL systems. https://www.mongodb.com/collateral/ comparative-benchmarks-mongodb-vs-couchbase-vs-cassandra, 2015. Último acesso em $10 / 1 / 2017.44$

[Ass15b] United Software Associates. Scalability benchmarking: MongoDB and NoSQL systems. https://www.mongodb.com/collateral/ scalability-benchmarking-mongodb-and-nosql-systems-report, Jun 2015. Último acesso em 10/1/2017. 44

[BB99] Mark Bakery e Rajkumar Buyya. Cluster computing at a glance. Em Rajkumar Buyya, editor, High Performance Cluster Computing: Architectures and System, volume 1, páginas 3-47. Prentice-Hall, May 1999. 1

[BC14] Kelly Rosa Braghetto e Daniel Cordeiro. Introdução à modelagem e execução de workflows científicos. Em Ana Carolina Salgado, Bernadette Farias Lóscio, Eduardo Alchieri e Priscila Solís Barreto, editors, XXXIII Jornadas de Atualização em Informática, páginas 1-40. Sociedade Brasileira de Computação, July 2014. xi, 1, $5,6,7,21$

$\left[\mathrm{BCD}^{+} 08\right]$ Shishir Bharathi, Ann Chervenak, Ewa Deelman, Gaurang Mehta, Mei-Hui Su e Karan Vahi. Characterization of scientific workflows. Em WORKS 2008: The Third Workshop on Workflows in Support of Large-Scale Science, páginas 1-10. IEEE, November 2008. 6

$\left[\mathrm{BYV}^{+}\right.$09] Rajkumar Buyya, Chee Shin Yeo, Srikumar Venugopal, James Broberg e Ivona Brandic. Cloud computing and emerging IT platforms: Vision, hype, and reality for delivering computing as the 5th utility. Future Generation Computer Systems, 25(6):599-616, 2009. 1

[Cat11] Rick Cattell. Scalable SQL and NoSQL data stores. SIGMOD Record, 39(4):12-27, May 2011. 13, 14, 17 
[CBGK13] Daniel Cordeiro, Kelly Rosa Braghetto, Alfredo Goldman e Fabio Kon. Da ciência à e-ciência: paradigmas da descoberta do conhecimento. Revista USP, 0(97):71-81, May 2013. 1, 2, 45

$\left[\mathrm{CDG}^{+} 10\right]$ Scott Callaghan, Ewa Deelman, Dan Gunter, Gideon Juve, Philip Maechling, Christopher Brooks, Karan Vahi, Kevin Milner, Robert Graves, Edward Field, David Okaya e Thomas Jordan. Scaling up workflow-based applications. Journal of Computer and System Sciences, 76(6):428 - 446, 2010. Special Issue: Scientific Workflow 2009. 2

[Cen] Southern California Earthquake Center. Southern California Earthquake Center. http://scec.org. Último acesso em 18/01/2017. 43

[CER13] CERN. Annual report 2013. http://cds.cern.ch/record/790794/files/Openlab_ 2013.pdf, 2013. Último acesso em 10/1/2017. 1

[Cod70] Edgar F. Codd. A relational model of data for large shared data banks. The Communications of the ACM, 13(6):377-387, 1970. 12, 20

[Col] LIGO Scientific Collaboration. LIGO scientific collaboration. http://ligo.org. Último acesso em 18/01/2017. 21, 43

[Cor] Oracle Corporation. MySQL: the world's most popular open source database. http: //www.mysql.com/. Último acesso em 10/1/2015. 9

[Cor15] EnterpriseDB Corporation. Using the NoSQL capabilities in postgres. http://info.enterprisedb.com/rs/enterprisedb/images/EDB_White_Paper_

Using_the_NoSQL_Features_in_Postgres.pdf, July 2015. Último acesso em 18/01/2017. 44

[Cou15] CouchBase. Why NoSQL? three trends disrupting the database status quo. http://info.couchbase.com/rs/northscale/images/whyNoSQL.whitePaper. FINAL.pdf, 2015. Último acesso em 10/1/2015. 12, 14

$\left[\mathrm{CVDK}^{+} 12\right]$ Víctor Cuevas-Vicenttín, Saumen Dey, Sven Köhler, Sean Riddle e Bertram Ludäscher. Scientific workflows and provenance: Introduction and research opportunities. Datenbank-Spektrum, 12(3):193-203, 2012. 5

[CZ14] C.L. Philip Chen e Chun Yang Zhang. Data-intensive applications, challenges, techniques and technologies: A survey on Big Data. Information Sciences, 275(0):314347, August 2014. 1

[dAGdOO $\left.{ }^{+} 12\right]$ João Carlos de A.R. Gonçalves, Daniel de Oliveira, Kary A. C. S. Ocaña, Eduardo Ogasawara e Marta Mattoso. Using Domain-Specific Data to Enhance Scientific Workflow Steering Queries, páginas 152-167. Springer Berlin Heidelberg, Berlin, Heidelberg, 2012. 9

[DG10] Jeffrey Dean e Sanjay Ghemawat. MapReduce: a flexible data processing tool. Communications of the ACM, 53(1):72-77, 2010. 1, 11, 19

[DGST09] Ewa Deelman, Dennis Gannon, Matthew Shields e Ian Taylor. Workflows and e-Science: An overview of workflow system features and capabilities. Future Generation Computer Systems, 25(5):528-540, 2009. 2

[Dha13] Vasant Dhar. Data science and prediction. Communications of the ACM, 56(12):6473, December 2013. 1 
[dOBNP15] Douglas Ericson M. de Oliveira, Cristina Boeres, Angelo Fausti Neto e Fábio Porto. Avaliação da localidade de dados intermediários na execução paralela de workflows BigData. Em Proceedings of 30th Brazilian Symposium on Databases, SBBD 2015, páginas 29-40, October 2015. 2, 19

[dOBP14] Douglas Ericson M. de Oliveira, Cristina Boeres e Fábio Porto. Análise de estratégias de acesso a grandes volumes de dados. Em Proceedings of 29th Brazilian Symposium on Databases, páginas 27-36, October 2014. 22

[dOOBM10] D. de Oliveira, E. Ogasawara, F. Baião e M. Mattoso. SciCumulus: A lightweight cloud middleware to explore many task computing paradigm in scientific workflows. Em The 2010 IEEE International Conference on Cloud Computing, páginas 378385 , July 2010. 2, 8, 9, 20

[DVJ'15] Ewa Deelman, Karan Vahi, Gideon Juve, Mats Rynge, Scott Callaghan, Philip J Maechling, Rajiv Mayani, Weiwei Chen, Rafael Ferreira da Silva, Miron Livny e Kent Wenger. Pegasus: a workflow management system for science automation. Future Generation Computer Systems, 46:17-35, 2015. 2, 8, 20, 43

[EN10] Ramez Elmasri e Shamkant Navathe. Fundamentals of Database Systems. AddisonWesley Publishing Company, 6th edição, March 2010. 12

[Eva04] Eric Evans. Domain-driven design: tackling complexity in the heart of software. Addison-Wesley Professional, 2004. 15

[FJdO14] Guilherme R. Ferreira, Carlos Filipe Jr e Daniel de Oliveira. Uso de SGBDs NoSQL na gerência da proveniência distribuída em workflows científicos. Em Proceedings of the 29th Brazilian Symposium on Databases, SBBD 2014, páginas 187-196, October 2014. 22

[Foua] Apache Software Foundation. Apache CouchDB. http://couchdb.apache.org/. Último acesso em 10/1/2015. 44

[Foub] Apache Software Foundation. Cassandra. http://cassandra.apache.org/. Último acesso em 10/1/2015. 9, 44

[GMLP08] Tristan Glatard, Johan Montagnat, Diane Lingrand e Xavier Pennec. Flexible and efficient workflow deployment of data-intensive applications on grids with MOTEUR. International Journal of High Performance Computing Applications, 22(3):347-360, August 2008. 21

[GR12] D. Ghoshal e L. Ramakrishnan. FRIEDA: Flexible robust intelligent elastic data management in cloud environments. Em SC Companion 2012: High Performance Computing, Networking, Storage and Analysis, páginas 1096-1105. IEEE, November 2012. 21

[Gro] The PostgreSQL Global Development Group. PostgreSQL. http://www.postgresql. org. Último acesso em 10/1/2015. 9

[HJ11] R. Hecht e S. Jablonski. NoSQL evaluation: A use case oriented survey. Em The 2011 International Conference on Cloud and Service Computing, páginas 336-341, December 2011. 13

[HT03] Antony Hey e Anne Trefethen. The Data Deluge: An e-Science perspective. Em F. Berman, G. C. Fox e A. J. G. Hey, editors, Grid Computing - Making the Global Infrastructure a Reality, páginas 809-824. John Wiley \& Sons, Ltd, 2003. 1 
[HTT09] Anthony Hey, Stewart Tansley e Kristin M. Tolle. The Fourth Paradigm: DataIntensive Scientific Discovery. Microsoft Research, October 2009. 1

[HYA $\left.{ }^{+} 14\right]$ Ibrahim Abaker Targio Hashem, Ibrar Yaqoob, Nor Badrul Anuar, Salimah Mokhtar, Abdullah Gani e Samee Ullah Khan. The rise of Big Data on cloud computing: Review and open research issues. Information Systems, 47(0):98-115, August 2014. 13

[IHB $\left.{ }^{+} 12\right]$ Mohammad Islam, Angelo K. Huang, Mohamed Battisha, Michelle Chiang, Santhosh Srinivasan, Craig Peters, Andreas Neumann e Alejandro Abdelnur. Oozie: Towards a scalable workflow management system for Hadoop. Em Proceedings of the 1st ACM SIGMOD Workshop on Scalable Workflow Execution Engines and Technologies, páginas 4:1-4:10. ACM, 2012. 19

[JDB $\left.{ }^{+} 12\right]$ Gideon Juve, Ewa Deelman, G. Bruce Berriman, Benjamin P. Berman e Philip Maechling. An evaluation of the cost and performance of scientific workflows on Amazon EC2. Journal of Grid Computing, 10(1):5-21, 2012. 22

$\left[\mathrm{JDV}^{+} 09\right]$ G. Juve, E. Deelman, K. Vahi, G. Mehta, B. Berriman, B. P. Berman e P. Maechling. Scientific workflow applications on amazon ec2. Em 2009 5th IEEE International Conference on E-Science Workshops, páginas 59-66, Dec 2009. 2

$\left[\mathrm{JDV}^{+} 10\right]$ G. Juve, E. Deelman, K. Vahi, G. Mehta, B. Berriman, B. P. Berman e P. Maechling. Data sharing options for scientific workflows on Amazon EC2. Em Proceedings of the 2010 ACM/IEEE International Conference for High Performance Computing, Networking, Storage and Analysis, SC10, páginas 1-9, Nov 2010. 9

[Kit14] Rob Kitchin. The real-time city? Big data and smart urbanism. GeoJournal, 79(1):1-14, November 2014. 1

[LdOdSP11] Bernadette Farias Lóscio, Hélio Rodrigues de Oliveira e Jonas César de Sousa Pontes. NoSQL no desenvolvimento de aplicações web colaborativas. Anais do VIII Simpósio Brasileiro de Sistemas Colaborativos, 8, October 2011. 13

[Lea10] N. Leavitt. Will NoSQL databases live up to their promise? Computer, 43(2):12-14, February 2010. 14

$\left[\mathrm{LLF}^{+}\right.$09] Cui Lin, Shiyong Lu, Xubo Fei, A. Chebotko, Darshan Pai, Zhaoqiang Lai, F. Fotouhi e Jing Hua. A reference architecture for scientific workflow management systems and the view soa solution. IEEE Transactions on Services Computing, 2(1):79-92, January 2009. 7

$\left[\mathrm{LMT}^{+} 05\right]$ Jin Li, David Maier, Kristin Tufte, Vassilis Papadimos e Peter A. Tucker. Semantics and evaluation techniques for window aggregates in data streams. Em Proceedings of the 2005 ACM SIGMOD International Conference on Management of Data, páginas 311-322. ACM, 2005. 33, 65

[LSP $\left.{ }^{+} 14\right]$ Ji Liu, Vítor Silva, Esther Pacitti, Patrick Valduriez e Marta Mattoso. Scientific Workflow Partitioning in Multisite Cloud, páginas 105-116. Springer International Publishing, Cham, 2014. 9

$\left[\mathrm{MCB}^{+} 11\right]$ James Manyika, Michael Chui, Brad Brown, Jacques Bughin, Richard Dobbs, Charles Roxburgh e Angela H Byers. Big data: The next frontier for innovation, competition, and productivity. The McKinsey Global Institute, 2011. 1 
$\left[\mathrm{MCD}^{+} 15\right]$ Michael McLennan, Steven Clark, Ewa Deelman, Mats Rynge, Karan Vahi, Frank McKenna, Derrick Kearney e Carol Song. Hubzero and pegasus: integrating scientific workflows into science gateways. Concurrency and Computation: Practice and Experience, 27(2):328-343, 2015. CPE-13-0332.R2. 2

[MdSO+ 16] Maria Luiza Mondelli, Matheus Tonelli de Souza, Kary Ocaña, Ana Tereza R. Vasconcelos e Luiz M. R. Gadelha Jr. HPSW-Prof: A Provenance-Based Framework for Profiling High Performance Scientific Workflows. Em Proceedings of 31th Brazilian Symposium on Databases, SBBD 2016, October 2016. 9

[MG09] Peter Mell e Tim Grance. The NIST definition of cloud computing. National Institute of Standards and Technology, 53(6):50, 2009. 1

[OCC ${ }^{+11]}$ Christopher Olston, Greg Chiou, Laukik Chitnis, Francis Liu, Yiping Han, Mattias Larsson, Andreas Neumann, Vellanki BN Rao, Vijayanand Sankarasubramanian, Siddharth Seth et al. Nova: continuous pig/hadoop workflows. Em Proceedings of the 2011 ACM SIGMOD International Conference on Management of data, páginas 1081-1090. ACM, 2011. 19

[OCWS16] J. Ozik, N. T. Collier, J. M. Wozniak e C. Spagnuolo. From desktop to large-scale model exploration with swift/t. Em 2016 Winter Simulation Conference (WSC), páginas 206-220, Dec 2016. 9

$\left[\mathrm{OOV}^{+}{ }^{11}\right]$ Eduardo Ogasawara, Daniel Oliveira, Patrick Valduriez, Jonas Dias, Fábio Porto e Marta Mattoso. An algebraic approach for data-centric scientific workflows. Proceedings of the VLDB Endowment, 4(12):1328-1339, 2011. 2, 20

[ORS $\left.{ }^{+} 08\right]$ Christopher Olston, Benjamin Reed, Utkarsh Srivastava, Ravi Kumar e Andrew Tomkins. Pig latin: A not-so-foreign language for data processing. Em Proceedings of the 2008 ACM SIGMOD International Conference on Management of Data, páginas 1099-1110. ACM, 2008. 19

[PA06] C. Pautasso e G. Alonso. Parallel computing patterns for grid workflows. Em Proceedings of the 6th Workshop on Workflows in Support of Large-Scale Science, WORKS '06, páginas 1-10, June 2006. 2, 9, 10

[Peg] Pegasus. Data transfers. https://pegasus.isi.edu/documentation/transfer.php. Último acesso em 18/01/2017. 9

[PgP] PgPoolII. Pgpool ii. http://www.pgpool.net/. Último acesso em 18/01/2017. 44

[PgT] PgTune. Parameters of your system. http://pgtune.leopard.in.ua. Último acesso em 18/01/2017. 46

[Plaa] Google Cloud Platform. Cloud Datastore. https://cloud.google.com/datastore. Último acesso em 18/01/2017. 44

[Plab] Google Cloud Platform. Cloud SQL. https://cloud.google.com/sql/. Último acesso em 18/01/2017. 44

[Plac] Google Cloud Platform. Cloud Storage. http://cloud.google.com/storage. Último acesso em 18/01/2017. 44

[Pok11] Jaroslav Pokorny. NoSQL databases: A step to database scalability in web environment. Em Proceedings of the 13th International Conference on Information Integration and Web-based Applications and Services, páginas 278-283. ACM, 2011. 
[Pri08] Dan Pritchett. BASE: An ACID alternative. http://queue.acm.org/detail.cfm?id= 1394128, July 2008. Último acesso em 10/1/2015. 14

[PXa] Postgres-XC. Postgres-XC 1.1 documentation. http://postgres-Xc.sourceforge.net/ docs/1_1/admin.html. Último acesso em 18/01/2017. 44

[PXb] Postgres-XL. Scalable open source PostgreSQL-based database cluster. http:// www.postgres-xl.org. Último acesso em 18/01/2017. 44

[PZ14] Fábio Porto e Artur Ziviani. Ciência de dados. Em Anais do 3o. Seminário de Grandes Desafios da Computação no Brasil, September 2014. 1, 19, 21

[RG03] Raghu Ramakrishnan e Johannes Gehrke. Database Management Systems. McGraw-Hill, 3 edição, 2003. 15

[RWH11] Charles Reiss, John Wilkes e Joseph L. Hellerstein. Google cluster-usage traces: format + schema. Technical report, Google Inc., Mountain View, CA, USA, Novembro 2011. Revised 2014-11-17 for version 2.1. Posted at https://github.com/ google/cluster-data. 49

[Sera] Amazon Web Services. Amazon Aurora. https://aws.amazon.com/pt/rds/aurora/. Último acesso em 18/01/2017. 44

[Serb] Amazon Web Services. Amazon DynamoDB. https://aws.amazon.com/pt/ dynamodb. Último acesso em 18/01/2017. 44

[Serc] Amazon Web Services. Amazon Relational Database Service. https://aws.amazon. $\mathrm{com} / \mathrm{pt} / \mathrm{rds} /$. Último acesso em 18/01/2017. 44

[Serd] Amazon Web Services. Amazon S3. https://aws.amazon.com/pt/s3/. Último acesso em 18/01/2017. 44

[SF12] Pramod J Sadalage e Martin Fowler. NoSQL distilled: a brief guide to the emerging world of polyglot persistence. Pearson Education, 2012. 3, 13, 14, 15, 16, 17, 33

[SLBA11] S. Sakr, A. Liu, D.M. Batista e M. Alomari. A survey of large scale data management approaches in cloud environments. IEEE Communications Surveys Tutorials, 13(3):311-336, April 2011. 1

[SQL] SQLite. Sqlite. https://www.sqlite.org/. Último acesso em 18/01/2017. 9

$\left[\mathrm{SSV}^{+} 08\right]$ Gurmeet Singh, Mei-Hui Su, Karan Vahi, Ewa Deelman, Bruce Berriman, John Good, Daniel S. Katz e Gaurang Mehta. Workflow task clustering for best effort systems with Pegasus. Em Proceedings of the 15th ACM Mardi Gras Conference, MG '08, páginas 9:1-9:8, 2008. 2

[SVR ${ }^{+}$07] G Singh, K Vahi, A Ramakrishnan, G Mehta, E Deelman, H Zhao, R Sakellariou, K Blackburn, D Brown, S Fairhurst et al. Optimizing workflow data footprint. Scientific Programming Journal dedicated to Dynamic Computational Workflows: Discovery, Optimisation and Scheduling, 2007. 2

$\left[\mathrm{TSJ}^{+}\right.$09] Ashish Thusoo, Joydeep Sen Sarma, Namit Jain, Zheng Shao, Prasad Chakka, Suresh Anthony, Hao Liu, Pete Wyckoff e Raghotham Murthy. Hive: A warehousing solution over a Map-Reduce framework. Proceedings of the VLDB Endowment, 2(2):1626-1629, August 2009. 19

[vDAHKB03] Wil M. P. van Der Aalst, Arthur H. M. Ter Hofstede, Bartek Kiepuszewski e Alistair P. Barros. Workflow patterns. Distributed and parallel databases, 14(1):5-51, 2003. 10 
[VRMCL08] Luis M. Vaquero, Luis Rodero-Merino, Juan Caceres e Maik Lindner. A break in the clouds: Towards a cloud definition. ACM SIGCOMM Computer Communication Review, 39(1):50-55, Dezembro 2008. 1

[WAW $\left.{ }^{+} 13\right]$ J. M. Wozniak, T. G. Armstrong, M. Wilde, D. S. Katz, E. Lusk e I. T. Foster. Swift/t: Large-scale application composition via distributed-memory dataflow processing. Em The 13th IEEE/ACM International Symposium on Cluster, Cloud, and Grid Computing, páginas 95-102, May 2013. 2, 8, 20

[WB16] Elaine N. Watanabe e Kelly R. Braghetto. Uso de anotações semânticas para exploração de paralelismo em workflows intensivos em dados. Em Proceedings of 31th Brazilian Symposium on Databases, SBBD 2016, páginas 271-276, October 2016. 3

[WGB16] Elaine Naomi Watanabe, Gabriel Guilhoto e Kelly Rosa Braghetto. SciwoncDataflow. https://elainenaomi.github.io/sciwonc-dataflow/, 2016. Último acesso em $21 / 01 / 2017.3,38,41,66$

[Whi09] Tom White. Hadoop: the definitive guide. O'Reilly Media, May 2009. 19

[WHW $\left.{ }^{+} 11\right]$ Michael Wilde, Mihael Hategan, Justin M. Wozniak, Ben Clifford, Daniel S. Katz e Ian Foster. Swift: A language for distributed parallel scripting. Parallel Computing, 37(9):633 - 652, September 2011. 2, 20

[Wri14] Alex Wright. Big data meets big science. Communications of the ACM, 57(7):13-15, July 2014. 1

[YB05] Jia Yu e Rajkumar Buyya. A taxonomy of scientific workflow systems for grid computing. SIGMOD Record, 34(3):44-49, September 2005. 5 